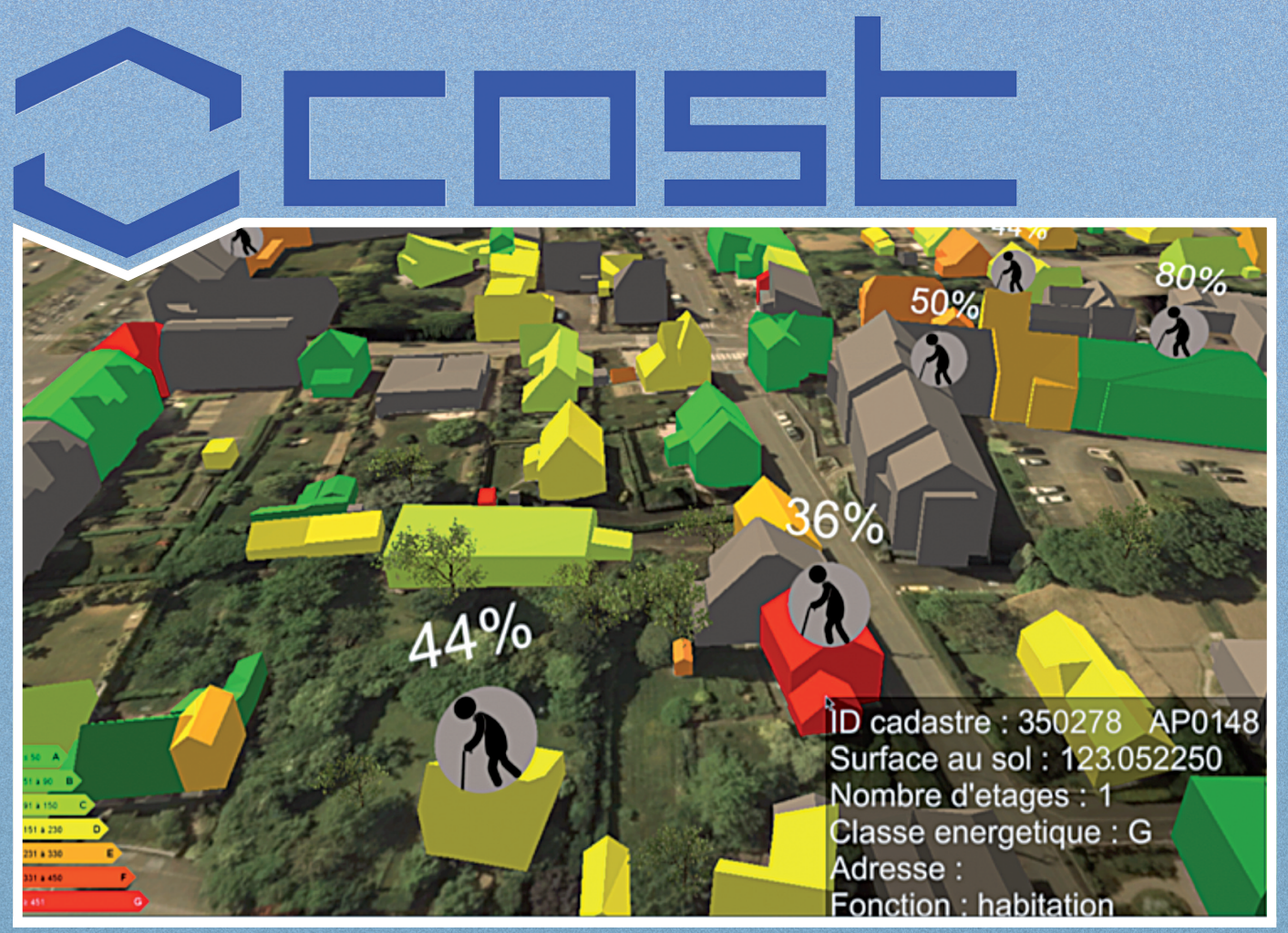

3D City Models and urban information: Current issues and perspectives

EUropean COST Action TU0801

R. Billen, A.F: Cutting-Decelle, O, Marina, JipP de Almejda, M. Cagj.jonj, G. Falguet, I. Leduc, C. Métral, G. Moreau, J. Perret, G. Rabjne, Ro San Jose, l. Yatskiv and S. Zlatanova 


\section{D City Models and urban information: Current issues and perspectives}

\section{European COST Action TU0801}

Final publication of the European Cost action TU0801 - Semantic enrichment of 3D city models for sustainable urban development

Eumarefan SIㅡㄹㅡ FロUNDRTION

ESF provides the COST Office through an EC contract
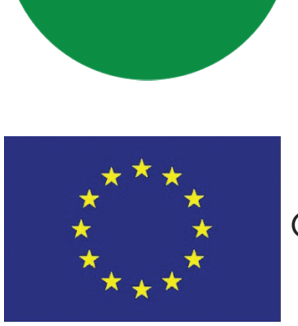

COST is supported by the EU RTD Framework program

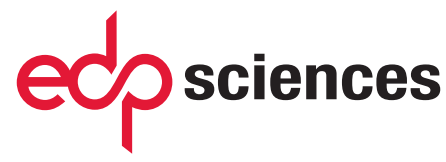

17 avenue du Hoggar, PA de Courtabœuf, B.P. 112,

91944 Les Ulis cedex A, France 
(C) Owned by the authors, published by EDP Sciences, 2014 DOI: $10.1051 /$ TU0801/201400001

This is an Open Access document distributed under the terms of the Creative Commons Attribution License 2.0, which permits unrestricted use, distribution, and reproduction in any medium, provided the original work is properly cited.

\section{Cover Figure}

(c) SIRADEL 


\section{Authors}

Roland Billen, Department of Geography, University of Liege, Belgium, rbillen@ulg.ac.be

Anne-Françoise Cutting-Decelle, Ecole centrale de Lille, France and ICLE, University of Geneva, Switzerland, afcd@skynet.be

Ognen Marina, Faculty of Architecture, Ss. Cyril and Methodius University in Skopie, Macedonia, ognen.marina@arh.ukim.edu.mk

José-Paulo de Almeida, Department of Mathematics (Geomatic Engineering Lab.), University of Coimbra, Portugal, zepaulo@mat.uc.pt

Matteo Caglioni, UMR 7300 ESPACE, University of Nice Sophia Antipolis, France, matteo.caglioni@unice.fr

Gilles Falquet, Centre universitaire d'informatique, University of Geneva, Switzerland, claudine.metral@unige.ch

Thomas Leduc, Laboratoire CERMA - UMR CNRS 1563, Ecole Nationale Supérieure d'Architecture de Nantes, France, thomas.leduc@cerma.archi.fr

Claudine Métral, Centre universitaire d'informatique, University of Geneva, Switzerland, claudine.metral@unige.ch

Guillaume Moreau, CERMA, Ecole Centrale de Nantes, France, guillaume.moreau@ec-nantes.fr

Julien Perret, Laboratoire COGIT, IGN, France, julien.perret@gmail.com

Giovanni Rabino, DIAP - Politecnico di Milano, Italy, giovanni.rabino@polimi.it 
Roberto San Jose, Department of Languages, Systems and Software Engineering, Technical University of Madrid (UPM), Madrid, Spain. roberto@fi.upm.es

Irina Yatskiv (Jackiva), Department of Mathematical Methods and Modelling, Transport and Telecommunication Institute, Riga, Latvia, Jackiva.I@tsi.Iv

Sisi Zlatanova, OTB, TU Delft, The Netherlands, S.Zlatanova@tudelft.nl 


\section{Foreword}

COST - the acronym for European Cooperation in Science and Technology is the oldest and widest European intergovernmental network for cooperation in research. Established by the Ministerial Conference in November 1971, COST is presently used by the scientific communities of 36 European countries to cooperate in common research projects supported by national funds.

The funds provided by COST - less than $1 \%$ of the total value of the projects - support the COST cooperation networks (COST Actions) through which, with EUR 30 million per year, more than 30000 European scientists are involved in research having a total value which exceeds EUR 2 billion per year. This is the financial worth of the European added value which COST achieves.

A "bottom up approach" (the initiative of launching a COST Action comes from the European scientists themselves), "à la carte participation" (only countries interested in the Action participate), "equality of access" (participation is open also to the scientific communities of countries not belonging to the European Union) and "flexible structure" leasy implementation and light management of the research initiatives) are the main characteristics of COST.

As precursor of advanced multidisciplinary research COST has a very important role for the realisation of the European Research Area (ERA) anticipating and complementing the activities of the Framework Programmes, constituting a "bridge" towards the scientific communities of emerging countries, increasing the mobility of researchers across Europe and fostering the establishment of "Networks of Excellence" in many key scientific domains such as: Biomedicine and Molecular Biosciences; Food and Agriculture; Forests, their Products and Services; Materials, Physical and Nanosciences; Chemistry and Molecular Sciences and Technologies; Earth System Science and Environmental Management; Information and 
Communication Technologies; Transport and Urban Development; Individuals, Societies, Cultures and Health. It covers basic and more applied research and also addresses issues of pre-normative nature or of societal importance.

The Action TU0801 is called: "Semantic Enrichment of 3D city models for sustainable urban development" and is one of the actions of the COST TUD domain (www.semcity.net). TU stands for Transport and Urban Development (www.cost. eu/domains_actions/tud) and is one of the COST key domains. It fosters research coordination in the fields of transport and the built environment, which play a strategic role in the modern society and economy. The Domain is by definition crosssectorial and multidisciplinary, encompassing a wide range of scientific expertises within the transport and land use planning, design, and management activities with a special emphasis on the strong interrelationships among the relevant policy fields as well on all aspects related to sustainable development.

Web: http://www.cost.eu

Action Website: www.semcity.net

Action COST page: http://w3.cost.esf.org/index. php? id=240\&action_number $=T$ TU080 1

wiki: http://semcity.unige.ch/semcity/doku.php/start

This publication is supported by COST 


\section{Table of content}

Authors

Foreword

\section{Chapter 1}

Introduction

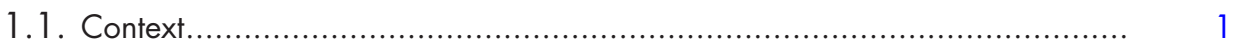

1.2. Presentation of the action ................................................................... 2

1.3. Objectives and structure of the report .................................................

\section{Chapter 2 \\ State-of-the-art}

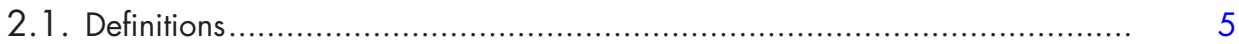

2.1.1. Urban knowledge ............................................................. 5

2.1.2. Meanings of "semantics" ........................................................ 7

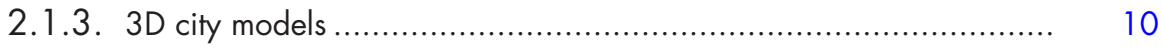

2.2. Building 3D city models............................................................ 13

2.2.1. 3D geometry acquisition....................................................... 13

2.2.2. Formats and languages ...................................................... 14

2.3. Usage and utility of enriched 3D city models .................................... 16 
2.4. Methods for enriching 3D city models ................................................ 24

2.4.1. Definitions - fundamental and theoretical concepts ....................... 24

2.4.2. Addition / Aggregation / Generalisation ................................... 25

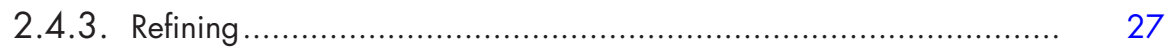

2.4.4. Hybrid methods................................................................. 28

2.5. Visualisation and user interaction ................................................... 29

2.5.1. Visualisation systems .......................................................... 29

2.5.2. Visualisation techniques for enriched 3D city models..................... 35

2.5.3. Usability of $3 \mathrm{D}$ city models visualisation interfaces ........................ 36

\section{Chapter 3 \\ Action's outputs}

3.1. Structure and action's organisation .................................................... 41

3.2. Scientific production .................................................................... 42

3.2.1. Activities..................................................................... 42

3.2.2. Scientific missions ................................................................. 43

3.2.3. Summer school .................................................................. 45

3.2.4. Working group specific outputs ................................................ 47

3.2.5. Dissemination ......................................................................... 51

3.3. Breakthroughs and prespectives .................................................... 59

3.3.1. Breakthroughs .............................................................. 59

3.3.2. Perspectives ......................................................................... 59

\section{Chapter 4 \\ Human aspects and perspectives}

4.1. Further thoughts on the use of 3D city models ................................. 67

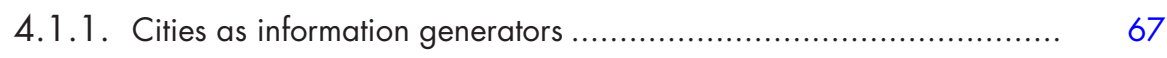

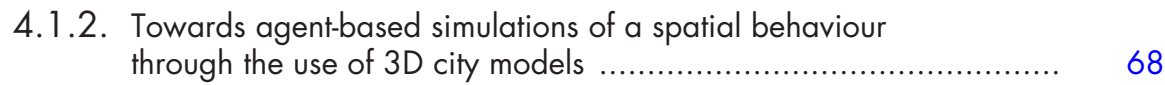

4.1.3. Interactive 3D city models for city planners .................................. 71

4.2. Towards a new paradigm for urban models....................................... 71

4.3. City modelling in education, or education to $3 \mathrm{D}$ city modelling? .......... 74

4.3.1. 3D virtual worlds ................................................................ 74

4.3.2. Second life game approaches .................................................. 74 


\section{Chapter 5}

\section{Conclusions}

5.1. Action's context and objectives ....................................................... 77

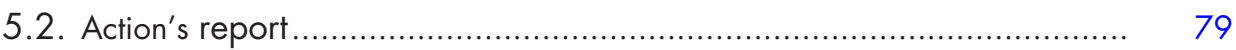

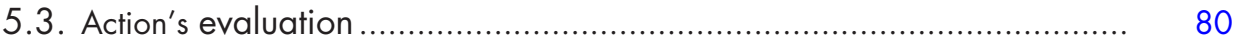

5.4. As a matter of perspectives............................................................. 81

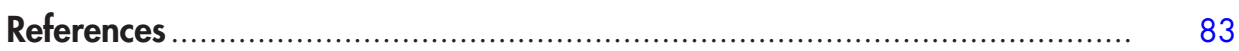

Annex 1 List of members ................................................................... 93

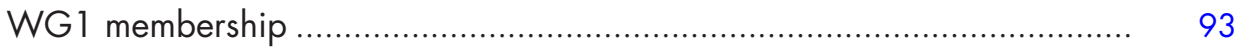

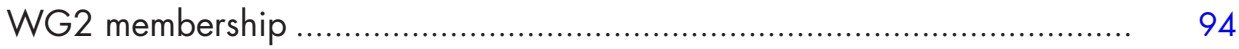

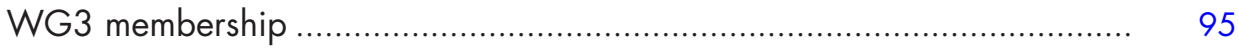

Annex 2 WG's questionnaires .............................................................. 97

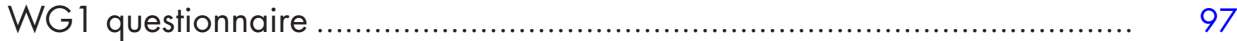

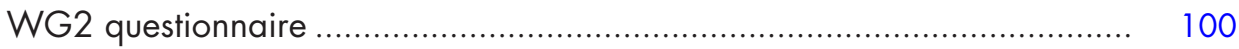

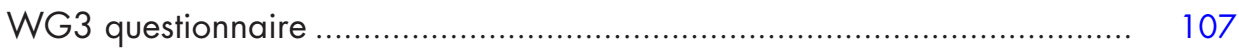

Annex 3 List of publications the COST-workshop "3D issues

for transport system" ............................................................... 109

Annex 4 List of publications the COST book "3D issues in urban and environmental systems"

Annex 5 List of publications of the book usage, usability, and utility of 3D city models

Annex 6 Final round table mind map .................................................. 117 
7 KVSDJHIQMQWRQDQLOIVEOQN 


\section{Chapter 1 \\ Introduction}

\subsection{Context}

Many urban or environmental models are defined with the objective of helping practitioners and stakeholders in their decision-making processes. Models which represent in three dimensions the geometric elements of a city are called 3D city models. These models are increasingly used in different cities and countries for an intended wide range of applications beyond mere visualisation. Indeed, unlike maps and drawings, 3D visualisation reflects a view of the environment that a lot of people are familiar with and acts as a communication tool. Non geometrical data (such as social, historic or acoustic data or statistics, for example) can be associated to urban geometrical objects (such as buildings or streets) that can be represented and visualized in 3D, leading to a localization as well as a better understanding of these data. By associating a domain (energy consumption, air quality, etc.) to these 3D models, we obtain richer 3D representations that can be used for simulations and reasoning (visual reasoning).

Considering sustainable development of cities implies investigating cities in a holistic way taking into account many interrelations between various urban or environmental issues. Could the above mentioned 3D City models be used to integrate urban and environmental knowledge? How could they be improved to fulfil such a role? We believe that enriching the semantics of current 3D city models would extend their functionality and usability; therefore, they could serve as integration platforms of the knowledge related to urban and environmental issues allowing a huge and significant improvement of city sustainable management and 
development. But which elements need to be added to 3D city models? What are the most efficient ways to achieve such improvement/enrichment? How to evaluate the usability of these improved 3D city models?

\subsection{Presentation of the action}

The action started in November 2008 and has ended in November 2012. The main motivation of the action was to explore ways to semantically enrich 3D models with urban knowledge and models, so as to extend their functionality and usability in a perspective of sustainability. It was an active research network of 75 permanent members gathering people from academia, industry, administration and regulation bodies from 23 participating countries (comprehensive lists are presented in annex 1).

The Action's Memorandum of Understanding (MoU) can be summarized as follows:

"Considering sustainable development of cities implies investigating cities in a holistic way taking into account many interrelations between various urban or environmental issues. From that respect, 3D modelling is a possible axis of integration of the knowledge related to these issues and a powerful basis for interactive exploration. We believe that enriching the semantics of current 3D city models with urban knowledge would extend their functionality and usability in a perspective of sustainability. The Action will identify knowledge (concepts) relevant for sustainable urban development and concepts related to 3D city models (top-down approach relying on literature and publications/ bottom-up approach coming from real problems and scenarios). Then, means for integrating or interconnecting these concepts either directly either by defining articulation patterns will be investigated. A particular attention will be put on the use of knowledge representation techniques such as ontologies to integrate or interconnect urban data and models within 3D city models".

In particular, the Action addresses conceptual issues related to the nature of the information and knowledge that must be added to the current models, technical issues about the feasibility of using 3D models as knowledge integration platform and issues related to the use, usage and usability of such enriched models.

The scientific goals are:

- To identify knowledge (concepts) relevant for sustainable urban development that could enrich current 3D city models.

- To investigate means for integrating or interconnecting these concepts either directly either by defining articulation patterns (such as ontologies).

- To assess the usability of enriched 3D city models, relatively to various urban issues.

- To promote the creation and use of enriched 3D city models.

- To provide a contribution towards European standards relative to 3D city models in relation with sustainable development. 
- To provide a methodology for creating and maintaining enriched 3D city models.

- To produce recommendations for decision makers, scientists and for education purposes.

This Action is highly interdisciplinary, target groups are the scientific communities dealing with urban issues (planners, geographers, sociologists, etc.), computer scientists, designers, engineers, environmentalists or any actor of the urban field, decision makers, mapping agencies and data providers.

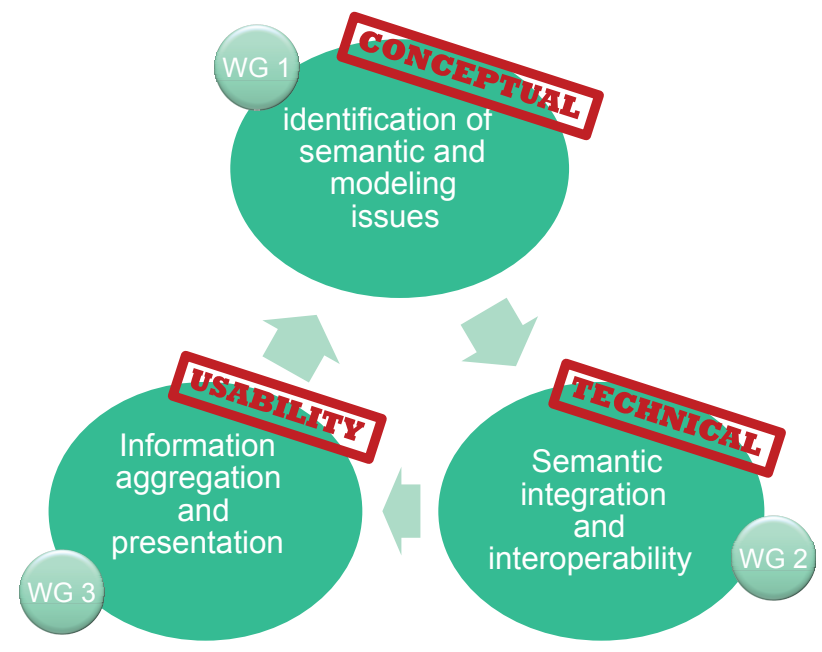

Fig. 1. Working groups of TU0801.

Three working groups (Fig. 1) were established:

- WG1 is an exchange and reflection platform about semantic and thematic 3D nature of urban space. Semantic and modelling issues were identified and analysed. This group is composed of urban experts as urban planners, urban geographers, sociologists, environmentalists, and of researchers from the spatial information field.

- WG2 focuses on integration and interoperability issues when combining semantic information and models with 3D city models. This group is composed of researchers in information sciences and representation techniques.

- WG3 addresses the stakes of information integration into decision processes to support urban development and sustainability. This implies a thorough understanding of those decision processes for a representative set of urban development and management processes, the identification of the users' needs for related information and knowledge on the urban fabric. 
Several activities have been organised; 10 workshops or conferences all over Europe, 15 research stays in different members' institutions and 1 summer school. Action's outputs are developed in the chapter 2 of this report.

\subsection{Objectives and structure of the report}

The Action TU0801 generated a lot of activities and contributions.

The aim of this report is to provide the necessary complementary information to the existing action output. It is a guide for practitioners, decision makers and scientists in the domain of 3D city modelling with the perspective of city dynamic modelling and smart cities.

The chapter 1 is a state-of-the art about the main concepts which have to be handled when considering enrichment of 3D city models. This work is an important contribution made by the members providing fundamental elements necessary for interdisciplinary collaborations within the Action. Indeed, we have encountered a lot of misunderstanding at the beginning of the action between members coming from various disciplines. It was therefore important to provide a comprehensive study about the main concepts used during the action.

The chapter 2 presents the output of the action and is divided into three parts. The first one concentrates on the scientific production of the action and lists all the activities, dissemination outputs (books, website, etc.). The second part summarises the main action's breakthroughs and presents some research perspectives.

The chapter 3 brings some complementary aspects which were not specifically addressed by working groups but which tend to be important when considering the uses of $3 D$ city models in a sustainable perspective. It gathers discussions about some human and social aspects (cities as information generators, human spatial behaviour, interactive 3D city models for city planners), some evolutions of urban modelling paradigms and finally some thoughts about 3D city modelling and education.

Finally, we conclude by discussing the course of the action and some perspectives for further uses of 3D city models. 


\section{Chapter 2 \\ State-of-the-art}

The objective of this section is to set up a state of the art of the situation of urban modelling, city models, and enrichment of city models, both at the beginning of the project and during the four-year work undertaken in the context of this COST Action.

We start with various definitions about urban knowledge, semantics, 3D urban and 3D city models... Then, we analyse the way of building 3D city models. The third part of this chapter focuses on the use and utility of enriched 3D city models. In the following section, we present some methods for enriching city models. This state of the art ends with the description of visualisation and user interaction techniques, and fundamental 3D city model features.

\subsection{Definitions}

This section proposes definitions of the main concepts used, studied, and enhanced within the framework of the project. Those definitions are very important since they have provided bases for discussions held during different project meetings.

\subsubsection{Urban knowledge}

The representation of urban knowledge deals with the formalisation of propositions about both physical and non-physical urban objects, their properties, and the relationships among the objects. 
Urban knowledge, i.e. knowledge about the urban environment, provides both the content and the goal of 3D urban models. It is what makes them useful beyond visualisation, commercial, or entertainment purposes. Urban knowledge generally refers to the a priori knowledge that the designer tries to embed into the model, beyond geometry. Such knowledge can inform on the nature of objects (industrial or residential buildings), on their function or usage, their history. Such a priori knowledge is often referred to as "semantic information".

Urban knowledge is also the goal of urban models. Many models of urban processes can be used in order to better understand urban systems (traffic models, land use models, air quality models, etc.) and to produce new knowledge. Direct results of such models are usually estimations of quantities (air pollution, traffic flow, etc.), but the most important results concern knowledge about the system and its processes (land use dynamics, population dynamics, etc.).

\section{Sustainable development and urban knowledge}

This evolution in the intent behind the construction of 3D urban models is necessary. We argue that a better understanding of the urban system is necessary in order to achieve sustainable development goals for cities. Accurate 3D urban models are an important tool for a better understanding of urban systems and thus for sustainable urban development.

An important work is being done within the framework of the EPIC EU project: http://www.epic-cities.eu/content/smart-cities (European Platform for Intelligent Cities). This project goes in the same direction as our sustainable development goal.

\section{Smart cities and urban knowledge}

According to the EPIC platform, the current worldwide economic crisis, combined with growing citizen expectations, is placing increasing pressure on European cities to provide better and more efficient infrastructures and services, often for less cost. This trend has contributed to the growing popularity and use of the term "Smart City." Definitions of a "Smart City" vary widely - ranging from the use of discrete new technology applications, such as RFID and the Internet, through to a more holistic conception of intelligent, integrated working that is closely linked to the concept of Living Labs and user-generated services. The former definition is widely used by ICT companies of all shapes and sizes. The latter, albeit with a greater emphasis on user-generated services rather than on ICT, has been loosely adopted by the European Commission. Since early 1995, the European Commission has attempted to improve government services, transactions, and interactions with European citizens and businesses through funding and deployment of a wide variety of strategic ICT initiatives. 


\subsubsection{Meanings of "semantics"}

Very relevant to this COST Action is the analysis on the meaning of the concept of "semantics" in the domain of geographical information. Globally, the word semantics is used to refer to the improvement of an information system by making information more explicit, especially in relation to the meaning of things. Applied to models and their implementation, we can see different interpretations of what semantics is in information systems. This has been presented in a paper produced during the COST TU0801 (Moreno et al., 2011).

\section{Semantics as opposed to geometry and images: data oriented semantics}

Very early, geographical data producers used the term semantics to refer to part of geographical data that were not geometric, and that were related to thematic properties of features and their attributes, such as the "number of lanes" for a road. In many virtual models, there are two kinds of data: coordinates and textures. Enriching such data with semantics can thus be interpreted as making explicit, at the level of data, features as well as their nature and properties. This is what is proposed in CityGML model (Kolbe et al., 2005). The authors use semantics to denote properties differently from spatial ones. They proposed to integrate into CityGML semantic elements relevant to disaster management using a taxonomy of classes that distinguishes between buildings, vegetation objects, water bodies, and transportation facilities such as streets and railways.

\section{Semantics as a formal connection with reality (nature oriented semantics)}

Another basic definition of semantics proposed by Kavouras et al. (2003) is given by the relationship between data and reality. Many works analyse how to represent this information, essentially in order to integrate heterogeneous data or in order to facilitate dataset discovery in catalogues. The underlying idea is that data integration is necessary to cope with various kinds of heterogeneities related to design choices made by producers when they define their geospatial data. These various kinds can be classified into system, syntax and structure, and semantic heterogeneities (Visser et al., 2005; Bittner et al., 2005). System refers to hardware, operating systems, and communications heterogeneity, such as communication protocols. Syntax and structure interoperability covers data representation, formatting, data models, and spatial schemas heterogeneity. Semantic interoperability reflects the meanings of objects. Through the use of new architectures and CityGML, most heterogeneities of the first group are solved; however semantic interoperability is the most challenging problem. With the development of Spatial Information Infrastructures (SII) the semantic interoperability is becoming a critical issue. Ontology is seen as a very promising approach for dealing with semantic interoperability. Besides, formalising 
our conceptualisation of the real world it is necessary to relate it to the digital city model. Most approaches consist in associating a real world feature type (also known as a category in an ontology) to a database feature type (Klein et al., 2006). Mustiere et al. (2003) and Abadie (2009) have proposed a more precise representation of the relationship between a geographical database representation construct and a category of the real world. Their model tracks every choice made by the data producer to create the database structure and to populate it from his observation of the real world - such as, the decision to decompose the representation of a road into road segments, or the decision not to put into the databases dead ends that are less than $20 \mathrm{~m}$ long.

The formal connection with reality can also be required at the level of instances. Digital city models should support the unambiguous designation of objects and places in a way that is both machine and human readable. This is typically useful for firefighters, civilians, or manages to communicate relevant information about the scene by phone. Street names and addresses are the common human readable elements of the reference system for urban objects. But it might be useful to have other ones (for instance, if a street name plate is destroyed or happens to be too far to be read). In most works, it is suggested to identify landmarks that can be used to reference things in the landscape. An interesting proposal is that of Morita's real scale map who defined objects in the real world (such as, a fire light) that, together with relationships such as "5 steps from", compose a fully functional reference system (Morita, 2007). An alternative way to solve this issue is to design identifiers for objects in the real world. This approach is investigated in the context of collaborative data and in the Semantic Web where people want to attach descriptors to a resource identified with a URL. Yet, those URL are not that much human readable, such as http://data.ordnancesurvey.co.uk/id/50kGazetteer/16354.

\section{Semantics as a connection with the usage (value oriented semantics)}

Kuhn has a different point of view on semantics, which is summarised in the following statement of the author: meaning is the use (Kuhn, 1996). This is what we call the value-oriented interpretation of semantics. An interesting work in this perspective is the proposal of the psychologist Gibson (1986) to describe the word in terms of activities supported by objects, i.e. the affordances: "The affordances of the environment are what it offers the animal, what it provides or furnishes, either for good or ill". Kuhn (2001) extended upon this work and model affordances in geographic information systems (GIS). Similarly, Jordan (Jordan et al., 1998) proposed to use affordances as relevant descriptors for places: a place to rest, a place to have a drink, and so on. 3D city models have a lot to bring to assessing this kind of semantics. In the context of fire disasters, affordances can be analysed in the perspective of several processes: the fire (example of affordances are, objects that burn well), escaping from the fire (examples of affordances are, objects that can be a good shelter waiting for the rescue team), fighting the fire and rescuing people (example of affordances 
are, water body and pumps to extinguish the fire). In here, we think it is most relevant to distinguish between:

- The information the user needs to take a decision (e.g. firefighters need to know if they can access specific doors and how close they can drive to them).

- The data needed to calculate this information. At this point, it is important to distinguish between different kinds of city models (the different LODs of 3D models, 2.5D and 2D).

Classical 3D virtual models, comprising a digital elevation model (DEM) and realistic textures are very useful for user visualisation. Indeed, a great difference between virtual globes and maps is that the virtual globe is closer to the user experience of the real world than the map. Those data can be provided by data producers or can be simulated if a specific landscape or atmosphere is required. Besides this, terrain information objects are necessary to perform some analysis as explained by Kolbe et al. (2005) when they present CityGML relevance for disaster management. With respect to the fire-fighting simulator introduced in the previous section, the relevant categories of objects are buildings (with floors and indoor details), roads, urban areas, and forest areas have been introduced. It is important to determine which dimensions are needed for these objects and which levels of details, because this could dramatically affect the number and structure of the categorisation. For example, the classification of buildings could be extended in order to take into account the skyscrapers typology. We distinguish between 2D, 2.5D, and 3D data. In 2D representation, coordinates are only planimetric. In $2.5 \mathrm{D}$ there is one altitude for each planimetric coordinate (such as, a DEM). In 3D it is possible to describe several points with different altitudes and the same planimetric coordinates (such as, on a wall or when a bridge crosses a river). From an algorithmic point of view, sometimes 2D data is more suitable than 3D. The calculation of solar radiation or wind effect at street level do not require the same accurate representation as the intervisibility problem, used to check if two objects (e.g., firefighter and injured people) could see each other inside a building. This combination of 2.5D and 3D objects, as well as the combination of different levels of data details, leads to interoperability problems. These problems become clearer when different heterogeneous data sources are used at the same time, for example, terrain data, buildings, road networks, and water resources map (such as, hydrants - a very important element in the fire-fighting process). Depending on data resolution and scale, the hydrant location in the virtual world could not be precisely aligned with respect to terrain data, as it would be required in the Virtual Reality Simulator. The solution for these situations is based on the utilisation of multi-resolution data, assuring data quality, alignment, and integration at a specific level. CityGML, along with the well-defined 5 LoDs, is a very handy 3D data representation, allowing multiple data source unification at a given LoD. 


\subsubsection{D city models}

\section{City/urban model}

A city model is a representation of a part of the real world that encompasses urban entities and the global urban environment where they are located. Each entity of the model corresponds to an urban feature of the considered part of the real world. Example: in the CityGML model of Berlin each entity corresponds to a real building, road, water body, etc. This category of model is called instance model or token model (Kühne, 2006).

\section{D city/urban model}

A 3D city model is a model of the urban environment in a 3-dimensional geometry. Here, "model" can have two different meanings. First one is "a three-dimensional representation of a person, thing, a proposed structure, or anything else typically on a smaller scale than the original" (Oxford dictionary). It is with this meaning of the concept of model that most 3D urban models are built: as 3D representations of an urban environment, the same way we build clay models or wood mock-ups of cities. The second one is "a simplified description, especially mathematical, of a system or process, to assist calculations and predictions". Here, the 3D urban model is not only a geometric model, but it can be used to study in a certain way the urban system. The next section proposes to make a clear distinction between both meanings.

Note: we generally use the term 'city model' but we rather mean "urban model" as, in most instances, a city model denotes a specific model of a given city. In this report, we use "city model" as a matter of homogeneity.

\section{Semantic 3D city model}

A semantic 3D city model refers to a 3D city model that contains urban knowledge or semantic information as opposed to a geometric 3D urban model that would contain pure geometric information. Such models integrate attributes of objects (nature, usage, etc.), but they can also contain relationships between objects (topological, spatial, etc.).

The more information the model contains the more uses it may have. Nevertheless, more information also means more potential conflicts between attributes and relationships and more complex consistency issues. The construction and the update of information also become a complex challenge.

In order to describe such a model, a typification of urban entities meant to be described is necessary. This typification can take the form of a UML class diagram, a formal logical ontology (e.g. in OWL), a database schema, an XML schema, etc. This category of model is called "type model" (Kühne, 2006). 


\section{Properties and relations in urban applications}

An important topic in urban applications is the management of spatial relationships between features located in space, such as "is visible from", "is at walking distance from" and the management of spatial properties of urban features, such as the shape of a building or the width of a street.

These are fundamental aspects within the context of this COST Action for several reasons, as follows:

- Relations and properties are important because they refer to the way people perceive, reason, and describe spatial information (Egenhofer and Mark, 1995).

- Relations are important as people try to adopt a systemic approach to city modelling and analysis: it is important to study and explicit relations that can be used to integrate one aspect with another (other methods do exist to integrate aspects in a systemic analysis; the method presented here is just one of them). In terms of data integration, spatial relations are often used to build integrity constraints that will control the integration process (Borges et al., 2002).

- Spatial relations and properties are important as the domain has experienced a rapid evolution in terms of digital representation and in terms of what can be derived from existing models.

There seems to be a common basis of properties and relations in most urban applications (see Table 1 below). Usually, spatial relations or properties can be assessed from coordinates (this is not always the case though since sometimes they need to be assessed and stored separately). In these cases, it should be underlined that the most adapted geometry is not always the finer 3D LOD, and that a generic city model should be a multi-representation with several LODs and several types of geometry (2D or 3D).

Table 1 below summarises important relations and properties to be found in urban applications, and distinguishes between them what seems to be closer to the human experience of reality or closer to the computation level.

In the context of urbanism, important building properties and relations are related to a single building, such as width, depth, rise, whereas others are related to a parcel, such as ratio between floor gross surface and open surface, cost land value, etc.. Others are related to neighbours, such as exposure to sun, intervisibility, and minimum distance.

In the domain of sketch maps, landmarks for pedestrian navigation and qualitative geography, authors identify properties and relations relevant for somebody to locate himself otherwise than through the use of coordinates in space (Kopczynski, 2006; Wang et al., 2011 1). These works concentrated on identifying relations and properties that can be perceived and that are discriminating, typically a property will be a comparative property relative to a context "the highest building in the neighbourhood". They also focus on how people express those relations, which includes vagueness. Finally, some relations are relative to a user point of view, such as "behind" (Bartie et al., 2011 ). 
Table 1. Some relations and properties much connected to semantics, and others more connected to computation (Bucher et al., 2012).

\begin{tabular}{|c|c|}
\hline \multicolumn{2}{|c|}{ Properties and relations strongly connected to our experience of reality } \\
\hline $\begin{array}{l}\text { - exposure to sun } \\
\text { - shape (width, depth, rise, pattern) of } \\
\text { features or of feature sets } \\
\text { - salience (the highest building around) } \\
\text { - size, level of detail } \\
\text { - belonging to a group, being isolated }\end{array}$ & $\begin{array}{l}\text { - intervisibility } \\
\text { - composition (building blocks, the different compo- } \\
\text { nents of a building) } \\
\text { - some distance relations (such as, the minimal dis- } \\
\text { tance between building, the walking distance) } \\
\text { - topological relations (such as, access to a buil- } \\
\text { ding from a street network, such as, being on one } \\
\text { side of a road, such as the possibility to drive } \\
\text { from one road to another in a road network) } \\
\text { - directional relations (such as, aligned buildings, } \\
\text { north of) } \\
\text { - vertical relations (such as, above) } \\
\text { - projectional relations (such as, opposite of). } \\
\text { - interface (ternary relation): a feature supporting } \\
\text { or preventing some communication/stream from } \\
\text { one feature to another (e.g. a bridge from one } \\
\text { side of town to the other for cars only, a wall } \\
\text { protecting buildings from motorway noise) }\end{array}$ \\
\hline \multicolumn{2}{|c|}{ Properties and relations strongly connected to computation } \\
\hline $\begin{array}{l}\text { - distribution, proportions, regularities, } \\
\text { symmetries } \\
\text { - convexity, etc. } \\
\text { - resolution, granularity }\end{array}$ & $\begin{array}{l}\text { - distance relations } \\
\text { - topological relations (RCC8) } \\
\text { - directional relations }\end{array}$ \\
\hline
\end{tabular}

\section{D city model interoperability}

According to the Business dictionary (http://www.businessdictionary.com), the definition of "interoperability" is the ability of a computer system to run application programs from different vendors, and to interact with other computers across local or wide-area networks regardless of their physical architecture and operating systems. Interoperability is feasible through hardware and software components that conform to open standards, such as those used for internet.

In the urban domain, interoperability means the ability to use several descriptions of the same spatial area (city or urban zone) at the same time and benefit from the combined knowledge they contain.

From the definition above, we foresee a few challenging issues that need to be considered:

- Models may be of different scales and contain different levels of details, also including redundant or partially inconsistent information whatever data type they may be (i.e. geometric or semantic data). 
- Models may suffer from temporal inconsistencies because they have been developed at different periods of time.

- Due to various file formats, models may contain information that is not represented in the same way according to the files. It might be necessary then to "align" and combine the different sources of information in the same structures (see ontologies).

Once the concepts used in 3D city models are defined, the following section consists of providing methods for building 3D city models. This is done in more detail in the second section of this report: the models are presented here only from the point of view of their construction.

\subsection{Building 3D city models}

In this section, we present the main features towards 3D city model construction, both in terms of geometrical data acquisition and in terms of languages used for model description. Different techniques have been developed to build city models based on different approaches. Those approaches can roughly be classified into two categories: automated or manual techniques. Survey-based re-construction and modelling can be considered as automated techniques for the creation of 3D city models. When automation is not possible, manual reconstruction and modelling techniques can be used.

We present below a way of building 3D city models through the acquisition of 3D geometry.

\subsubsection{D geometry acquisition}

Many cities and administrations of EU countries have added 3D city models to their local data infrastructures for development planning as well as transportation, logistic, energy, climate, air quality, fire propagation, health and public safety studies. Computer-aided design (CAD) now offers powerful tools for creating digital models of cities. These tools need data to model the real-world infrastructures. Manual measurement and data entry are not easy to do, so researchers have preferred others methods, notably based on the use of sensors, to acquire accurate data for 3D urban landscapes. However, data acquisition methods strongly influence models characteristics and usefulness. Those methods can be clustered to other methods based on photogrammetry, active sensors, and hybrid sensor systems.

Photogrammetric techniques use 2D image sensors to model systems developed for terrestrial, panoramic, and aerial images. Terrestrial images provide high fidelity ground, vegetation, and building façade details, but the limited area visible in each image and the calibration needed to stitch images together make it difficult to construct large urban areas. Panoramic photographs are acquired by cameras with special lenses or mirror systems to acquire images, or an image processing 
software stitches them together from multiple planar projection images. Imagebased rendering techniques can create a 3D representation of an urban area from a collection of panoramic images. Since existing approaches do not provide explicit 3D-geometry data, integrating panoramic images with other data and scaling them to larger areas is difficult. Aerial images have several advantages over terrestrial images. In fact, besides providing accurate building footprints and roof heights, they can be rectified into orthoprojections that facilitate the merging process of multiple images to cover large geographic areas. Orthoprojections also facilitate fusion with 2D GIS systems, integrating models with rich information databases. The complexity and the quantity of data needed to represent large urban areas make fully automatic techniques highly desirable. Many barriers to fully automated systems exist, however. For example, image noise, lightening conditions, occlusions, and scene complexity make building segmentation (their individual identification in a image) an awkward process. Moreover, 3D reconstruction of complete buildings is difficult when a single building is made of complex substructures. Aerial images often lack of façade information, resulting in models with no visual realism. Integrating façade data is usually a manual process and requires additional sensor data.

Active sensors directly measure the depth of objects, which provide an ideal data set for urban modelling. Sensors can be further divided into two categories: ground based and airborne-based (LiDAR, light detection and ranging). Semiautomatic model construction requires a fair amount of operator intervention and results in painfully slow evolution of wide area models. Automatic LiDAR modelling requires automatic structure segmentation and $3 D$ reconstruction, which is rather complex process because of occlusions between buildings or vegetation against buildings.

Merging together ground and aerial image sensors, aerial active sensors, and 2D footprint data from GIS or CAD data can generate more accurate and automatic urban models (hybrid sensor systems).

\subsubsection{Formats and languages}

Various formats and languages have been developed to represent city related information. We review some of them in this section. The following two sections ("Building information modelling" and "3D computer graphics and geovisualisation / X3D \& KML") is directly derived from the work of Kolbe (2009).

\section{Building information modelling (BIM)}

Building Information Modelling (BIM) means the semantic modelling of objects and processes in the field of $A E C / F M$ and CAAD, such as in CityGML, where thematic objects are represented with their 3D spatial properties and interrelationships. Data are typically exchanged using the Industry Foundation Classes (IFC), an ISO standard describing a product model and data exchange format for the 
built-up environment developed by the International Alliance for Interoperability (IAI). IFC provides a very detailed semantic model for 3D building representations using constructive elements such as beams, walls etc. Such as in GML, IFC geometries are spatial properties of semantic objects. IFC has a very flexible geometry model (CSG, BRep, and Sweep representations), but does not provide support for coordinate reference systems; geo-referencing is not yet possible. Since the scope of IFC is restricted to buildings and sites, no topographic feature classes, such as terrain, vegetation, water bodies etc., are included.

\section{D computer graphics and geovisualisation}

3D computer graphics standards, such as X3D, VRML, or COLLADA, and geovisualisation standards, such as KML address the way to efficiently and nicely visualise 3D models and how to interact with them. Both in X3D and KML geo-referencing by using coordinates is possible. Although it is in principle possible to also exchange semantic information using $\mathrm{X} 3 \mathrm{D}$ or $\mathrm{KML}$, both specifications do not standardise the way how to represent complex geographic features and their interrelationships. CityGML should be considered a rich source format from which X3D or KML can easily be derived. CityGML is not optimised with respect to efficient visualisation.

The different 3D city model exchange formats are summarised in Table 2 below.

Table 2. Different formats applicable to 3D city models (courtesy of Thomas Kolbe).

\section{D City/Landscape Model Exchange Formats}

\begin{tabular}{|l|c|c|c|c|c|c|c|}
\hline & X3D & COLLADA & KML & Shape & CityGML & IFC & DXF \\
\hline $\begin{array}{l}\text { general purpose / } \\
\text { information model }\end{array}$ & gp & gp & gp & gp & im & im & gp \\
\hline 3D geometry & + & + & $\bullet$ & $\bullet$ & + & ++ & $\bullet$ \\
\hline georeferencing & + & $\bullet$ & $\bullet$ & + & ++ & $\bullet$ & \\
\hline appearance & ++ & ++ & $\bullet$ & & + & $\bullet$ & \\
\hline 3D topology & $\bullet$ & $\bullet$ & & & + & + & \\
\hline semantics & $\bullet$ & $\bullet$ & $\bullet$ & $\bullet$ & ++ & ++ & \\
\hline levels of detail & + & + & $\bullet$ & & ++ & $\bullet$ & \\
\hline links/embedding & + & ++ & ++ & & ++ & & \\
\hline extensibility & + & ++ & + & & ++ & $\bullet$ & \\
\hline fast rendering & ++ & ++ & + & + & + & $\bullet /+$ & + \\
\hline
\end{tabular}

Legend: $\cdot$ = basic,$+=$ sophisticated,$++=$ comprehensive; empty = not supported 
In a chapter about the state of the art in terms of 3D city models, an important aspect is the analysis of the use made of such models. This is the object of study of the following section.

\subsection{Usage and utility of enriched 3D city models}

The applications of 3D city models are potentially wide ranging from urban planning to tourism or air quality computation. Such uses are made possible by defining enriched 3D city models - where the geometrical aspects have been extended with other aspects related to air quality, urban wind flows, visibility, etc. - and by presenting such enriched 3D city models in a way that allows decisionmaking processes to be carried out from the best choices among sets of objectives, and across issues and levels of details.

During our COST Action, several experiences and projects have been presented covering a wide range of applications. For illustration purposes, we present presenting this section a selection of those.

We present in this section the following examples: The Netherlands 3D pilot project, the 3D Cadastre project, the 3D SDI project Rotterdam, the CFD modelling of urban wind flows, and the Air quality and human exposure project.

\section{Netherlands 3D pilot}

The Netherlands has completed a two-phases project named 3D pilot. The pilot was initiated by Dutch Kadaster, Geonovum (the National Spatial Data Infrastructure executive committee in the Netherlands, which develops and manages the geo-standards), The Netherlands's Geodetic Commission (NCG), and the Dutch Ministry of Infrastructure and Environment. The first phase took place between January 2010 and June 2011 and the general purpose of the project was to explore the need and use of 3D city models. The main goal was to establish a uniform approach for acquiring, maintaining, and disseminating 3D geo-information. The first phase was executed with 65 stakeholders in The Netherlands (Stoter et al., 2012). The findings of the pilot project were formally expressed in a national 3D standard achieved as a CityGML Application Domain Extension (ADE). The ADE completely integrates the OGC CityGML Encoding Standard with a new version of the existing National Information Model for Geo-information (called IMGeo). IMGeo contains object definitions for large-scale representations of roads, water, land use/land cover, bridges, tunnels, etc., and prescribes 2D point, curve, or surface geometry for all objects. IMGeo version 2.0 allows extensions to $2.5 \mathrm{D}$ representations (i.e. as height surfaces; equivalent to CityGML LODO) and 3D (i.e. volumetric; i.e. CityGML LOD1, LOD2 and LOD3) representations of the objects according to the geometric and semantic principles of CityGML. Further technical details about the ADE are reported in (van den Brink et al., 2013). The new standard is operational since 2012 . 
In the development process of CityGML ADE IMGeo 2.0 a number of topics requiring further attention were identified. For example, the need to understand how the national 3D standard works in practice, e.g. how to preserve the links between the different Levels of Detail (LODs), and how to upgrade 2D LOD to higher LODs. It is also important to make sure that 3D IMGeo data can be read and visualised by CityGML-compliant software. For example, whether software systems are compatible with IMGeo extensions, and, if not, which changes are necessary. Finally, further research is needed concerning the creation and management of CityGML-IMGeo data. Which approaches are most appropriate to generate CityGML-IMGeo data? How should this data be validated and maintained?

These issues have been the main focus of the second phase of the 3D Pilot, which took place in October 2012. The second phase's goals were more resultoriented and aimed at writing best practice documents and instructions by joint efforts of the 3D Pilot community. About 100 organisations participated in the second phase and completed six activities (see www.3dpilot.nl). The second phase was closed with technical specification for the reconstruction of 3D Ingeo CityGML data (available at: http://www.geonovum.nl/sites/default/files/3D/ toolkit/3DFinalReport_2013_1.01.pdf).

The 3D pilot in The Netherlands has clearly revealed several important aspects of 3D city models. On one hand many specialists need and appreciate the use of 3D city models but either do not have access to such data or are not aware of their availability. On the other hand, producers of 3D data have difficulties to estimate what kind of applications might need their 3D data. The discussion between the two groups helped largely to reach agreements for quality and accuracy of the different applications. The semantic aspect of the data becomes much more evident to both groups. Traditionally, Dutch 2D information models contain rich thematic semantics and this semantics was brought into the development of the IMGeo $A D E$. The $3 D$ pilot contributed also to the definition of several use cases, used to identify needed objects, attributes, relationships and expected functionalities to be provided by 3D systems.

\section{D cadastre}

3D cadastre is another application that increasingly needs 3D data. 3D cadastre is discussed in many countries (e.g. Australia, Norway, Russia, China, Israel) and several projects have been working on prototype systems. Cadastral objects (parcels) differ than topographic data. Typically the boundaries of the cadastral objects may not necessarily coincide with topographic boundaries. Furthermore, cadastral units need to be correct volumes.

A pilot project for a 3D cadastre was achieved in the Russian federation (2010-2011) as the goal was to develop a data model and propose a system architecture for management and visualisation of cadastral information (van Oosterom et al., 2012) (Vandysheva et al., 2012). The developments did not change much the existing data model, but many discussions were carried out 
on how to visualise the information on the Web. The administrative properties of the cadastral units do not change at all and 3D geometries (polyhedron-based) also require no (or very little) changes to the geometric side of the database. The 3D polyhedrons do fit in Oracle spatial SDO_GEOMETRY type. Several different approaches were investigated for Web visualisation and all current 3D standards were taken into consideration (Zlatanova et al., 2012). CityGML was proposed as appropriate for the exchange of information and X3D as the standard for visualisation on the Web. A Web application was developed allowing visualisation of geometry and attributes, as well as simple interactions with the geometry. The application allows cadastral units to be shifted away from the main body of the building to better investigate individual units. This project has shown that various technical solutions can be applied to meet user requirements. The more severe challenges found were related to the way of getting 3D properties constructed. No automatic procedure could be used to obtain the needed 3D units and therefore several 3D cadastral units were created manually.

\section{D SDI project Rotterdam}

The 3D SDI project of Port Rotterdam (Zlatanova et al., 2013) is a typical example of 3D data integration. Such kind of problem can be observed in many large civil engineering projects where data from above and underground has to be maintained and updated during the entire duration of the project (Tegtmeier et al., 2009). Rotterdam is particularly interesting because of the continuous development and maintenance of infrastructures, facilities, logistics, and other assets in the territory of the local port. A large number of public and private stakeholders (companies, environmental authorities, municipalities, various institutions, and citizens) are constantly involved in the exchange of information. Much of this information concerns interdependent infrastructural features that are embedded in a dynamic environment. The information is spatially distributed above ground (topography, cadastral parcels, buildings, streets, parking areas), underground (cables and pipes, geological and geotechnical data, tunnels), in the air (sensors for measurement of air quality, radar coverage, camera coverage), and in the water (depth of the harbour). Data models and data formats with varying dimensionality, granularity, accuracy, and level of up-to-datedness are in use. Several issues can be identified as major bottlenecks:

- Low dimensionality: a substantial part of data sets in the management and design processes of the port consists of traditional 2D line drawings. In many applications, such as calculation of radar shadows by buildings, noise emission simulations, the distribution of emission from chimneys, or the analysis of exact spatial configurations of complex layers of underground features (cables, pipes, tunnels, garages, underground), associate flat representations need to be remodelled in their full three dimensional spatial extend.

- High complexity of data sets. This complexity concerns several aspects. Geometric diversity: the variety of topographic and other thematic maps, high resolution measurement data from various sensors (optical, laser, water-lever 
sensors, etc.), voxel sets of representing geology and design information, provided by both public and commercial services, results in large amounts of data which are awkward to process. Semantic diversity: for data based on existing semantically rich data models problems arise from matching and mapping different semantic concepts for an integration of heterogeneous data into a single model. Granularity \& accuracy: with varying geometric and topological detail of available data sets, abstraction, simplification and the provision of multiple levels of detail are necessary to facilitate the decision making process. The majority of data transferred between stakeholders and Port of Rotterdam is encoded in proprietary files (such as, shapefile, $\mathrm{dwg}, \mathrm{dgn}$ ) that require the use of a large range of specialised applications and tools with a high total cost of ownership/operation.

Based on initial studies on data exchange and processing, communication with clients and companies, and the needed data for management and maintenance of assets, it was concluded that a generic 3D model (or set of models) had to be envisaged to allow integration of different data sets in a single environment and for different department/client goals. This model aims at the alignment, harmonization and integration of existing spatial data models as well as the development of additional umbrella meta-models and missing domain models. Related to the model, two aspects require special attention:

- The set of objects (features) which have to be included in the model considering their semantics, geometry, topology, appearance, granularity or levels of detail (LOD). Currently, one real-world phenomenon might be represented in several department systems, having different attributes and sometimes even different geometric representations. Going to 3D, it should be also evaluated which concept BIM (e.g. IFC) or GIS (e.g. CityGML) would be more relevant for the generic model. In this relation, it should be investigated which new objects need to be defined.

- The data structure that would be most appropriate to maintain the objects, their properties, and their relationships. At the present, individual departments maintain many data sets, though large parts of the information are managed centrally in a database management system (DBMS). A central management will facilitate consistency and will allow the re-use of information, but also requires a data model that serves the needs of all departments.

The starting point will be the investigation of 3D semantically rich standards as CityGML and IFC. All objects that may be found in other existing models (standards) will be reused. If needed, specialisations may be introduced following approaches similar to the one used in the development of IMGeo SDI. The specialisations may affect semantics (defining new classes), geometry (extending with 3D geometry), or attributes. It is very much possible that some applications may require a topological data structure to be introduced. The ultimate goal is to developed one 3D model (similar to the real situation) from which sections (even in 2D) can be made for different tasks performed at the Port of Rotterdam area by different types of users (Fig. 2). 


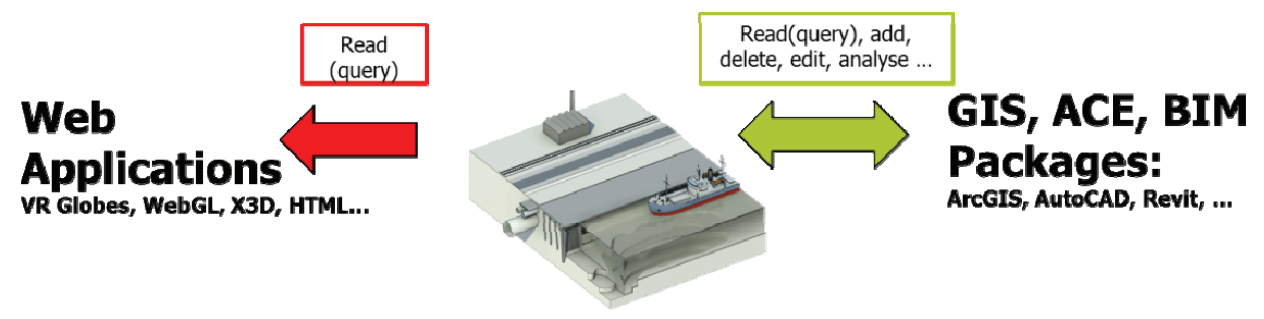

3D Generic model

Objects, attributes, relations, appearance

Fig. 2. Idealistic vew of the intended 3D model (above and under surface, air and water, and design objects) with the two types of uses witin the port (right) and by clients (left).

\section{CFD modelling of urban wind flows}

There is currently an overall consensus that urban structure (including the city shape, size, and densityl can have a significant effect on urban climate and on air quality levels. This has been shown for several cities around the globe, as for Melbourne in Australia (Marquez and Smith, 1999), Macao in China (Tang and Wang, 2007), New York in the US (Civerolo et al., 2007), Ruhr in Germany (De Ridder et al., 2008a,b), Porto in Portugal (Martins, 2012), or even in idealised cities (Borrego et al., 2006; Hang et al., 2009). Research has shown that the physical characteristics of an urban street canyon (including the geometry of buildings, the orientation merging wind and sun, materials, the existence of trees, etc.) are crucial elements on human comfort and health, since they modify the patterns of air temperature, wind, turbulence, and pollutants levels (Britter and Hanna, 2003; Borrego et al., 2004, 2012; Ishaque and Boland, 2008; Gallagher et al., 2012).

High-resolution computational fluid dynamics (CFD) models are the most powerful numerical tools today for the simulation of wind flow behaviour and air pollutant dispersion in complex urban environments (e.g., Borrego et al., 2003; Martins et al., 2009; Schatzmann et al., 2010). Moreover, with the exponential increase of hardware performances CFD applications are becoming increasingly more wide, detailed and accurate. Compared with measurements, CFD models allow a detailed understanding of the 3D study domain (on any parameter of interest: wind speed, turbulence, flows, temperature, among others), they are able to evaluate hypothetical situations and, specifically, the impacts of scenarios (e.g., climate) and alternatives (e.g., urban planning, traffic management, new vehicle technologies and fuels) and, finally, they are cheaper than measurements.

However, this type of advanced numerical tool is extremely demanding with regards to input requirements, with a special focus on the description and definition of the virtual domain in which calculations will be performed. In fact, the definition 
of urban elements is a crucial step towards the ultimate accuracy of simulations. The positioning and shape (i.e. 3D coordinates of each vertex) of buildings belong to the list of parameters whose knowledge is necessary. The integration of 3D city models (as CityGML) in air quality models can provide the missing information they require to be more precise and effective, while 3D city models can be enriched with the data originated by air quality modelling (Métral et al., 2008).

The modelling application by Amorim et al. (2012a) shows how the configuration of buildings can shape the winds within an urban area. In this paper, the multipurpose CFD Fluent code was applied to the Portuguese city of Aveiro. The results revealed a highly complex flow (see Fig. 3 below) that is induced by the aerodynamic effects of buildings and some isolated trees, as also by the incoming flow from the secondary streets, which lead to the formation of vortices of variable magnitude and impact. A highly complex spiraling flow is formed due the blocking effect of the taller buildings and the strong updrafts that occur especially in this area.

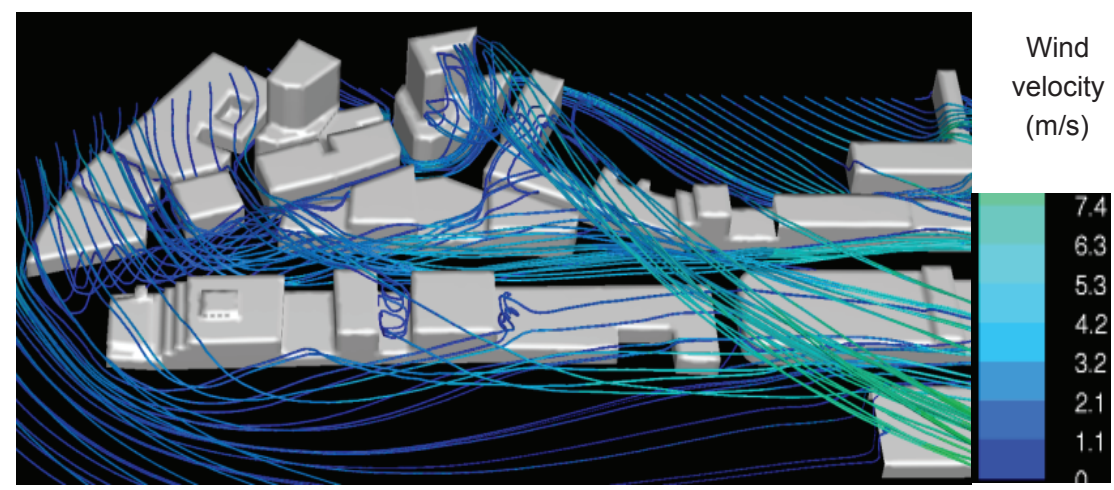

Fig. 3. Visualisation of wind flow path lines in the main avenue of the Portuguese city of Aveiro. Zoom in over the western part of the avenue.

The characteristics of the wind flow determine the suitability of outdoor spaces for human usage. In the particular case of the assessment of human comfort levels by the use of CFD models, 3D city models are able to provide additional and more detailed information to support the evaluation of the fulfillment of international wind comfort criteria (e.g., Penwarden, 1973; Willemsen and Wisse, 2007).

\section{Air quality and human exposure}

Air quality levels of an urban area are intimately related with the wind behaviour previously addressed because of the manifold recirculation regions and complex wake structures that develop in-between buildings and other urban structures and furniture. In fact, computational models, field scale measurements, and laboratory experiments (namely in wind tunnel) have shown that the dispersion of air pollutants in a street-canyon is significantly affected by the geometry and typology 
of urban elements (e.g., Sini et al., 1996; Grimmond and Oke, 1999; Vardoulakis et al., 2003; Milliez and Carissimo, 2007; Gromke et al., 2008; Hang et al., 2009; Martins et al., 2009; Gallagher et al., 2012).

Beyond buildings themselves, other urban physical elements are capable of disrupting the air flow patterns in urban street canyons, such as solid free standing walls (McNabola, 2010), trees (Buccolieri et al., 2009; Amorim et al., 2010), or parked cars (Gallagher et al., 2011). Tree canopies are particularly critical in what relates to computation because of its dynamical behaviour in time (growth and leaf fall), which affects the height (total and crown base) and the porosity or permeability (given by the leaf area density, LAD, or leaf area index, LAI). Figure 3 presents the effect of vegetation on the dispersion of traffic-emitted carbon monoxide (CO) in the city centre of Lisbon obtained with Fluent (Amorim et al., 2010). An increase of CO concentration on the leeward side (right side buildings) of the street canyon is observed when trees are considered in the simulation. This behaviour is induced by a counter-clockwise swirling flow that develops along the canyon, which transports the pollutant emitted near ground level towards the leeward side through the open space under the trees crowns. The $\mathrm{CO}$ is then trapped by the decreased vertical exchange rate of air with the above roof-level atmosphere.

(a)

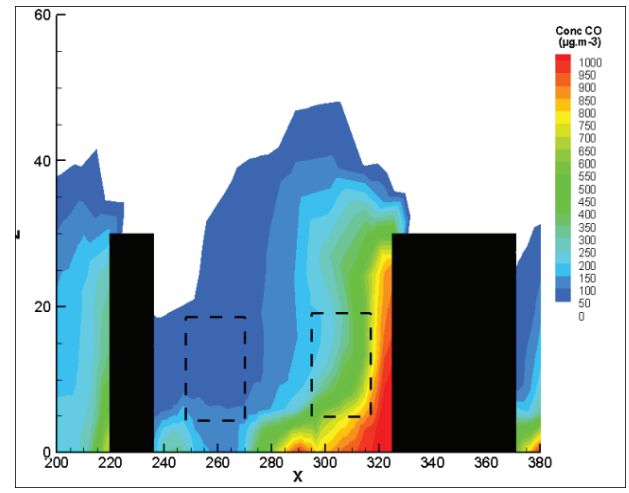

(b)

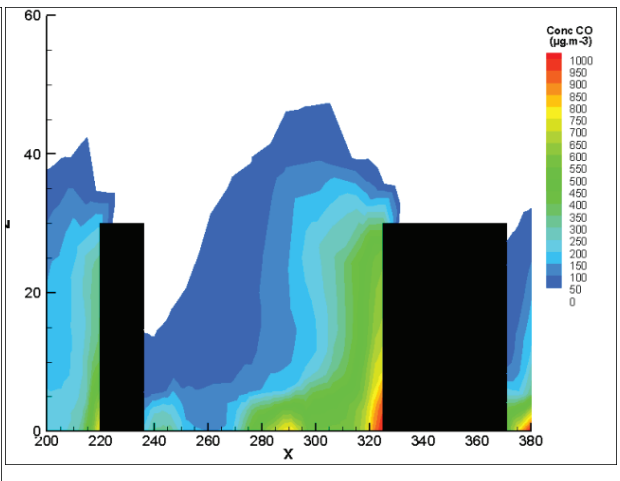

Fig. 4. Comparison of vertical CO concentration fields with (a) and without (b) the effect of trees, for the period between 8 and 9 a.m. Black filled rectangles represent buildings on both sides of the street while unfilled rectangles indicate the trees.

However, the effect shown in Figure 4 cannot be directly extrapolated to other situations since the action of trees on air quality is highly spatially dependent (varying with meteorological conditions, configuration of the canyon, positioning and characteristics of trees, etc.). Consequently, depending on the features of the urban wind flow, trees can promote or inhibit the natural ventilation of vehicle's emissions in a street-canyon (e.g., Amorim et al., 2010).

As a result from the heterogeneous spatial distribution of traffic-emitted air pollutants in a given urban area it is expectable that the exposure of pedestrians to 
pollution can vary depending on the route. This has been shown by Amorim et al. (2012a) and Valente et al. (2012) considering alternative walking ways for children on their way to school in the city of Aveiro, Portugal (Fig. 5). Exposure results were obtained by crossing the modelled CO concentrations (with VADIS (Borrego et al., 2003)| with the time evolution of geo-referenced location of an individual. As it can be seen from the analysis of Figure $4 a$, values of the individual exposure to $\mathrm{CO}$ vary significantly with time in the different walking routes to the school. Consequently, the average exposure also assumes distinct values, as shown in Figure $4 \mathrm{~b}$. This behaviour is a direct consequence from the asymmetric distribution of $\mathrm{CO}$ in the domain, characterised by the formation of hot-spots.

All those conclusions showed the importance of using detailed urban geometric properties for this type of analysis. The accuracy and spatial resolution (detail) of the virtual domain used by the model will ultimately affect the behaviour of the wind flow in the street-canyons, the dispersion of the emitted air pollutants, and finally, the concentration (and its distribution in the 3D space) to which individuals are exposed.

(a)

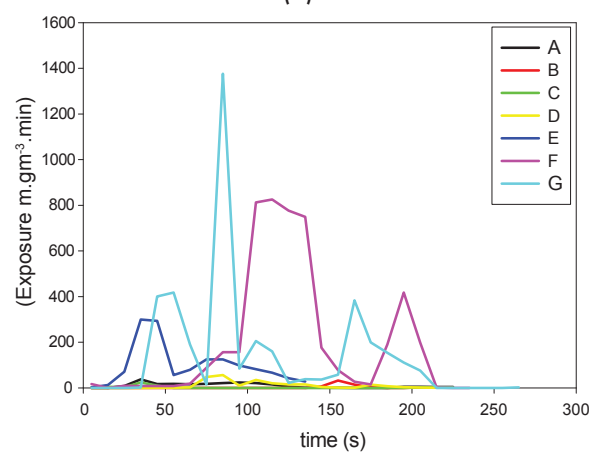

(b)

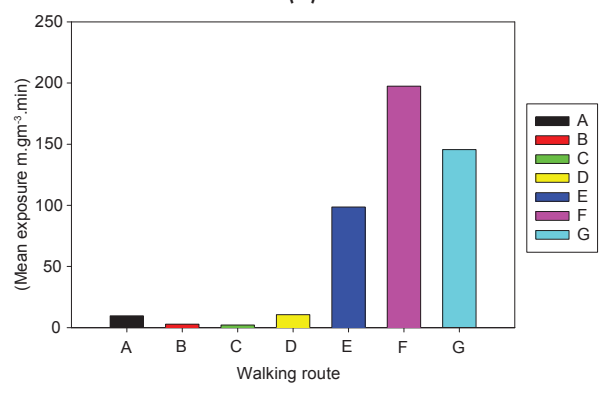

Fig. 5. (a) Time evolution of the individual $\mathrm{CO}$ exposure (in $\mu \mathrm{g} \cdot \mathrm{m}^{-3} \cdot \mathrm{min}$ ) for alternative walking pathways of children to school. (b) Comparison of the mean exposure in each route.

The usability and the usefulness of 3D city models models (in particular of buildings with enhanced detail, as LoD2 and LoD3) for the CFD modelling of urban environments (e.g. pedestrian comfort, outdoor/indoor air quality) is under discussion. The effect of building façades (e.g. balconies, type/material of the surface) and roofs (e.g. orientation, slope) on the wind flow is an important topic on urban studies. Implications for wind comfort, thermal comfort, energy efficiency of buildings, and indoor/outdoor air quality are significant and far from being entirely understood.

Despite the extensive use of 3D city models, some research questions remain open, such as:

- which model to use for this task; which level of detail; or

- which 3D visualisation technique to use for this kind of user. 
The topics above are related to the usability of enriched 3D city models that differ from the utility of such models. Some examples are discussed in Section 2.5.3.

In this part we have mentioned different uses of enriched 3D city models. However, the enrichment process of this kind of model is another important point to be analysed in this report: this matter is covered in the next section.

\subsection{Methods for enriching $3 D$ city models}

In this section we present methods for enriching 3D city models. However, in to be sure we share the same vocabulary, we start with some definitions about the concepts proposed.

\subsubsection{Definitions - fundamental and theoretical concepts}

The semantic enrichment of 3D city models consists of adding elements to a city model to better connect it to the real world. In other words, the goal is to represent in the model a deeper knowledge about the same part of real world. This can take several forms, such as adding more attributes/values to the representation of urban entities, adding new relationships between entities, or else adding entities of a new type (Kühne, 2006).

\section{Types of semantic enrichment for 3D city models:}

a) Enrichment in the same information model: in this case the information model remains the same but new more precise data are added to the (token) model. For instance, an undefined value is replaced with a defined value for an attribute, or the classification of an entity is made more precise (a GeometricObject is reclassified as a Bridge).

The main issue here arises when we try to automate this enrichment process. This implies explicit knowledge inference from implicit one (i.e. knowledge extraction) either by logical or by statistical means. This topic has been extensively studied in machine learning and automated reasoning. Nevertheless, specific techniques tailored to the 3D city models context should be defined.

b) Enrichment that involves a modification of the information model: to enrich a 3D city models with information that pertains to a specific domain it is necessary to extend the city information model with new attributes, entity types, or relation types. For instance, enriching CityGML with air quality information involves the creation of entity types to represent air flows (vector fields), pollutant concentrations (scalar fields), or attributes to represent average pollutant concentration inside a room.

There are many technical issues related to this type of enrichment:

- How to ensure that a 3D city information model can be extended without losing compatibility with already existing data sets? The CityGML Application Domain Extension (ADE) mechanism is a way to address this issue; 
- When there already exist a domain information model for the extension (e.g. a transportation information model),

- How to transform a domain model into extension entities (new classes, attributes, etc.) of the 3DCIM?

- How to specify this transformation?

- How to handle multiple competing domain models (e.g. several transportation models)?

- How can we apply the ontology-based data integration techniques to 3D city models enrichment?

- What are the relative merits of direct model extensions and ontology-based enrichment?

- How to handle existing data:

- How to map them to the enriched model?

- How to specify the required data mappings?

- Can we automatically deduce the data mapping functions from the information model mappings?

- How to connect object-based models and computational models (e.g. equation-based models with solvers)?

Let us present in the section below some methods leading to semantic enrichment.

\subsubsection{Addition / Aggregation / Generalisation}

Starting from an initial 3D CM, new 3D CM at lower LODs can be derived by generalisation, the process of reducing un-important details according to the working scale. Generalisation has a long history in cartography with the goal of emphasising the most important map elements while still representing the world in the most faithful and recognisable way. 3D generalisation shares the same goal but faces more challenging issue in both geographic and geometric complexity. Map generalisation operators, such as simplification, aggregation, typification, classification, symbolisation, and so on, are highly expected to be adapted for 3D city models, as well as algorithms that implement particular operators.

However, generalisation algorithms for 3D city objects need overall to be specifically designed due to their particularity in features and attributes. As far as buildings are concerned, well-developed geometry simplification algorithms for generic polygonal 3D models can hardly be adopted. This is mainly because buildings are already low-polygon objects together with parallel and orthogonal attributes that should be respected during simplification. Among all city objects, 3D generalisation has been mainly applied to terrain and buildings, especially buildings. 
Regarding terrain generalisation, filters from image processing which remove high or low frequency components from the signal can be used to generalise gridded terrain models (Weibel, 1991) (Li, 2008). Weibel (1992) proposed to generalise terrain based on structure lines (e.g. drainage and ridge network) that are extracted from the terrain model. As for the generalisation of multi-resolution terrain, Pajarola pointed out that terrain geometry can be easily generalised for smooth view-dependent rendering, as connected triangular irregular networks (TIN) and grid structures can be simplified using many techniques (Pajarola, 2007), for instance, line simplification method applied to terrain (Fei, 2009).

Buildings are the most significant city objects and have spurred the advancement of 3D building generalisation. A number of algorithms have been developed for generalising single buildings. Thiemann (2004) proposed to segment a building into basic 3D primitives and to decompose the whole generalisation process into segmentation, interpretation and generalisation phases. Forberg (2004) developed scale-space techniques for simplifying buildings, partly based on the opening and closing morphological operators. Kada (2007) proposed to divide buildings into cells by half-planes and to detect features by primitive instancing. Without semantic information, these methods mainly detect building features based on pure geometry. By taking semantic information into account, Fan et al. (2009) proposed a method for generalising CityGML building models to lower LODs from LOD3, further extended to LOD4 by Fan and Meng (2009). With different emphases, many other algorithms have been developed for single building generalisation. Other researches have focused on different aspects. Emphasising progressively removing details, Sester and Klein (1999) introduced a rule base which can guide the façade generalisation including aggregation of neighbouring windows, elimination, enlargement, or displacement of small façade features depending on their relative importance. Kada (2002) proposed an algorithm of constrained invasive edge reduction. Rau et al. (2006) focused on automatic generation of pseudo-continuous LOD polyhedral 3D building models, using only one parameter, i.e. feature resolution. For the purpose of simplifying and emphasising 3D buildings, Thiemann and Sester (2006) presented adaptive 3D templates by categorising building models into a limited number of classes with characteristic shapes.

The generalisation target is also enlarged to a set of buildings and/or including other city objects. Anders (2005) proposed an approach to the aggregation of linearly arranged building groups by computing their 2D silhouettes from three orthogonal projections. Guercke et al. (2011) studied the aggregation of LOD1 building models in the form of Mixed Integer Programming (MIP) problems. He et al. (2012a) proposed an approach to the generalisation of 3D building groups from medium LOD by converting 3D tasks into 2D issues via footprints. Techniques start emerging for generalising 3D building groups in the context of city visualisation. Glander and Döllner (2009) proposed cell-base generalisation by maintaining a hierarchy of landmarks. In each cell, only landmark buildings can be seen, the other buildings are typified by a cellblock. Other researches focused on different 
aspects. Chang et al. (2008) presented a city scale simplification approach based on "urban legibility" intended for better preserving understandability. Guercke and Brenner (2009) proposed a framework for the generalisation of 3D city models, within which custom feature types and generalisation algorithms can be defined. Glander et al. (2011) discussed the concepts for automatic generalisation of virtual 3D landscape models.

Geometry has been the main attribute for generalisation, but studies on texture generalisation started to emerge as well. Jahnke et al. (2011) quantitatively measured the relation between level of abstraction (generalised texture), information density (percentage of original texture) and storage capacity (kb). Zhang et al. (2012) introduced a new component structure - called FEdge - for managing both geometry and texture, and a multiple representation structure - called EBT (Evolved Buffer-Tree) - which supports more flexible LODs.

\subsubsection{Refining}

Starting from an initial 3D city models, new models at higher LODs can be derived by adding details, which are usually unknown. Thereby, the first task is to find or estimate the missing details. A popular way is to convey more information through texture mapping, which has been a success in representing complex materials that are hard to model and render. But texture mapping needs to assign a texture coordinate to each vertex of a polygon surface. So texture images should be well tailored and properly assigned, which are mostly done manually. Consequently, a mapped texture has to be remapped if geometry changes. Besides, rendering texture in a large amount would remarkably drag down the overall rendering performance. Due to the limitations of texture mapping, researchers started exploring geometry detailing methods, such as procedural modelling.

Procedural modelling is a flexible technique, which can be used for modelling from scratch and also for deriving new models starting from an initial 3D city models at any level of detail. Geometry details can be procedurally added by a controlled process defined by shape grammar and production rules, starting from the configuration of a finite set of basic shapes. For instance, in the context of buildings, production rules first create a raw volumetric model of a building, then continue to structure the façade, and finally add details for windows, doors, and ornaments (Müller, 2006). Of course, geo-referenced data of real cities can be used to configure the basic shape set. For example, CityEngine supports the import of most forms of GIS data for generating raw volumetric buildings at LOD 1. But other structures, such as roof, window, door, and balcony, are still unknown in most cases. If they are not crucial to the users, random split of the façades and similar structures may be satisfying, and a high level of automation can be achieved. Otherwise, different rules should be assigned to different buildings, yet the load of human work will largely increase. Therefore, a trade-off between automation and authenticity is hard to be avoided in practice. He et al., 
(2012b) applied a procedural method for automatically deriving building models from LOD2 to LOD3 by using impostor structures.

Besides detailing the overall appearance, adding semantic details is also useful to convey information, such as indicating street names, landmark signs, land use, administrative division, population distribution, and so forth. In a sense, a 3D city models can be seen as a platform combining heterogeneous information to represent the underlying city in a variety of aspects beyond the physical world.

\subsubsection{Hybrid methods}

The ideal case for deriving new 3D city models is to have an initial 3D city models covering the whole city area, at a high LOD, with an abundance of city objects. Unfortunately, for the time being, most available models with a city coverage extent are at low LODs. Partial models with small coverage extent and individual models of city objects may reach medium or high LODs. But these models are usually produced by different organisations using different tools and standards for different purposes, thereby resulting in a variety of data source with different structures and formats at different LODs. Therefore, the derivation solution has to be properly designed according to the available data source, usually needing a combination of several techniques.

Integration of different data source is probably the first issue in practice, and the complexity highly depends on the input data and on the requirements of specific applications. Exchanges between different standards and formats are naturally crucial, and many efforts have been made in improving interoperability. De Laat and Van Berlo (2011) studied the integration of BIM and GIS with emphasis on both sides, and described the development of a CityGML extension called GeoBIM to get semantic IFC data into a GIS context. Döllner and Hagedorn (2007) developed an interoperable 3D viewer client within the CAD/GIS/BIM thread of the Web Services Initiative Phase 4 of the Open Geospatial Consortium. After having obtained a 3D city models by integration, model derivation can be performed towards both directions: reducing details and adding details. For example, $\mathrm{He}$ et al. (2012b) developed a hybrid solution to deriving all range and heterogeneous multiscale 3D city models, by using a combination of techniques: extrusion, integration, generalisation, and procedural modelling.

Other methods exist to enrich city models, among which: XML schema extensions, UML based techniques and ontology based techniques. However they will not be mentioned in this state of the art since the work done within the framework of the COST Action has not provided specific contributions in those domains.

In the last part of this state of the art, we focus on the visualisation aspect of city models, and on the different ways of user interaction with models. 


\subsection{Visualisation and user interaction}

We discuss here the visualisation systems applicable to 3D city models and the corresponding techniques. We also review visualisation interfaces currently available.

\subsubsection{Visualisation systems}

Visualisation systems transform 3D city models into interactive 3D representations. "They provide at least 3D visualisation capabilities and navigation tools to navigate through the model. And often they also provide further functionalities to interact with the scene, i.e. content control, import and export functions, querying and selection tools, and others more. Due to the historical development of the research topic, especially the influences from the CAD/CAM domain and the GIS domain and the differentiated requirements regarding their functionalities and capabilities, many approaches to 3D visualisations of 3D city models have been developed. These can be differentiated according to their historic origin (systems based on CAD vs. GIS vs. game engines) or their system environment (web-based vs. desktop). However, these categories are neither exclusive nor explicit" (Ross, 2010).

Visualisation systems for driving immersive interactive 3D (i3D) displays are generally characterised by a combination of three hardware components (Szymanski 2004). The first is computational power, which includes the CPU, mainly memory and storage systems. The second is the graphic power, which, at the core, is the GPU (Graphics Processing Unit). Most of modern graphic cards are usually able to provide outputs to one or more channels where each channel is then connected to a projector that is displaying unto an i3D system.

The third component is the communication device, which is the glue that holds the first two together. Many modern supercomputers are capable of having multiple CPUs and GPUs, as well as an internal architecture that interconnects them with high-speed buses. These systems easily support multi-projector systems and have been commonly used as the image generator for i3D displays. However, there is a growing trend to use commodity off-the-shelf hardware and PC workstations to drive multiwall visualisation display systems. In order to display on a multiwall system, a cluster of PCs needs to be interconnected through hardware with software that allows multiple synchronised images to be rendered.

"Another trend observed is the increasing adoption of systems based on service-oriented architectures (SOA) or web-based clients, especially in the academic world but also in the industry. Usually, these come in a three-tiered system architecture, consisting of a data layer, a processing layer, and an application layer. Often the idea behind this approach is to implement systems for the collaboration and participation of spatially distributed users over the Internet. "However, webbased processing services, such as those presented in (Göbel and Zipf, 2008; 
Walenciak et al., 2009), prove that also analyses and data manipulation functions can be implemented based on Internet technologies and OpenGIS standards. In fact, these solutions do achieve a close integration of virtual 3D city models and functionalities into networks and are therefore predestined for applications that aim at the shared, collaborative use of virtual 3D city models in urban planning and management" (Ross, 2010).

Specific systems must be used for very large data sets. Indeed, data from simulations at the petascale level are too large to store and study directly with conventional post-processing visualisation tools. This problem will become even more severe as we reach exascale computing. A plausible, attractive solution involves processing data at simulation time (called in situ visualisation) to reduce the data that must be transferred over networks and stored, and to prepare data for more cost-effective post-processing visualisation (Kwan-Liu, 2009). In this approach, the strategy is to have both simulation and visualisation calculations run on the same parallel supercomputer so that data can be shared. Such simulation-time co-processing can render images directly or extract features-which are much smaller than full raw data-to be stored for later examination. So, reducing both data storage and transfer cost early in the data analysis pipeline, optimises the overall scientific discovery process. In situ visualisation presents many new challenges to both simulation and visualisation scientists. Before accomplishing this approach, researchers must answer several questions, e.g. about the way simulation and visualisation calculations share the same processor, memory space, and domain decomposition, what fraction of the supercomputer time should we devote to in situ data processing and visualisation and if existing commercial and open source visualisation software tools can be directly extended to support in situ visualisation at extreme scales.

New trends in visualisation for 3D city models are as follows:

\section{Visualisation on mobile devices}

Mobile 3D maps portray the real environment as a virtual one, similar to their desktop counterparts, but they run-or should run-in mobile devices (Nurminen, 2008).

In mobile devices, the computational power, memory, storage, and networking capabilities are increasing. They are being equipped with graphic hardware. For the first time, it might be possible to portray the environment with direct one-to-one mapping as $3 \mathrm{D}$, real-time rendered mobile virtual environments. With wireless networking capabilities and GPS tracking, these environments could even be populated with real-world entities, such as people and vehicles.

Developing mobile 3D maps is no longer hindered by the lack of 3D programming interfaces: the underlying rasterizer OpenGL ES is well supported on a range of devices, as is the Java-based scene graph renderer JSR-184. In addition, the VRML viewing library Pocket Cortona is available for MobileWindows, as is Direct3D Mobile. 
Photorealistic 3D cities from C3 Technologies, the leading provider of 3D mapping solutions, are now available on Ovi Maps, Nokia's free mapping and location service: (http://europe.nokia.com/support/product-support/ maps-support/compatibility-and-download)'. Nokia Corporation has licensed C3 photorealistic 3D cities for Ovi Maps, Nokia's free mapping and location services.

The first release includes 20 major cities around the world as well as 3D street views for some European cities, including Copenhagen and London. "Today, Nokia is adding a new dimension to the way people experience maps on the web," said Mattias Åström, C3 Technologies CEO.

C3's Metro database of more than 100 cities in 3D is available as a platform for new social and commercial applications serving local search, real estate, travel, tourism, media, and entertainment, as well as uses in civil government, utilities, and telecommunications.

\section{Web-based visualisation}

A current trend is related to web-based visualisation aiming at e-governance. As an illustration, we describe here the visualisation platform implemented by LAQ-TIP. This platform integrates virtual reality, geo-web, and visual analytics to empower large number of stakeholders and citizens across the Internet, in expressing choices and evaluating the impacts of policies for their cities or regions (Bazzanella et al., 2011). The main aim of this platform is to clarify and communicate complex policies in easy way to stakeholders, and, above all, laypeople. Governments and Agencies can use the platform to develop and implement policies with public participation, actively engaging the public in the policy-making process (Fig. 6).

The visualisation platform should be used as the final step of a structured process in which first stakeholders express choices and expectations on a policy applied to a certain area. Then, the impacts of the individual's choices are simulated for given places in the future.

The output from any simulation model with, at least, a geo-referenced variable is communicated within a Web page with synchronised windows:

- Geo-web and virtual reality: the platform associates to data generative procedures to create: 1) realistic representations of 3D objects, models of buildings and infrastructures, these are effective and engaging visualisations for the citizens; 2) symbolic representations of 3D objects, e.g. histograms, extrusions or blankets. Each data in a field corresponds to one of the models generated.

1. FreshNew.Com, C3 Technologies 3D Cities Now Part Of Nokia Ovi Maps, http://www. freshnews.com/news/482791/c3-technologies-3d-cities-now-part-of-nokia-ovi-maps/. 
- Geo-visual analytics: the platform integrates a number of motion visual representations and analytic tools that the user can choose. For instance, in parallel axes each data field is represented with an axis in a XY diagram. Several axes can be placed side by side: the number is constrained just by the size and resolution of the screen, thus representing various different fields simultaneously. Each data in a field corresponds to a point on the respective axis.

- Geo-web and Geo-visual analytics are coupled: selecting a data field in one view highlights the corresponding representation in the other view. This is a particularly clear mean of communication for geo-visualisation since the stakeholders can build their understanding of interdependencies of relationships among policy choices and options. The representation of the simulated personal scenario in its geographical context is underpinned by the concept of spatial dependence, which assists the stakeholders in interpreting and understanding the individual vision augmented through the "first law of geography", also known as Tobler's first law: "everything is related to everything else, but near things are more related than distant things" (Tobler, 1970).

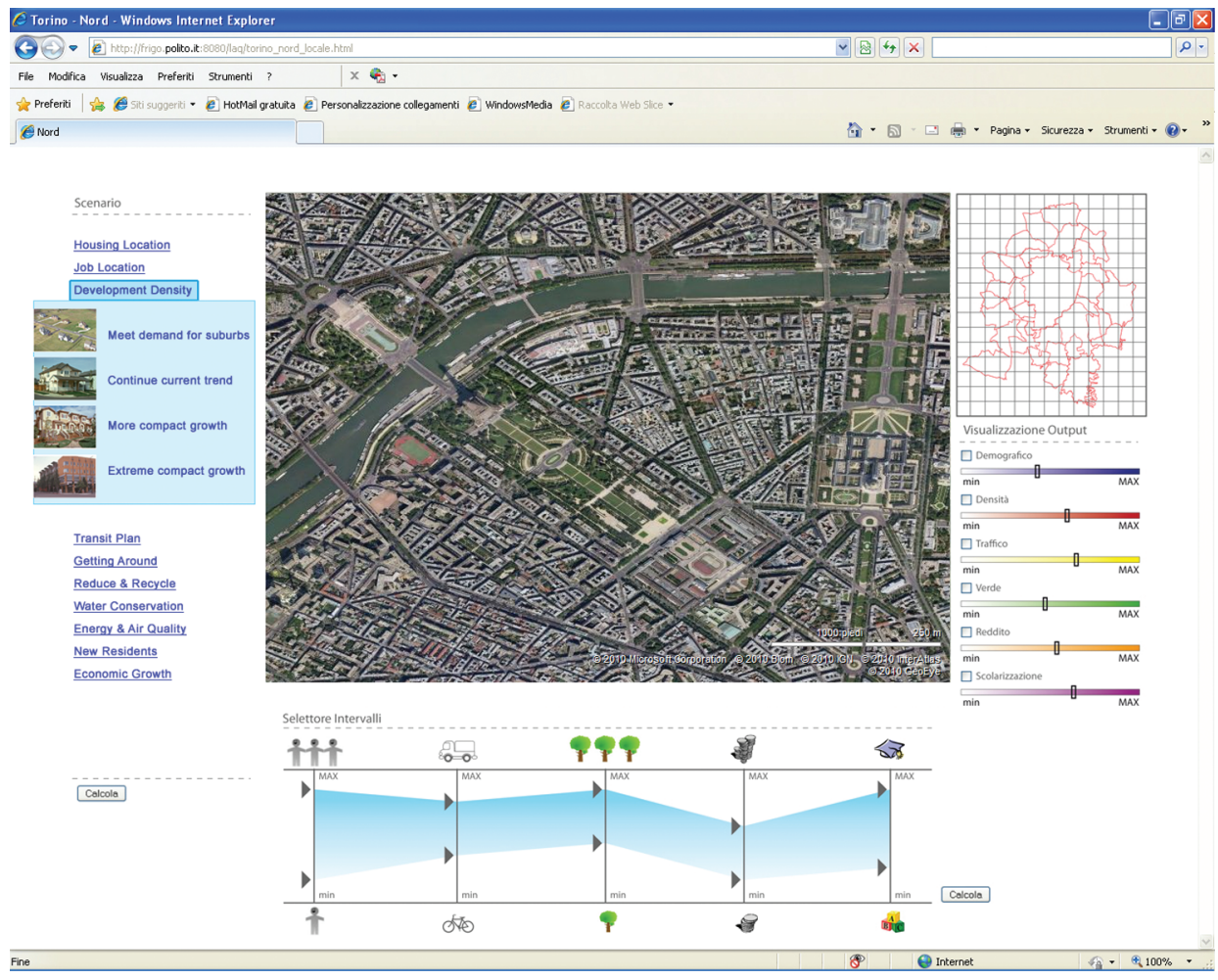

Fig. 6. LAQ-TIP visualisation platform for e-governance. 
Visions explicitly deals with the time dimension of a policy for given a place, thus many of their properties are not solely for geography but common for geography and time. Geo-web and Geo-visual analytics are interrelated on the time axis too, and benefit from visualisation and interaction in Google Earth 4D (3D + time).

Since "a picture is worth a thousand words", the interaction with Geo-web and Geo-visual analytics is much more intuitive than its description: in Geo-web selecting individuals or groups of Objects highlights in Geo-visual analytics their values and the connecting trajectories (sequences of polylines connecting the values). And vice versa: selecting several values or polylines (records) in Geo-visual analytics, highlights the relevant Object/s in Geo-web.

\section{Immersive virtual reality}

LAQ-TIP has designed and implemented an immersive virtual reality theatre (Fig. 7), equipped with a large planar rear-projection screen $(9 \times 4 \mathrm{~m}$., $4200 \times 2100$ pixel), computer hardware, graphics and audio systems and interaction devices.

A video presentation of LAQ-TIP theatre is available online http://www.laq-tip. polito.it/video/index.html/.

The VR system is implemented through distributed rendering performed by a cluster of 6 multi-CPU and multi-GPU workstations on planar or elliptical display wall. Each cluster node generates high-resolution scene content (a tile) synchronised in real- time through a fibre optic network, thus providing the effect of a single large display system. A frame-based 3D terrain simulation is performed by a display module which loads the data and interprets input parameters, such as view point and view angle, then finds the visibility data, and finally draws them.

The cluster simulates the acoustic of the virtual spaces, and in the theatre is reconstructed the accurate spatialisation and real-time interactive sonic to increase the immersing experience. In order to make the simulation system run more fluently and higher efficiently, the fulfilment of the real-time requirement has been guaranteed by a multithreaded execution. The system has been calibrated by means of a three-step procedure:

1) A projector registration to correct oblique projection and compensate for the variation of the geometric properties of the individual display units;

2) A luminance compensation to balance the intensity variations in each projector (intra-projector calibration);

3) A chromatic compensation to match the colours of different projectors (interprojector calibration). 


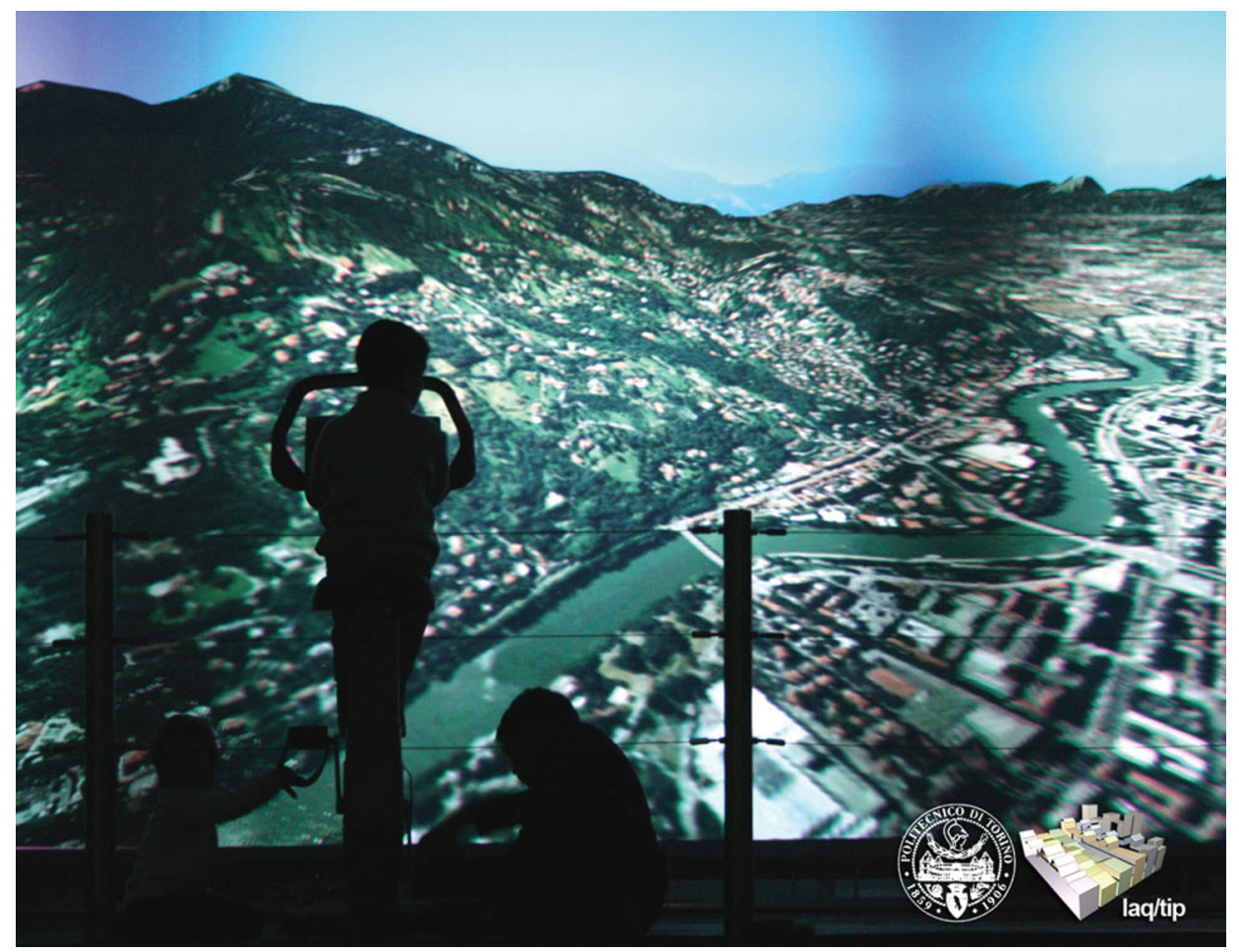

Fig. 7. LAQ-TIP Virtual reality Theater.

An example, visualisation of transportation information (geometry and enrichment data): understanding the regional or "big picture" transportation status can be complex. Many of today issues involve new concepts that the public-and even professionals in the field-have difficulty grasping (Pisarski, 2007).

Examples of difficult-to-explain transportation problems are:

- How does traffic build up when a blockage occurs on a freeway? Why does the build-up take so long to dissipate after the blockage is gone?

- Why do ramp meters work? How does congestion pricing play a similar role?

- How would a high-occupancy toll lane work?

- How would it help nonusers?

- How do shrinking or expanding market sheds or economic corridors affect access to employment, employees, suppliers, or a greater range of housing choices?

The CATT Lab (Pack, 2010) has developed a 4D, wide-area traffic visualisation tool to help incident management personnel, emergency management personnel, and the general public achieve situational awareness in as close to a real-world setting as possible (see Fig. 8). The lab's researchers combined OpenGL 
and modelling techniques to develop an interactive "virtual helicopter." The tool renders GIS (geographic information system) and transportation infrastructure data combined with traffic sensor, transit, and accident data.

The prototype system interacts with real-time traffic databases to show animations of traffic, incident, and weather data. With the virtual helicopter, users can travel through the region to inspect conditions from different angles, at different distances. Users can monitor and interact with traffic control devices such as dynamic message signs, closed-circuit TV feeds, and traffic sensors. They can even track and view fleets of ground or air vehicles equipped with GPS transponders.

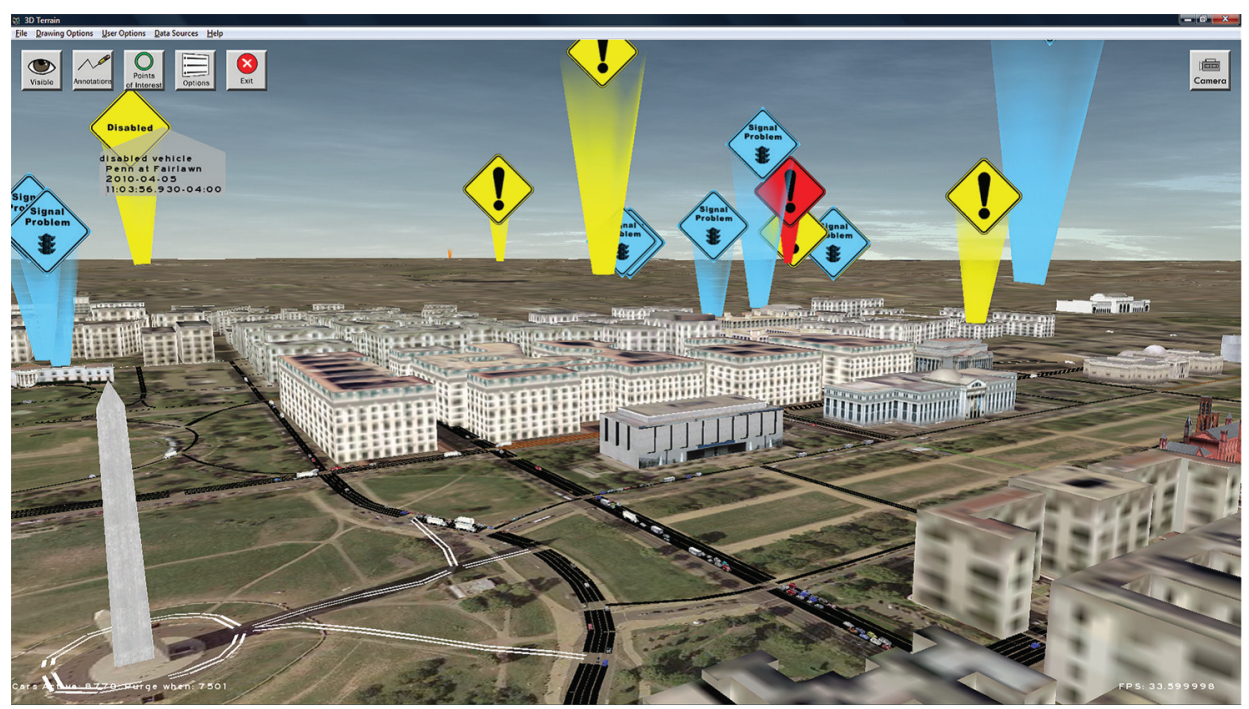

Fig. 8. Screenshot of a 4D real-time visualisation system displaying traffic conditions on a wide scale (Pack, 2010) (courtesy of M. Pack).

\subsubsection{Visualisation techniques for enriched 3D city models}

When designing an enriched 3D city model, the designer faces the problem of choosing the most relevant visualisation technique for viewing both geometric and enrichment data. A designer of 3D city model should consider existing techniques in order to reuse them and reduce time and costs instead of starting off from nothing. The selection of relevant technique(s) must be done according to the task(s) performed by the user and to the visual context where the tasks are meant to take place.

More precisely the selected techniques must at least:

- Be able to display the desired information (effectiveness);

- Efficiently support the user task(s). 
Furthermore, visualisation techniques face issues, such as:

- Techniques used in the same scene do not negatively interfere with each other (e.g. by hiding information).

- Techniques that are suitable for each data taken individually may be incompatible when taken together;

- Simple addition/superposition of visualisation techniques associated to different data may imply cognitive overload thus generating an incomprehensible 3D scene.

Thus, data have to be visualised from a set of suitable visualisation techniques taking into account compatibility - incompatibility rules between the techniques.

Learning about existing 3D user interfaces is not the only way for an advanced $3 \mathrm{D}$ designer to deal with the problems of offering effective and useful displays of enriched 3D city models. This domain is quite rich and large, so it is time consuming to be aware of all the novelties that may be useful in a particular case to display an amount of information (data set) within a 3D environment. Another solution for selecting a visualisation technique for enriched 3D city models relies on the existence of a knowledge base of visualisation techniques. Such a knowledge base should allow a designer to describe his needs and get all the information related to the techniques that may be useful to display his data set in the desired context.

Métral et al. (2012a and 2012b) addressed the problem related to visualisation of enriched 3D city models by proposing a methodology for defining such a knowledge base. If formalising the representation of $3 \mathrm{D}$ visualisation techniques for enrichment data is the first step to perform, it is not enough for defining and using the resulting knowledge base. To define and decide about the usability of such techniques in real cases, all information related to their evaluation has to be collected and organised, particularly the information related to the context (Abowd et al., 1999) and tasks (Limbourg and Vanderdonckt, 2003). The authors defined a formal representation of usability evaluation for enriched 3D city models in two steps: a first step to classify evaluation methods and identify their metrics; a second step to take into account the context and tasks of the evaluation. The authors also showed how this ontology can be used for computational reasoning and help for the selection of visualisation techniques by checking if a technique is compatible with a dataset to display or to a technique already selected and used in the same scene.

\subsubsection{Usability of 3D city models visualisation interfaces}

While enriched 3D city models have proved their utility for various purposes, they have generally not been extensively evaluated. 


\section{General definitions and methodologies}

As stated by Hornbæe (2006), how to measure usability is an important question in human computer interaction research and user interface evaluation. From an exhaustive review of literature, Hornbæek has defined usability aspects in terms of effectiveness, efficiency, and satisfaction, the usability being the effectiveness, efficiency, and satisfaction with which specified users can achieve goals in particular environments. He also differentiated objective measures from subjective measures. Subjective measures concern the user's perception of or attitude towards the user interface, the interaction or the outcome, whereas objective measures refer to aspects of the interaction not dependent on the user's perception (see Fig. 9).

\begin{tabular}{|c|c|c|c|c|}
\hline & Usability aspects & $\begin{array}{l}\text { Objective } \\
\text { measures }\end{array}$ & $\begin{array}{l}\text { Subjective } \\
\text { measures }\end{array}$ & \\
\hline $\begin{array}{l}\text { Relations } \\
\text { between } \\
\text { aspects? }\end{array}$ & $\begin{array}{l}\text { Outcomes } \\
\text { (effectiveness) }\end{array}$ & $\begin{array}{l}\text { Time, } \\
\text { usage patterns, } \\
\text { learnability }\end{array}$ & $\begin{array}{l}\text { Users' perception } \\
\text { of outcome } \\
\text { Subjectively } \\
\text { experienced } \\
\text { duration, } \\
\text { mental workload, } \\
\text { perception of task } \\
\text { difficulty }\end{array}$ & $\begin{array}{l}\text { Long-term use and } \\
\text { developments over } \\
\text { time? } \\
\text { Macro or micro } \\
\text { perspectives on } \\
\text { tasks? }\end{array}$ \\
\hline
\end{tabular}

Fig. 9. Challenges in measuring 3D city models usability (Hornbæk, 2006).

\section{Usability evaluation methods for 3D user interfaces}

Most of the evaluation methods have been originally designed for a 2D usability evaluation and they were then adapted and extended to support 3D user interfaces evaluation (Sebrechts et al., 1999). Bowman et al. (2004) took the initiative to write about the concept of 3D user interfaces in order to give a large literature reviews and a set of examples and guidelines to understand this research field (see Fig. 10).

The number of evaluation methods of 3D user interfaces usability is continuously growing. There are different kinds of evaluation methods such as heuristic evaluation (Nielsen and Molich, 1992) or formative evaluation (Hix and Harston, 1993). Each evaluation method uses its own metrics to measure the usability (system performance, task performance, user performance). 


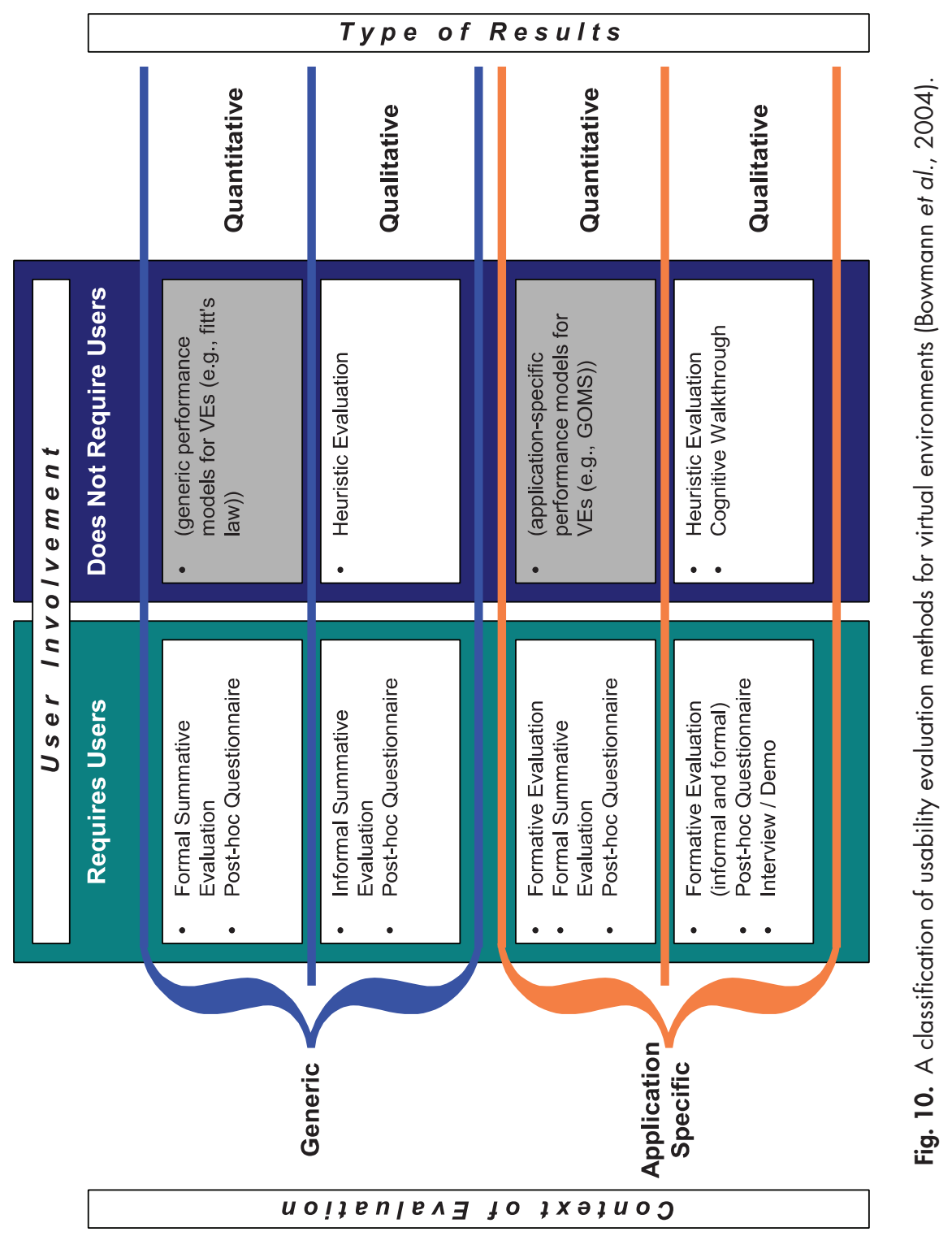




\section{Specific case of applications based on enriched 3D city models}

In order to be able to decide about the usability of applications based on enriched 3D city models, designers should use evaluation methods. Those methods should take into account types of interfaces usually found in enriched 3D city models, and the complexity of the tasks performed by the users of such interfaces.

If $2 D$ views are possible, 3D city models are usually visualised as 3D scenes, or $4 \mathrm{D}$, and $5 \mathrm{D}$ scenes when time and level of detail are taken into account too. Thus, usability evaluation methods for 3D user interfaces can be used for 3D city models. But enriched 3D city models have also some specificity in terms of data, tasks, and context.

Visualisation of enriched 3D city models is related to tasks performed by the user of such models for which he/she has to navigate in or over the 3D model.

More precisely, such tasks imply the visualization of data that:

- Originate from different fields, such as transport, construction, etc.;

- Are of different kinds, such as quantitative measures of noise, qualitative soundscapes, etc.;

- Take different forms (from structured data provided by GIS to unstructured documents);

- Have different scales (city as a whole, streets, buildings, etc.);

- Are not directly geo-referenced (legal text for example, although they have a spatial-temporal coverage).

Typical tasks include evaluation of urban projects in terms of quality of life (including visual aspects), evaluation of the impact of projects on the urban landscape and on other factors. Thus, evaluation of enriched 3D city models implies to take into account this complexity.

Furthermore, such tasks are performed in a variety of visual contexts and a visualisation technique relevant for a specific context (a city with large streets, for example) may be not relevant for another context (such as, an old town with narrow streets). 
7 KVSDJHIQMQWRQDQLOIVEOQN 


\section{Chapter 3}

\section{Action's outputs}

\subsection{Structure and action's organisation}

This part of the report concentrates on action's outputs description and identified breakthroughs and perspectives. We start with a presentation of the scientific production of the action through a list of activities, a list of scientific missions, reports of working groups and dissemination products such as books and website. Then, we focus on what was acknowledged as breakthroughs and research perspectives by the members.

Before detailing Action's outputs, it is necessary to recall the Action organisation and strategy.

Three working groups were set up at the beginning of the Action. Each of them brought specific contributions (see below). WG chairs managed groups meetings, discussions and deliverables production. If WGs had specific tasks to fulfil, they were highly integrated. It is the reason why we organised sometimes Joint WG meetings or specific meetings.

Each working group had a more specific contribution, as follows:

- WG 1: Identification and semantic analysis of issues and models.

- WG2: Semantic integration and interoperability.

- WG3: Information aggregation and presentation for decision processes. 
The main purpose of WG1 was to be an exchange and reflection platform about semantic and thematic 3D nature of urban space. Semantic and modelling issues were identified and analysed. This group was composed of urban experts as urban planners, urban geographers, sociologists, environmentalists, and researchers coming from the spatial information field.

WG2 focused on integration and interoperability issues when combining semantic information and models with 3D city models. This group was composed of researchers in information sciences and representation techniques.

WG3 addressed the stakes of information integration into decision processes to support urban development and sustainability. This implied a thorough understanding of those decision processes for a representative set of urban development and management processes, the identification of the user needs for related information and knowledge on the urban fabric, and the elicitation of possible analytical processes (modelling and computation of indices and indicators) and exploratory processes (3D visualisation and interaction) to address them in a $3 D$ environment. This group was composed of members of WG1 and WG2, end-users of 3D city models and urban data producers and managers (e.g. from National Mapping Agencies).

\subsection{Scientific production}

\subsubsection{Activities}

The Table 3 contains a comprehensive list of the Action's activities from the kickoff meeting till the final conference. It gives a timeline of the Action and contains, when existing, links to specific documents or websites.

Table 3. List of TU0801 activities.

\begin{tabular}{|c|c|c|c|c|}
\hline $\mathbf{N}^{\circ}$ & Type of activities & Title & Dates & Location \\
\hline 1 & Kick-off & & $04 / 11 / 2008$ & Brussels (BE) \\
\hline 2 & $\begin{array}{l}\text { Joint Management Committee } \\
\text { and Working Group meeting }\end{array}$ & & $27 / 04 / 2009$ & Berlin (DE) \\
\hline 3 & Summer school & $\begin{array}{l}\text { 3D geo-information for } \\
\text { Disaster management }\end{array}$ & $05 / 10 / 2009$ & Delft (NL) \\
\hline \multirow[t]{2}{*}{4} & $\begin{array}{l}\text { Joint Management Committee } \\
\text { and Working Group meeting }\end{array}$ & $\begin{array}{l}\text { A global view on } \\
\text { semantic enrichment of } \\
3 \mathrm{D} \text { urban models }\end{array}$ & $23 / 11 / 2009$ & Liege (BE) \\
\hline & \multicolumn{4}{|l|}{ www.geo.ulg.ac.be/cost } \\
\hline \multirow[t]{2}{*}{5} & $\begin{array}{l}\text { Joint Management Committee } \\
\text { and Working Group meeting }\end{array}$ & $\begin{array}{l}\text { 3D City Models in } \\
\text { Planning }\end{array}$ & $10-11 / 05 / 2010$ & Milan (IT) \\
\hline & \multicolumn{4}{|c|}{ http://www.metmodlab.org/events/COST2010/ } \\
\hline 6 & WG2 meeting & $\begin{array}{l}\text { In conjunction with } \\
\text { "3D Geolnfo" }\end{array}$ & $3-4 / 11 / 2010$ & Berlin (DE) \\
\hline 7 & WG1 and WG3 meeting & $\begin{array}{l}\text { In conjunction with } \\
\text { "WSEAS/CIEO Inter- } \\
\text { national Conference" }\end{array}$ & $3-5 / 11 / 2010$ & Faro (PT) \\
\hline
\end{tabular}




\begin{tabular}{|c|c|c|c|c|}
\hline 8 & WG2 meeting & & $13 / 12 / 2011$ & Brussels (BE) \\
\hline 9 & WG2 meeting & & $31 / 05 / 2012$ & Brussels (BE) \\
\hline 10 & Workshop & $\begin{array}{l}\text { 3D issues in transport } \\
\text { system }\end{array}$ & $20-21 / 10 / 2011$ & Riga (LV) \\
\hline & \multicolumn{4}{|l|}{ http://ts-3d.tsi.lv/ } \\
\hline 11 & Workshop & Historical 3D models & $15-16 / 11 / 2011$ & Liege (BE) \\
\hline \multirow[t]{2}{*}{12} & Workshop & $\begin{array}{l}\text { Evaluation of 3D city } \\
\text { models and pedestrian } \\
\text { navigation }\end{array}$ & $8-9 / 03 / 2012$ & Skopje (MK) \\
\hline & \multicolumn{4}{|c|}{ http://semcity.arh.ukim.edu.mk/ } \\
\hline \multirow[t]{2}{*}{13} & Workshop & $\begin{array}{l}\text { 3D issues in environ- } \\
\text { mental and urban sys- } \\
\text { tems }\end{array}$ & $12-13 / 04 / 2012$ & Madrid (SP) \\
\hline & \multicolumn{4}{|c|}{ http://titanio.Ima.fi.upm.es/cost801/ } \\
\hline 14 & $\begin{array}{l}\text { Joint Management Committee } \\
\text { and Working Group meeting }\end{array}$ & $\begin{array}{l}\text { Relevant relations and } \\
\text { properties in urban } \\
\text { application }\end{array}$ & $31 / 05 / 2012$ & Brussels (BE) \\
\hline 15 & Steering committee meeting & Final report & $18-20 / 06 / 2012$ & Liege (BE) \\
\hline \multirow[t]{2}{*}{16} & Final conference & $3 u 3 d$ & $29-31 / 10 / 2012$ & Nantes (FR) \\
\hline & \multicolumn{4}{|c|}{ http://3u3d2012.sciencesconf.org/ } \\
\hline
\end{tabular}

\subsubsection{Scientific missions}

The aim of a Short-Term Scientific Mission (STSM) is to contribute to the scientific objectives of a COST Action. These Missions (Exchange Visits) are aimed at strengthening the existing networks by allowing scientists to go to an institution or laboratory in another COST Country to foster collaboration, to learn a new technique or to take measurements using instruments and/or methods not available in their own institution/laboratory. They are particularly intended for young scientists.

STSMs are therefore core components of COST Action scientific activities. 15 STSMs were organised in the framework of TU0801.

In this report, we list all of them. The reader can access each of the individual mission report by using provided links in the following list.

\begin{tabular}{|l|l|c|c|c|c|}
\hline Last Name & First Name & Start date & End date & From & To \\
\hline Karafili & Erisa & $3 / 12 / 2009$ & $19 / 12 / 2009$ & $\begin{array}{l}\text { Università degli } \\
\text { studi di Verona (IT) }\end{array}$ & TU Delft (NL) \\
\hline Title & \multicolumn{6}{|l|}{ Defining a vocabulary for Emergency Response } \\
\hline Link & \multicolumn{6}{|l|}{ http://www.semcity.net/cms/uploads/docs/ErisaKarafili_STSM_report\%20.pdf } \\
\hline
\end{tabular}

\begin{tabular}{|l|l|c|c|c|c|}
\hline Last Name & First Name & Start date & End date & From & To \\
\hline Sainovic & lvana & $1 / 10 / 2009$ & $1 / 12 / 2009$ & $\begin{array}{l}\text { University of } \\
\text { Liege (BE) }\end{array}$ & TU Delft (NL) \\
\hline Title & \multicolumn{5}{|l|}{ Semantically enriched model for underground cables and pipes } \\
\hline Link & \multicolumn{6}{|l|}{ http://www. semcity.net/cms/uploads/docs/Sainovic-STSM-report.pdf } \\
\hline
\end{tabular}




\begin{tabular}{|l|l|c|c|l|l|}
\hline Last Name & First Name & \multicolumn{1}{c|}{ Start date } & End date & \multicolumn{1}{c|}{ From } & \multicolumn{1}{c|}{ To } \\
\hline $\begin{array}{l}\text { Cutting- } \\
\text { Decelle }\end{array}$ & $\begin{array}{l}\text { Anne- } \\
\text { Françoise }\end{array}$ & $17 / 05 / 2010$ & $22 / 05 / 2010$ & $\begin{array}{l}\text { Ecole Centrale de } \\
\text { Lille (FR) }\end{array}$ & $\begin{array}{l}\text { University of } \\
\text { Geneva (CH) }\end{array}$ \\
\hline Title & $\begin{array}{l}\text { Interoperability of environmental data models: an approach based on correspond- } \\
\text { ences between ontologies }\end{array}$ \\
\hline Link & http://www.semcity.net/cms/uploads/docs/afcd-stsm-report.pdf \\
\hline
\end{tabular}

\begin{tabular}{|l|l|c|c|c|c|}
\hline Last Name & First Name & Start date & End date & From & To \\
\hline Gavin & Brown & $28 / 02 / 2011$ & $14 / 03 / 2011$ & TU Berlin (DE) & Tu Delff (NL) \\
\hline Title & $\begin{array}{l}\text { Sementic modelling for indoor navigation and tackling semantic impedance of the } \\
\text { ontologies for indoor navigation and building models }\end{array}$ \\
\hline Link & http://www.semcity.net/cms/uploads/docs/20110421_GBrown_STSM_Report.pdf \\
\hline
\end{tabular}

\begin{tabular}{|l|l|c|c|c|c|}
\hline Last Name & First Name & Start date & End date & \multicolumn{1}{c|}{ From } & \multicolumn{1}{c|}{ To } \\
\hline Zaki & $\begin{array}{l}\text { Chamsed- } \\
\text { dine }\end{array}$ & $\begin{array}{l}4 / 04 / 2011 \\
2 / 05 / 2011\end{array}$ & $9 / 04 / 2011$ & $\begin{array}{l}\text { LUNAM University } \\
\text { (FR) }\end{array}$ & $\begin{array}{l}\text { University of } \\
\text { Liege (BE) }\end{array}$ \\
\hline Title & $\begin{array}{l}\text { Data \& Knowledge characterization and representation: prospects for } \\
\text { applications in Geographic Information Science }\end{array}$ \\
\hline Link & http://www.semcity.net/cms/uploads/docs/rapportliege.pdf \\
\hline
\end{tabular}

\begin{tabular}{|l|l|c|c|c|c|}
\hline Last Name & First Name & Start date & End date & From & To \\
\hline Leduc & Thomas & $12 / 06 / 2011$ & $24 / 06 / 2011$ & CERMA Lab. (FR) & $\begin{array}{l}\text { University Col- } \\
\text { lege London (UK) }\end{array}$ \\
\hline Title & $\begin{array}{l}\text { One more step towards a synthesis city - How to model (a part of) buildings } \\
\text { envelopes using the surroundings of a pedestrian }\end{array}$ \\
\hline Link & http://www.semcity.net/cms/uploads/docs/stsm_report.pdf \\
\hline
\end{tabular}

\begin{tabular}{|l|l|c|c|c|c|}
\hline Last Name & First Name & Start date & End date & From & To \\
\hline Jankovska & Ilze & $25 / 07 / 2011$ & $25 / 08 / 2011$ & $\begin{array}{l}\text { Latvia University of } \\
\text { Agriculture (LV) }\end{array}$ & $\begin{array}{l}\text { University of } \\
\text { Algarve (PT) }\end{array}$ \\
\hline Title & \multicolumn{4}{|l|}{ Semantic enrichment of 3D city models for sustainable urban development } \\
\hline Link & http://www.semcity.net/cms/uploads/docs/stsm_report_Jankovska.pdf \\
\hline
\end{tabular}

\begin{tabular}{|l|l|c|c|c|c|}
\hline Last Name & First Name & Start date & End date & From & \multicolumn{1}{c|}{ To } \\
\hline Scharnhrost & Eric & $20 / 01 / 2011$ & $21 / 10 / 2011$ & $\begin{array}{l}\text { Royal Danish } \\
\text { Academy of Archi- } \\
\text { tecture (DK) }\end{array}$ & $\begin{array}{l}\text { Transport and } \\
\text { Telecommunica- } \\
\text { tion Institute (LV) }\end{array}$ \\
\hline Title & \multicolumn{3}{|l|}{ Semantic Enrichment of 3D City Models for Sustainable Urban Development } \\
\hline Link & $\begin{array}{l}\text { http://www.semcity.net/cms/uploads/docs/STSM_8649_COST_TU0801_Scharn- } \\
\text { horst_Eric.doc }\end{array}$ \\
\hline
\end{tabular}

\begin{tabular}{|l|l|c|c|c|c|}
\hline Last Name & First Name & \multicolumn{1}{c|}{ Start date } & End date & From & To \\
\hline Moreno & Aitor & $2 / 11 / 2011$ & $26 / 11 / 2011$ & Vicomtech-IK4 (SP) & TU Delft (NL) \\
\hline Title & Improve VR fire fighting simulator with semantic technologies \\
\hline Link & $\begin{array}{l}\text { http://www.semcity.net/cms/uploads/docs/amoreno-TU_Delft-STSM-Final- } \\
\text { Report_006.pdf }\end{array}$ \\
\hline
\end{tabular}




\begin{tabular}{|l|l|c|c|c|c|}
\hline \multicolumn{1}{|c|}{ Last Name } & First Name & Start date & End date & From & To \\
\hline Wen & Wan & $14 / 10 / 2011$ & $15 / 12 / 2011$ & $\begin{array}{l}\text { Aalborg Univer- } \\
\text { sity (DK) }\end{array}$ & TU Delft (NL) \\
\hline Title & \multicolumn{3}{|l|}{ Scales in Space and Time for Geographic Modelling } \\
\hline Link & \multicolumn{2}{l|}{ http://www.semcity.net/cms/uploads/docs/STSM_Report_Wan.pdf } \\
\hline
\end{tabular}

\begin{tabular}{|l|l|c|c|c|c|}
\hline \multicolumn{1}{|c|}{ Last Name } & First Name & \multicolumn{1}{c|}{ Start date } & End date & \multicolumn{1}{c|}{ From } & \multicolumn{1}{c|}{ To } \\
\hline Carneiro & Claudio & $3 / 12 / 2011$ & $17 / 12 / 2011$ & EPFL (CH) & $\begin{array}{l}\text { University of } \\
\text { Aveiro (PT) }\end{array}$ \\
\hline Title & $\begin{array}{l}\text { Evaluation of the usefulness of CityGML models and LiDAR data for the CFD model- } \\
\text { ling of urban air quality }\end{array}$ \\
\hline Link & $\begin{array}{l}\text { http://www.semcity.net/cms/uploads/docs/ScientificReport_Collaborative_Pro- } \\
\text { iect_COST_TU0801_UAveiro_UBerlin_EPFLausanne.pdf }\end{array}$ \\
\hline
\end{tabular}

\begin{tabular}{|l|l|c|c|c|c|}
\hline \multicolumn{1}{|c|}{ Last Name } & First Name & Start date & End date & \multicolumn{1}{c|}{ From } & To \\
\hline Sainovic & Ivana & $7 / 09 / 2011$ & $7 / 11 / 2011$ & $\begin{array}{l}\text { University of } \\
\text { Liege (BE) }\end{array}$ & $\begin{array}{l}\text { University of } \\
\text { Zagreb (CR) }\end{array}$ \\
\hline Title & \multicolumn{4}{|l}{ Semantically enriched model for underground cables and pipes } \\
\hline Link & \multicolumn{2}{l|}{ http://www.semcity.net/cms/uploads/docs/Sainovic-STSM-UniZG.pdf } \\
\hline
\end{tabular}

\begin{tabular}{|l|l|c|c|c|c|}
\hline \multicolumn{1}{|c|}{ Last Name } & First Name & Start date & End date & \multicolumn{1}{c|}{ From } & To \\
\hline Bostenaru & Maria & $1 / 09 / 2012$ & $7 / 09 / 2012$ & $\begin{array}{l}\text { University of } \\
\text { Bucharest (RO) }\end{array}$ & $\begin{array}{l}\text { University of } \\
\text { Algarve (PT) }\end{array}$ \\
\hline Title & \multicolumn{4}{|l|}{ Semantic enrichment of 3D city models for sustainable urban development } \\
\hline Link & \multicolumn{3}{|l|}{ http://www.semcity.net/cms/uploads/docs/STSMreport_final3.pdf } \\
\hline
\end{tabular}

\begin{tabular}{|l|l|c|c|c|c|}
\hline \multicolumn{1}{|c|}{ Last Name } & First Name & \multicolumn{1}{c|}{ Start date } & End date & From & \multicolumn{1}{c|}{ To } \\
\hline Wang & Zhiyong & $20 / 10 / 2012$ & $10 / 11 / 2012$ & TU Delft (NL) & $\begin{array}{l}\text { Vicomtech-IK4 } \\
\text { (SP) }\end{array}$ \\
\hline Title & \multicolumn{3}{|l|}{ Integrating the fire simulation model and semantics into the routing process } \\
\hline Link & http://www.semcity.net/cms/uploads/docs/Report_ZhiongWang.pdf \\
\hline
\end{tabular}

\begin{tabular}{|l|l|c|c|c|c|}
\hline \multicolumn{1}{|c|}{ Last Name } & First Name & \multicolumn{1}{c|}{ Start date } & End date & \multicolumn{1}{c|}{ From } & To \\
\hline $\begin{array}{l}\text { Elvas Duarte } \\
\text { de Almeida }\end{array}$ & José-Paulo & $24 / 09 / 2012$ & $3 / 11 / 2012$ & $\begin{array}{l}\text { University of } \\
\text { Coimbra (PT) }\end{array}$ & $\begin{array}{l}\text { University Col- } \\
\text { lege London (UK) }\end{array}$ \\
\hline Title & Semantic aspects of 3D cadastres. Towards a 3D model in Portugal \\
\hline Link & $\begin{array}{l}\text { http://www.semcity.net/cms/uploads/docs/STSM-TU080 1-1 1553\%20scien- } \\
\text { tific\%2Oreport.pdf }\end{array}$ \\
\hline
\end{tabular}

\subsubsection{Summer school}

The school was organised in response to the increased need for better, more elaborated and appropriate means for facing man-made and natural risks and reducing vulnerability of certain regions. As much of the problems are related to the search, integration, analysis and understanding of geo-information, this school 
aimed at investigating new ideas for dealing with geo-information. Special attention was given to semantics and semantic enrichment of 3D city models. As stated in the program of the school, the learning goals covered two challenging aspects of disaster management: 3D modelling and semantics.

The program was designed in such a way that the students can get maximum information on the different phases and characteristics of risk and disaster management, the roles and responsibilities of actors involved in risk and disaster management and existing and potential 3D applications for risk and disaster management. The exercises and the practical's were organised to stimulate the students to analyse the potential of current 3D GIS technology in support of decision making, to guide them in examination of the current bottlenecks in the use of 3D GIS technologies, to encourage them to introduce new 3D GIS technologies when appropriate and to challenge them to understand the domain semantics and analyse to which extent a semantic enrichment could overcome the current limitations and which semantics would be suitable to risk issues.

The school offered lectures, exercises, a workshop (organised by E-semble www.e-semble.com), visits to the Netherlands Institute for Safety (www.nifv.nl) and Geodan (www.geodan.nl). All the visited institutions are dealing with risk and emergency management:

- Risk and Emergency Management Basics (Delft).

- 3D Geo-information technology (Delft).

- Gl technologies for Disaster Management in practice (Arnhem).

- Interoperability and semantic enrichment (Delft).

- Decision Support Systems (Amsterdam).

Experienced researchers shared their knowledge on risk and emergency management and 3D geo-information technology as follows Roland Billen (University of Liege, Belgium), Wietske Bijker (ITC, Netherlands), Partic Broijmans (Ministry of Defence, Netherlands), Matteo Cristani (University of Verona, Italy), Eduardo Dias (Free University Amsterdam, Netherlands), Laura Díaz (University Jaume I, Spain), Gilles Falquet (University of Geneva, Switzerland), Steven Fruijtier (Geodan, Netherlands), Tim Grant (Defence Academy, Netherlands), Michel Grothe (Geonovum, Netherlands) Thomas Kolbe (Germany), Peter van Oosterom (Delft University of Technology, Netherlands), Chris Phillips (Ordnance Survey, UK), Arda Riedijk (Free University Amsterdam, Netherlands), Henk Scholten (Free University Amsterdam, Netherlands), Sisi Zlatanova (Delft University of Technology, Netherlands). Most of the international lectures (i.e. Billen, Cristani, Falquet and Kolbe) are members of the COST action.

The students were selected among 38 applicants. Most of the students were already working in the area of disaster management and wanted to learn more about 3D technologies and their use for managing disasters. Few of the students were already applying 3D technologies in emergency response. The selection 
procedure considered the experience of the students, their motivation to attend the school, the application filed as well as the country they are coming from. Since they were supposed to work in groups, it was considered important to get students from all over Europe to be able to cover the different organisational, technological and legal aspects. There were 26 students from 15 countries (one from Korea). Prior coming to the Delft, the students have prepared short presentations about their research and collected information about a disaster management case (which was later used for the group assignments). The lectures and the presentations of the students are available at http://www.gdmc.nl/zlatanova/downloads/ COST_3D4DM.rar.

\subsubsection{Working group specific outputs}

\section{WG 1 contributions}

The idea of a city as an urban space that is sustained by human connections requires suitable models that recognize the sound interplay between physical and phenomenological aspects of the urban system. The management of such a complex systems requires models and tools that will be able to cope with the challenge of managing such an amazing amount of data. It is our believe that the problem today is not the availability of data but rather the production of comprehensive knowledge about the urban structure with useful level of detail, organised in systematic way and updated in manner that will serve the purpose.

These conceptual questions of the comprehensive understanding of urban phenomenon through semantically enriched 3D city models have been addressed within the work of WG1. Our work has twofold objectives: (1) to explore the feasibility of creating urban knowledge base relevant for the urban context, and (2) to demonstrate the usefulness of this tool in terms of exploratory scenario-based case studies and how to enrich the existing 3D models. To structure our work, we developed a questionnaire aiming at helping describing existing projects (see annex 2). Such approach facilitates analysis and comparison of projects.

The identified objectives have been challenged through research performed by working group members in three different areas:

- Models of urban morphology and urban dynamics related to the structure of the city, energy consumption, urban density, historic development and generative potential of 3D city models.

- Models of urban transport related to the modelling of traffic systems within the city and modelling of pedestrian behaviour through use of agent based modelling, visual analysis and urban mobility.

- Models of climate and environment related processes focused on the modelling of global climate dynamics and on the modelling of urban and locally based microclimate processes and changes. 
The work of the researchers in the group has clearly determined a necessity of integration of urban data gained though variety of sources into a comprehensive knowledge. Hence, several cooperations between WG 1 members have been initiated within the Action that has resulted in the series of joint research on the following topics:

- Models of climate and environment related processes focused on the modelling of global climate dynamics and on the modelling of urban and locally based microclimate processes and changes.

- Mixed approach combining visibility and mobility studies for analysis.

- Modelling development of urban form in residential areas in Skopje.

- Interoperability of different modelling techniques in 3D analysis of the Old Bazaar in Skopje.

- Modelling buildings and sites of historic heritage in Liege and Nantes.

Finally, the most prominent result of the work of the members of WG1 has been a productive debate regarding the issues and topics related to the future of semantically enriched 3D city models and the future research topics related to the domain, acknowledging the importance of integrated urban knowledge providing relevant and useful tool for better understanding of the urban phenomenon.

\section{WG 2 contributions}

WG 2 focused its work on integration and interoperability issues that arise when adding semantic information to $3 \mathrm{D}$ city models, or when combining 3D city models with semantic data models. In this context, WG2 pursued two main goals: to explore and evaluate the usability of ontology-based approaches; to find out how integration issues were addressed in existing applications and models.

The enrichment of a 3D city model with semantic information (e.g. information about the nature of the objects represented in the 3D geometry, their non-geometric properties, their semantic relationships, or their use) can be seen as an interconnection problem. The 3D city model, expressed in CityGML or in another formalism must be connected with the semantic information represented in data files, databases, or other sources. Every information entity in the semantic source must be mapped to an object or a set of objects of the 3D city model.

In the field of information integration and interoperability, the use of ontologies has long been advocated as a mean to solve heterogeneity problems by providing common reference vocabularies. There is an abundant literature about theoretical and practical tools that rely on ontologies for interconnecting heterogeneous data sources. 
Subgroups of WG 2 studied different aspect of the possible use of ontologies in the context of semantic enrichment. The main outputs produced by these subgroups are:

- a catalogue of ontologies (and other knowledge organization systems) that cover different part of the urban domain and could therefore serve as reference ontologies in an interconnection process,

- a technique and a tool, based on ontology alignment, to evaluate the "urban coverage" of an ontology. This technique essentially consists in automatically aligning the studied ontology with the Urbamet thesaurus (with an appropriate alignment algorithm) and evaluating which parts of Urbamet are covered,

- a representation of the CityGML model as a formal ontology, expressed in the OWL ontology language. Since CityGML contains semantic (nongeometric) information, it can serve as reference ontology for interconnecting other semantic resources. However, its current representation as an XML schema is incompatible with formal logical reasoning. The OWL version ${ }^{2}$ of CityGML forms a solid basis to either interconnect CityGML with other models or to define semantic extensions of CityGML.

Members of WG 2 also developed a technique to enrich 3D city models with documents (Tardy et al., 2012). This technique relies on the CityGML/OWL ontology.

To find out how semantic enrichment and integration have been practically achieved in existing applications the WG 2 members organized several meetings to define a questionnaire to be filled by people or organizations that developed such applications. One of the goals of the questionnaire is to determine the type of integration that was performed. For this purpose WG 2 developed a classification scheme that comprises:

- implicit integration: the application directly uses several models/datasets without any explicit integration phase,

- ontology mapping: the (local) ontologies/schemata and data have been mapped and explicit mapping records have been created,

- common ontology creation: in addition to mappings, a common global ontology has been created.

Several versions of the questionnaire have been tested by application developers to arrive at a final usable version.

2. http://cui.unige.ch/isi/onto//citygml2.0.owl/. 


\section{WG 3 contributions}

Starting from a clear understanding of the current usages of 3D city models (provided, in part, by the other working groups), the working group attempted to identify the main bottlenecks for a wider usage of such models. But before going into more detail, let's go back to a few definitions:

The utility of data, models or software is their ability to provide the features the users need.

Their usability determines how easy these features are to use.

In order to be useful, data, models and software have to assure both utility and usability.

In order to address the question "why are 3D city models not used more?", the working group identified several issues both in utility and in usability of existing 3D city models and their tools. The approach taken by the group consisted in starting from a few case studies that were discussed in detail and generalizing from there (see the developed questionnaire in annex 2). Using a task based approach to usability and utility, a questionnaire was design to roughly describe these case studies, their context, and their potential for usability testing (which, in fact, includes utility testing). Finally, the questionnaire attempted to capture the benefits of using 3D city models in these specific use cases and the open problems and issues to be addressed in the future.

Several issues were identified by the working as impediments to a wider usage of 3D city models:

- Unavailable or difficult to obtain data (indoor plans for instance).

- Data management and interoperability issues with other 3D data or with 2D data (synchronized updates of 2D and 3D for instance).

- Accessibility issues in terms of software and effort to switch to 3D (related to education).

- Acceptability of 3D city models, related to education, appropriation (lack of landmarks, egocentric vs. exocentric point of view, "this is not my house, I do not see my flowers and my curtains are red not blue" effect, photorealism, cognitive charge, etc.) and trust (users are used to 2D data and their flaws - they know them - but might have trouble trusting 3D data, especially when their precisions are not properly informed and that key elements are missing).

Nevertheless, many experiences using 3D city models have shown that they can provide huge benefits for better decision making in several crucial areas (urban planning, emergency response, GeoDesign, etc.). A more general framework for usability testing of $3 \mathrm{D}$ city models is probably of the most promising perspective the user group identified. 
Generally speaking, most 3D city models are created for the purpose of visualization and not for a specific use case (like urban planning or emergency exit simulation). One cannot expect such data to be adapted to such specific usages, just like one does not expect OSM data to provide us with reliable housing prices. It is not what it was designed to do. Which does not mean it might not be able to provide it someday.

A clear understanding of the uses allowed by the models is needed in order for a comprehensive decision to be made before producing 3D city models. More work should be done starting from potential applications and identifying the features (in terms of data and software) needed to provide the most significant added values.

\subsubsection{Dissemination}

\section{Books}

Proceedings of the $11^{\text {th }}$ International Conference Reliability and Statistics in Transportation and Communication (RelStat-11), I. Kabashkin \& I. Yatskiv (eds.), 19-22 october 201 1, Riga, Latvia, ISBN 978-9984-818-46-7, 108 p.

The COST-Workshop "3D issues for Transport System" meeting of the WG 1 and WG3 of TU0801 took place in Riga, Latvia from 20/10/2011 to $21 / 11 / 2010$. The workshop was held under the framework of the International Scientific Conference RelStat' 11. Special emphasis was given to using 3D Models in Transport Area. 25 delegates from 13 countries participated at the workshop. Papers presented during the workshop were published in the Proceedings of Relstat- 11 as a special session. Titles of papers, their authors and links to pdf copies on the web are listed in annex 3.

\section{D Issues in Urban and Environmental Systems (2012). R. Billen, M. Cagli- oni, O. Marina, G. Rabino \& R. San Josè (eds.), Bologna, Italy: Società Editrice Esculapio SRL., ISBN 978-88-7488-546-6, 125 p.}

This book gathers contributions from three workshops of the Action.

The workshop "3D City Models in Planning" held in Milan, Italy, on the 10-1 1 th May 2010, was a "turning point" in the Action progresses, moving from the "preliminary works" (defining the state-of-art, establishing relations among the action members, etc.) towards the accomplishment of the action goals (create an integrative platform, using an ontology-based methodology, assess the usability of the integrated platform for decision making).

The workshop "Evaluation of 3D city models and pedestrian behaviour" held in Skopje, Macedonia, on the 8-9th March 2012 had for main objective to debate and determine the criteria for assessment and evaluation of $3 D$ city 
models focused on modelling pedestrian behaviour in urban environments. This is in order to be able to assess the contribution of new 3D models of pedestrian activity to the semantic enrichment of the 3D City models and ultimately to the better understanding of the way those urban environments is structured and comprehends by its citizens.

The workshop "3D issues in environmental and urban systems" held in Madrid, Spain, on the 12-13 April 2012 focused on physical phenomena. Knowing that environmental information is heterogeneous, integration into 3D city models is particularly complex but represents a great potential for evaluate environmental conditions and feed global urban management system

The book is organised in five chapters with diverse problems and different points of view on 3D city models. The first one deals with semantic enrichment of 3D City Models. The second chapter treats about enhanced visualisation, i.e. new ways for objects visualisation, and new ways for providing information through visualisation. The third chapter deals with visibility issues. The fourth chapter is dedicated to models about air quality and pollution in 3D city environment. The last chapter concentrates on multi-agent systems, which are used to simulate pedestrian's movements and behaviour in 3D city environment and their interactions with 3D objects. Titles of papers, their authors and links to pdf copies on the web are listed in annex 4.

\section{Usage, Usability, and Utility of 3D City models (2012). T. Leduc, G. Moreau, G \& R. Billen (EDS.). Les Ulis, France: EDP sciences, 320 p.}

As the final event of this COST Action, the "3u3d2012: Usage, Usability, and Utility of 3D City models" conference addressed the three following issues that actually gave their names to the conference. In computer science, it is often said that to ensure value to an organisation, a software program must usable, useful and actually used. Therefore the conference was named after those concepts applied to 3D City models:

- Are 3D city models usable, i.e. do they embed enough information and thus semantics to be of real value in urban planning and management processes?

- Are 3D City models useful, i.e. do they provide services that are not available with 2D city models?

- Are 3D city models actually used, i.e. are 3D city models really used in the decision making process or are decisions still made with 2D maps?

The papers published in this book of proceedings cover a wide diversity of scientific themes, including:

- Semantic modelling for 3D city models.

- Integration of GIS models and CA(A)D models. 
- Management of multiple representations: multi-scale (levels of detail), versions, history.

- Data integration and homogenization.

- Innovative visualisation techniques.

- New paradigms for 3D GIS.

- Applications of 3D city models beyond visualisation.

- Sensible approaches of the 3D city models.

- 3D and mobility issues.

- 3D and interoperability.

- Ontology for 3D urban model.

Titles of papers, their authors and links to pdf copies on the web are listed in annex 5. Open Access version can be found here: http://3u3d.edpsciences.org/.

\section{Websites}

\section{Cost action page}

Maintained by the COST office, this official page of the Action TU0801 in the COST website (Fig. 11) contains official information about memberships, annual report, fact sheet, etc.

http://w3.cost.esf.org/index.php?id=240\&action_number=TU0801/. 


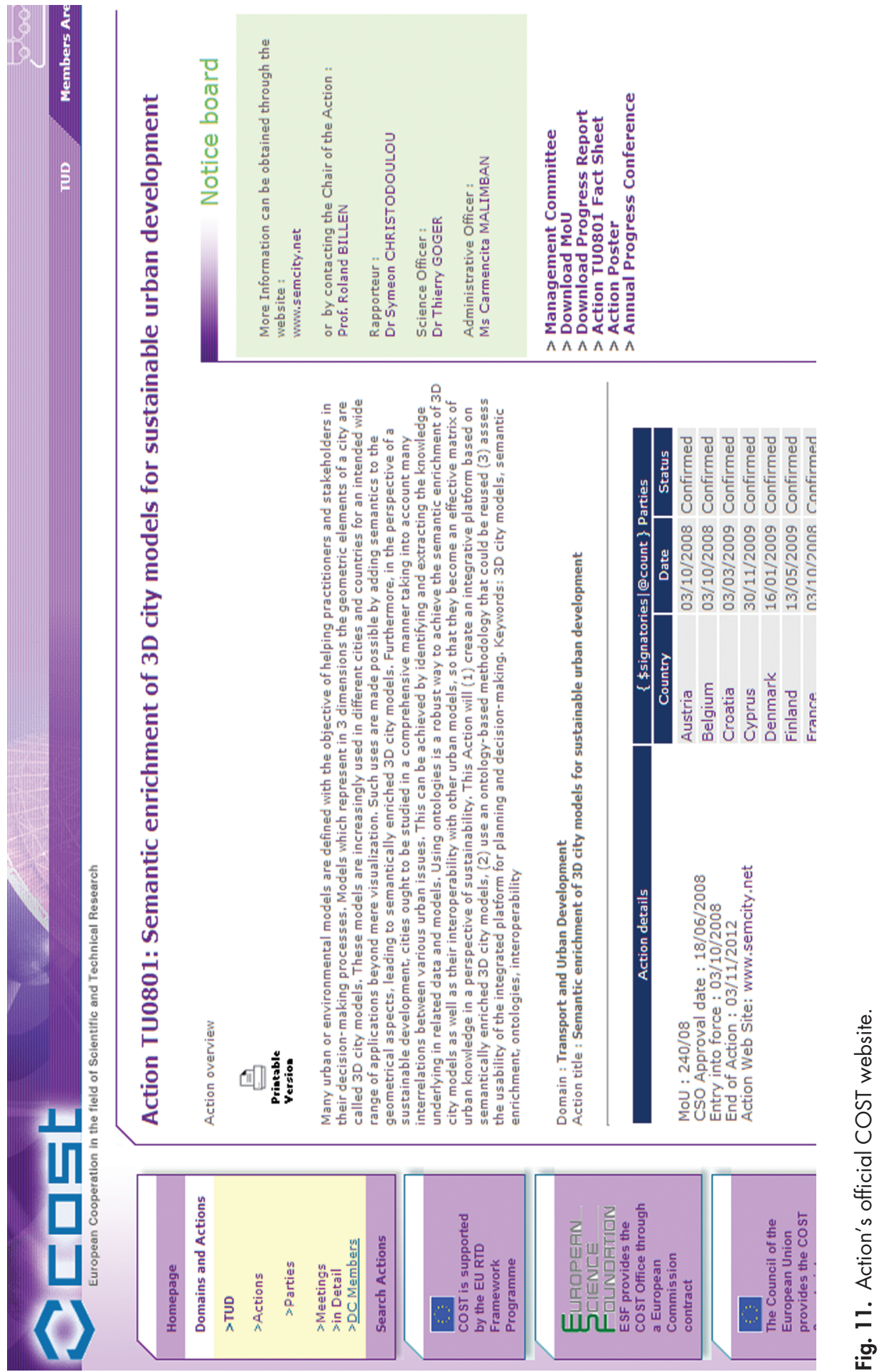




\section{Action's website}

Maintained by the chair of the Action, this website (Fig. 12) contains information about members, all the documentations related to the STSMs and reports, links to Action's activities, etc.

http://www.semcity.net/.

\section{Semantic Enrichment of 3d city models for sustainable urban development}

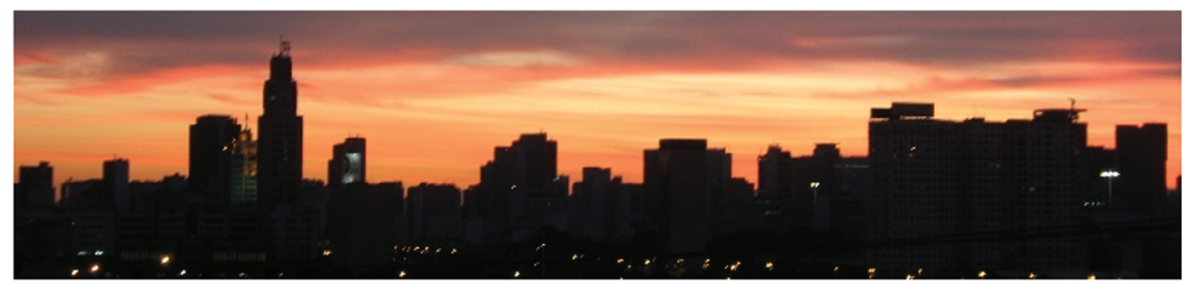

\begin{tabular}{l}
$\mid$ Home \\
$\mid$ Programme \\
| Participants \\
| Resources \\
| Contact \\
| Member Login \\
\hline WG2 questionnaire \\
Apr 11, 2012 \\
We entirely revisited \\
our test case \\
evaluation \\
questionnaire and \\
produced a much \\
shorter and \\
(hopefully) simpler \\
document. \\
[More]
\end{tabular}

The main objective of the action is to semantically enrich 3D models with urban knowledge and models, so as to extend their functionality and usability in a perspective of sustainability.

\section{Final conference}

http://3u3d2012.sciencesconf.org/

\section{D city models}

A 3D city model is a three dimensional digital representation of a city or urban environment, using data derived from multiple sources such as stereo aerial images, airborne Lidar data and high resolution satellite data. It contains a large number of objects of different classes and different data models and structures.

It is an important tool used in various fields such as urban planning and management, facility location, or car-navigation systems, as well as for research and 3D visual representation of the urban environment as textured images or fly-throughs. CityGML is an information model for the representation of $3 D$ urban objects. It defines the classes and relations for the objects with respect to their geometrical, topological, semantical, and appearance properties.

\section{Sustainable development}

Sustainable development of cities implies investigating cities in a holistic way taking into account many interrelations between various urban or environmental issues, such as spatial planning, traffic and transport, energy, air quality, health, risks, and cultural heritage.

Fig. 12. Action's website. 


\section{Wiki}

Maintained by Geneva University partners, this wiki contains various materials and documentation as well as WG's working papers (see Fig. 3). http://semcity. unige.ch/semcity/doku.php/start/.

The wiki proposes also an inventory of tools for ontologies creation (Fig. 14), http://semcity.unige.ch/semcity/doku.php/tools, and an inventory of ontologies related to the urban context (Fig. 15) http://semcity.unige.ch/semcity/doku.php/ urban_ontologies/.

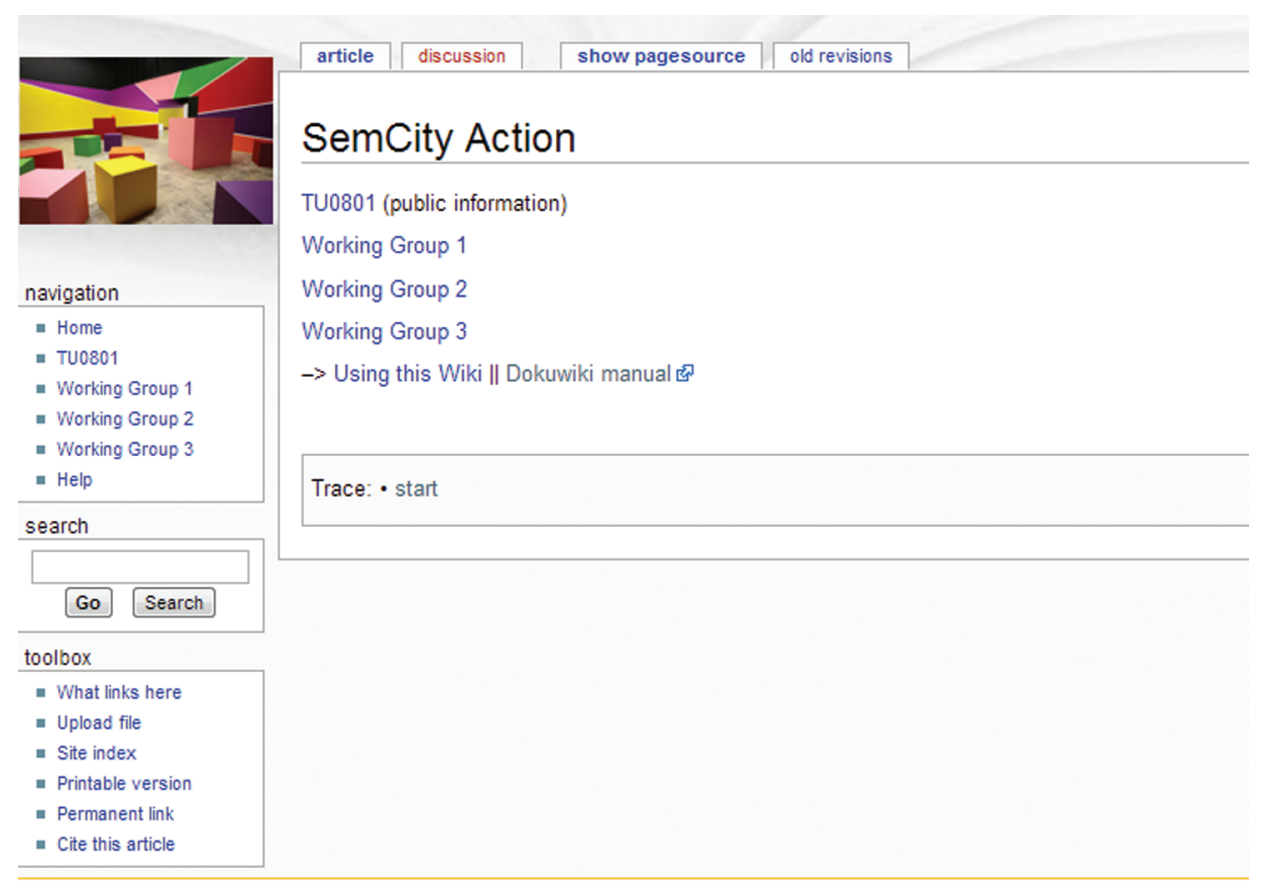

Fig. 13. Wiki of the Action. 


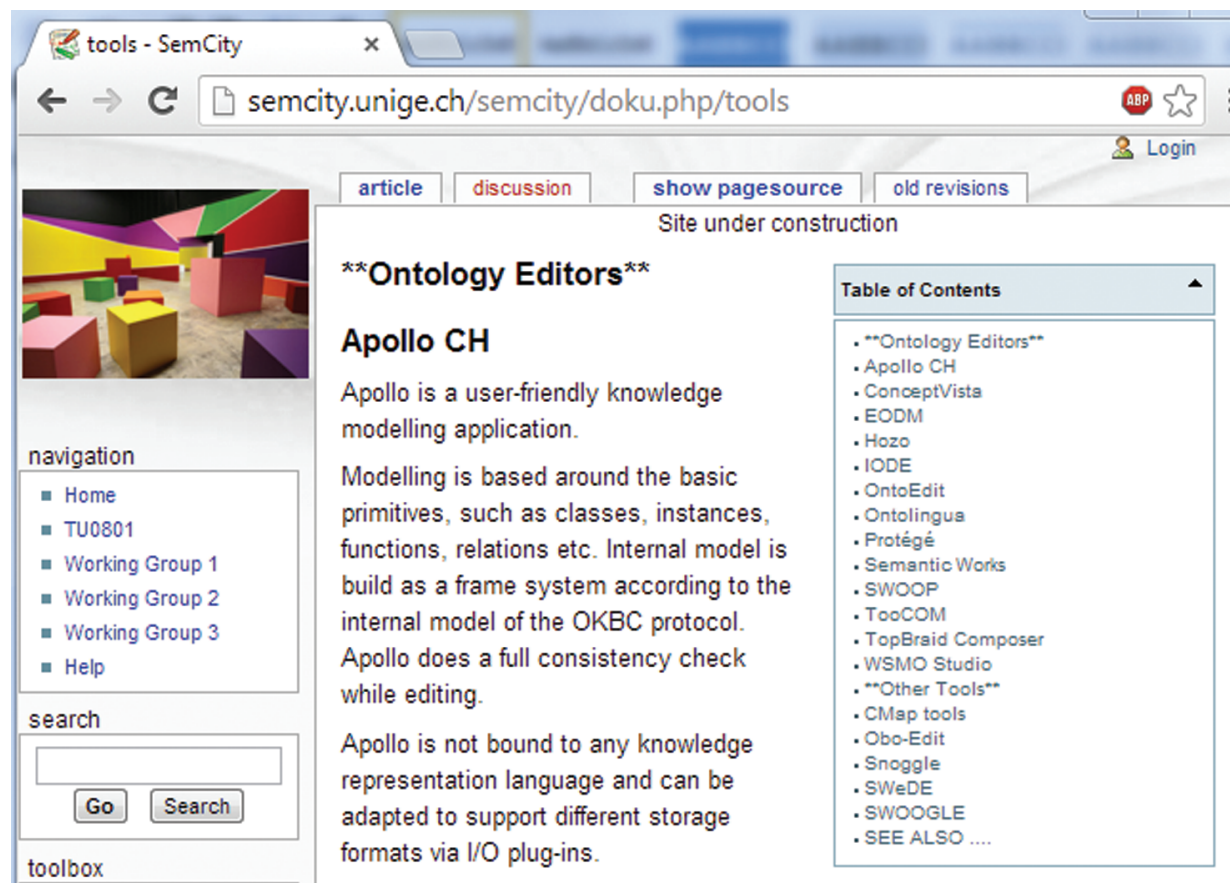

-What links here

- Upload file

n Site index

- Printable version

- Permanent link

- Cite this article

Apollo's user interface has an open architecture (view based) and allows for implementation of additional views of the knowledge base.

\begin{tabular}{|c|c|}
\hline Purpose & ontology editor \\
\hline Development language & Java \\
\hline Ontological language & XML \\
\hline Home URL & http://apollo.open.ac.uk/index.html 四 \\
\hline Resource URL & http://apollo.open.ac.uk/download/Apollo.zip \\
\hline
\end{tabular}

\section{ConceptVista}

ConceptVISTA, an ontology creation and visualization tool developed by researchers at the GeoVISTA Center, allows users to define and link concepts

Fig. 14. Inventory of tools for creating ontologies. 


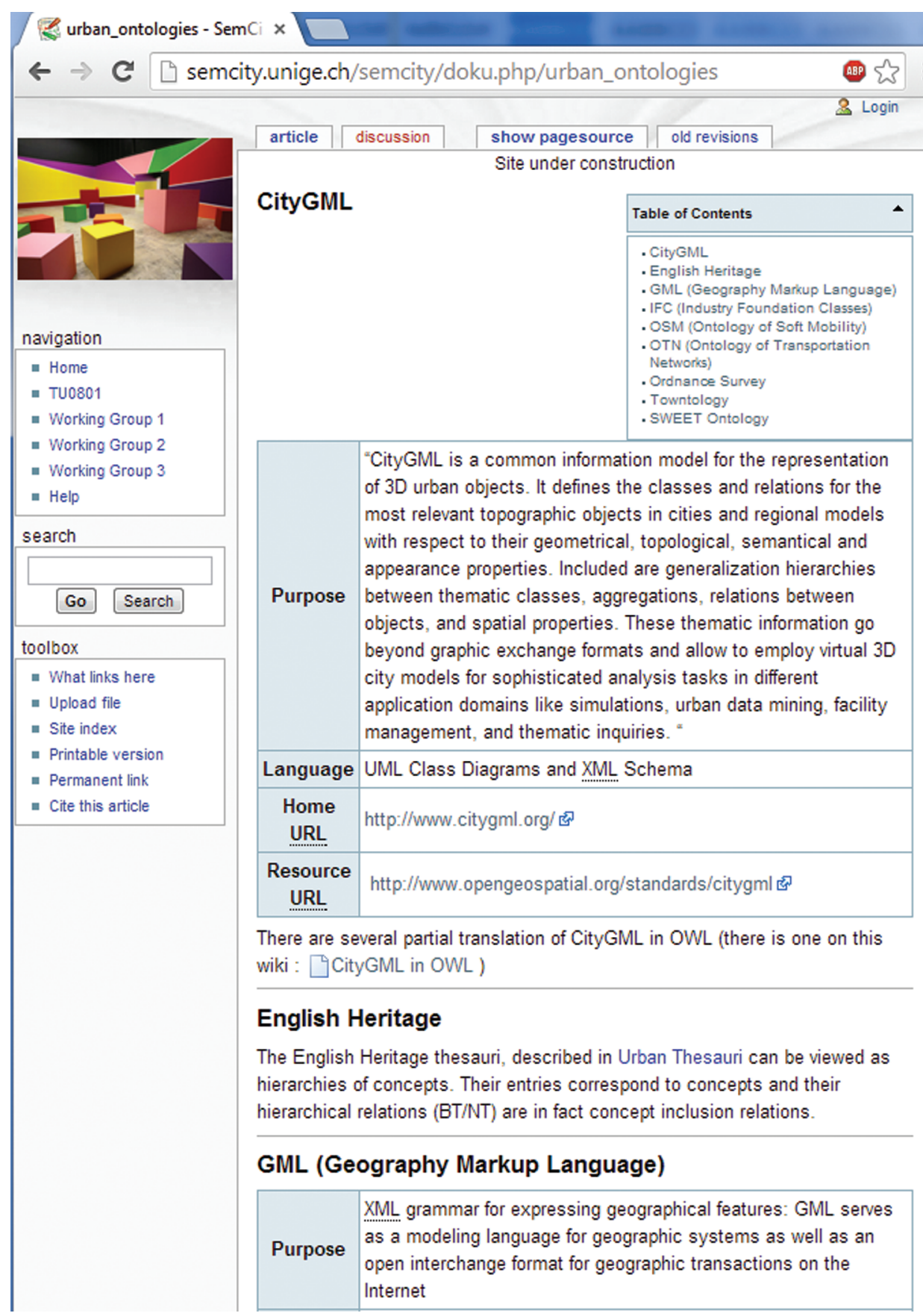

Fig. 15. Some ontologies related to the urban context. 


\subsection{Breakthroughs and prespectives}

\subsubsection{Breakthroughs}

At the beginning of the Action, 3D was diversely understood and used by the members. The main achievement of the Action has been to create a common vision of the natures and the usages of 3D City Models.

From our diverse activities, it becomes clear that using enriched 3D city models improves doubtlessly each of the studied application, and it is also clear that combining these models would be a major (crucial) improvement for urban sustainable development strategies. All the studied cases have shown that the use of 3D improves significantly the related applications (pollution /transport /visibility simulations, planning, disaster management, etc.) in a sustainable perspective. The role of 3D City Models as integrator of urban and environmental knowledge has been strongly acknowledged. A new community has emerged and is spreading beyond the Action; the final conference and the interest shown by external participants is one very good example of such dissemination.

This emerging vision will have major impacts in one hand on standardisation bodies, decision makers, data producers and consequently on the industry and on the other hand on urban experts and scientists. Indeed, considering enriched 3D City Models as urban knowledge integration platform implies (re)definition of geospatial standards, new data production / integration strategies, development of new applications... Enriched 3D City Models are the foundation of future Smart Cities.

Beyond these considerations, conceptual and technical issues still remain; types of semantic enrichment, ways of enriching 3D City Models, ways of visualizing enrichment information and knowledge and even 3D City Models definitions are still debatable. Indeed, we have demonstrated that by considering 3D City Models we gather a lot of disciplines and applications, which are diverse and not traditionally integrated. In other words, 3D City Models is the basic ground for integrating urban knowledge, but such integration is complex and new. It is not just an extension of traditional 2D maps, or geometrical 3D City models, but creation of spatial model of complex urban networks of relationships between elements, attributes and configurations. This integration and production of new urban knowledge has been exercised through several joint research projects within TU0801 where various tools and models have been used simultaneously for comprehensive modelling of urban environment.

\subsubsection{Perspectives}

As a consequence of the four years joint works and activities, a global view of the issues and challenges of the use of 3D city models for urban knowledge integration has emerged. It was summarized in a mind map created during an expert 
panel session organised during the last conference in Nantes (see Annex 6). This vision has been adopted to structure this section of the report dedicated to the recommendations for research and development.

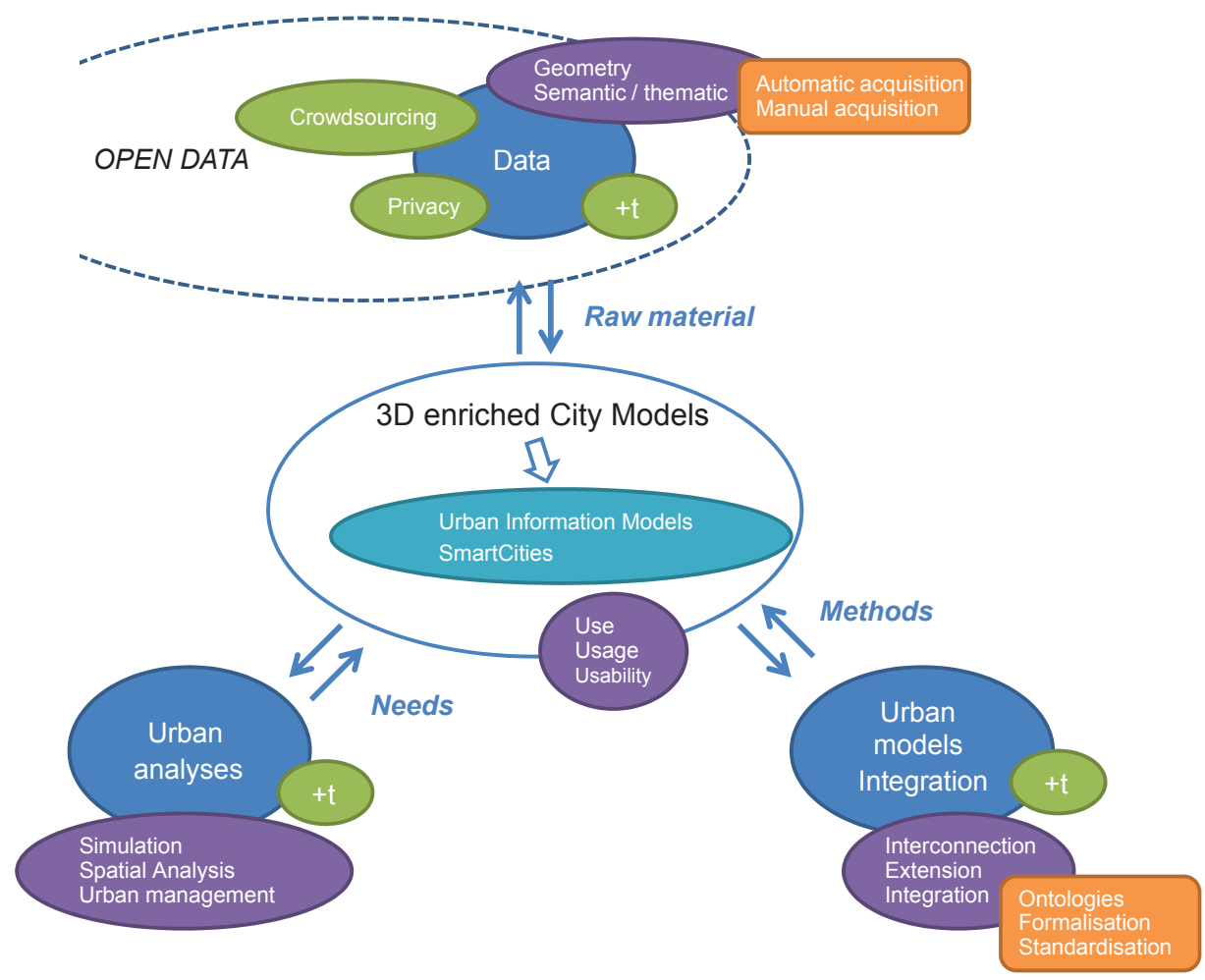

Fig. 16. A global view on 3D enriched city models.

This shared global view has four main components (Fig. 16); 3D enriched city models, urban models integration, urban analyses and data. The central component gathers questions about use, usage and usability of 3D enriched city models and their possible evolution or connection with urban information models and smartcities. The whole issue of 3D enrichment and the role of 3D models as urban knowledge integrator can be addressed through urban models integration, urban analyses and data. This division in four components allows to present open questions and recommendations in a flexible way.

\section{D enriched City models}

\section{Context}

One of the most important points that came out the Action was that definition, usage and use of 3D enriched City Models was far to be clearly identified and shared amongst the members. Beyond the work presented in chapter 2 gathering 
important definitions, there is still work to do for outlining the nature and the scope of such models. This lack of consensus is due to the high diversity of usages that such models offer and the high diversity of disciplines involved. Indeed, this integration role goes far beyond what is known in 2D (through 2D GIS). This is a major scale issue which implies new paradigms. Up to now, we had a rather clear division between applications deeply rooted in mixing (2D) urban information at city level and applications using fragmented 3D urban information. Moving towards 3D city models brings together people that were not considering the same scale and extension of the urban phenomena. This leads to new communication issues between actors and consequently interoperability issues between systems.

It is becoming clear for most of the researchers and urban specialists that 3D city models should go beyond a simple geometric representation of the City (buildings, roads, vegetation) and progressively evolve towards 3D dynamic representation of above and underground, physical and abstract objects, allowing combining multiple sources of information. This evolution leads to what one could call an urban information model. Such model will be necessary for the future management of cities; from that respect it is closely related to the concept of smartcities.

Semantic enrichment is a rather broad concept which corresponds to different realities depending on domains and applications. Although we have identified several types of semantic enrichment and identified ways to enrich models, namely annotations, ontologies, model's extensions... there is still work to do for providing a comprehensive and usable inventory of methods.

Although they have been addressed during the Action, the following points still need further developments.

\section{Research program}

- Inventory of uses and usage of enriched 3D city models.

- Inventory of types of semantic enrichment of 3D city models.

- Inventory of objects to be included in enriched 3D city models.

- Study on evolution of paradigm (3D city model / urban information model/ smartcities).

- Methods for the evaluation of 3D city models usability.

\section{Urban models integration}

\section{Context}

Most of the work undertaken under TU0801 was dedicated to models integration. Other methodological issues such as model's annotation were not considered as of prime importance and were not addressed. Strategies for extending models, interconnecting models and integrating models were envisaged. In all the cases, 
use of standards was promoted as well as ontological approaches. One of the most evident methodological questions was how to facilitate the integration of simulation models (e.g. air quality models) with 3D city models. Specific collaborations (e.g. STSM) talked this issue, notably involving the use of CityGML but also other geometric standards models (e.g. Collada and X3D). Another point was related to the integration 3D city models with models coming from the BIM domain (e.g. IFC). It seems also crucial to ensure the integration of 2D city models allowing combining the best of both worlds.

The question of integration of 3D city models with other semantic models (e.g. historical model) was also addressed. For all these cases, there is no universal solution; model's extension, models interconnection, models integration through ontologies... all of these present pros and cons. On the other side, there is a clear need to continue to develop modeling and meta-modeling methodologies and ontological approaches. Enriching 3D City models is strongly related with interoperability issues. There is a need to support and to influence existing standardization initiatives;

- promoting communication between models (ex: CityGML and IFC),

- identifying 3D standardisation priorities (ex: make distinction between core and application models),

- promoting development of standard compliant systems.

This initiative requires continuing to work at a high level on 3D urban paradigms (ex: relevant relations and properties) with focus on spatial integration of urban knowledge through 3D City models. It represents a huge impact on standardization bodies (e.g. OGC, INSPIRE). Furthermore, time cannot be forgotten; 3D city models and their applications require most of the time to consider dynamic aspects and temporality issues. It implies also deep conceptual thinking and standardization efforts.

\section{Research program}

- Investigate ways of interconnecting 3D models.

- Investigate ways of extending 3D models.

- Investigate ways of integrating 3D models.

- Improvement of conceptualisation and formalization of 3D urban model.

- Development/improvement of standards for 3D/4D urban models.

\section{Urban analyses}

\section{Context}

The fundamental reason which motivates the use of 3D city models as a platform for the integration of urban knowledge is to improve urban analyses and urban management. In other words, the identified and prospective needs for a 
better management of cities and understanding of urban phenomena impose the use of enriched 3D city models and the underlying development of urban information systems which are the foundation of future smart cities.

Performing simulations in 3D significantly improves the quality of the output in most of the applications studied all along the action TU0801. It implies 3D simulation models which can take benefit of existing 3D city models (instead of developing non-standard ad-hoc solutions) and associated 3D data (instead of acquiring expensive one-shot data). However, there is still need to assess the benefit of such 3D approaches in all aspects of urban management (economy, environment, social, cultural, etc.)

In the perspective of a standardized and integrated 3D urban information system, there is a need to develop an urban analysis toolkit providing analyses, simulation and management functionalities which could be combined and shared. If we can think about performing and combining various queries and processes, it represents several challenges in terms of processes standardisations, technical and semantic interoperability, etc. The relevance of such combined analyses is also debatable, and at least assessment methods should be developed.

Since the beginning of the Action, the question of the enrichment of 3D city models by simulations and spatial analyses was raised. Indeed, up-to-now, the interaction between 3D data models and simulation models (such as an AQM for example) is one directional; the simulation is performed using 3D data and simulation output is not permanently linked with the 3D data. We discussed the opportunity to keep in a 3D city model simulation result either by a change of 3D city model object attributes, or by the creation of new objects within the 3D city models. It has been identified as a possible kind of enrichment. It raises once again standardisation and integration issues and also question about the assessment of the quality of produced information.

The Action also focused on visualization. Indeed, the growing variety of 3D information (new types of data, simulation outputs, etc.) implies to adopt the most efficient visualisation techniques. This is a core issue knowing that visualisation is the most important communication media with the users; it depends on application, data and process. Works is needed to categorize and formalized visualisation techniques, anticipating mobile devices and technological evolution.

\section{Research program}

- Inventory of 3D simulation / analysis models.

- Study of existing and prospective needs of 3D simulation / analysis in the urban context.

- Development of new 3D simulation / analysis models possible in an enriched 3D city model context. 
- Development of a 3D tool kit for urban management.

- Categorization and formalization of visualization techniques.

- Study of the enrichment of 3D city models with simulation / analyses output.

\section{Data}

\section{Context}

Over the past 20 years, data was considered as the main limitation of the development of 3D city models or more generally 3D GIS. It is changing. First, photogrammetry and land surveying techniques have evolved and thanks to automation and sensors evolution, 3D acquisition becomes easier. Furthermore, a lot of other technologies have emerged such as GNSS, satellite photogrammetry, laser scanning and combined solutions such as mobile mapping, drones, etc. The amount of 3D geometric data is exploding. Data related to underground utilities or soil structures have to be taken into account as well. The data production context has changed too; we came from a world led by NMAs and some big companies to a world with multiple specialised data producers, emerging collaborative communities and some powerful web solutions developers which tend to impose their business model. This evolution impacts the way data should be produced; as mentioned in the other sections, there is a trend to collaborative solutions and data co-production. It is not possible to ignore the open data and big data streams which hold on 3D data like on any other kinds of data.

3D data face the same issue than other types of data; privacy and quality. $3 D$ makes more critical the privacy issues as the 3D data is closer to real world and therefore usually well understood by common users. Data quality and production of standardized metadata is also an important matter. There is a need to clarify and formalized ways to describe data geometry such as concept of level-of-details, resolution, precision and accuracy. There is also a bigger pressure for providing up-to-date data to users; as mentioned above, they are more sensitive to data obsolescence since they can associate them more easily to real world features. There is a huge challenge about temporality and dynamic information.

But 3D data are not only limited to 3D geometry but they also imply to consider semantic data and environmental data. 3D analyses, 3D models and consequently 3D urban management systems require performing crossed analyses on various types of data, and not only geometric features. There is a need to organize the production and collection of semantic data which can be integrated in a 3D environment (census data, cadastral data, etc.). They could also come from simulation or analyses as mentioned in the previous section. Environmental sensors provide also huge amount of data about air quality, noise, etc. It is essential to consider these data to feed 3D integration platform and move towards smart cities. 


\section{Research program}

- Inventory and assessment of 3D acquisition techniques.

- Development of coproduction strategies including data updating.

- Identification and formalization of semantic and environmental data collection techniques.

- Further studies on 3D data privacy issues, and development of ethical rules. 
7 KVSDJHIQMQWRQDQLOIVEOQN 


\section{Chapter 4 \\ Human aspects and perspectives}

This section focuses on the human aspects of $3 D$ city models used to represent urban information: cities have been built by humans and for humans. As such they can be considered as very important generators/providers of information about humans, in relation to administrations and local authorities.

3D city models are aimed at humans; city planners provide an important category of users of this kind of information. This data, or information, or else knowledge based approach of the city can be considered as a new paradigm of the urban model, with a strong influence on the way of teaching information about the city, also on the way the different professionals of the construction sector design and build the city. Virtual reality and games based on virtual environments contribute to increase the needs for 3D approaches of the city, since more and more young people, living in the city, are familiar with this kind of visualisation.

\subsection{Further thoughts on the use of 3D city models}

\subsubsection{Cities as information generators}

Cities, the biggest and most complex creations of mankind, may be best recognized by their distinctive shape, their complex organisation and dynamics (Portugali, 1999). Cities are complex systems made of physical elements interrelated into elaborated spatial relations. This complexity is increased by constant changes evolving shapes and structures. Therefore, the management process of such systems requires institutions and tools able to cope with the challenge of managing such amazing amounts of data. 
In spite of the complexity of this task almost all the municipal governments and administrations on a daily basis, make collection, documentation and management of the data that affect most of the inhabitants of the local community. Collected data come under diverse formats, different levels of detail and precision and with ambiguous availability and usability. City departments gather administrative data for different purposes, usually for exercising the regulatory and planning policies (building permits) or taxation and others are used for management, planning and policy decisions. Most of the time they are recognized more as a documentation rather than information. However, this documentation represents a huge resource of information relevant to the life of cities and their inhabitants, and the systems for collecting and storing data within the "memory" of the city administration have been developed on strong bases, with a confirmed practice so that they can operate beyond the mere usability of the data collected (Carrera and Ferreira, 2007).

Through the recognition, by the cities, of the existence of such a systematic collection of huge amounts of data, and through a precise storage of those data, regardless of their usability, we can clearly determine that the cities and the city administration are an excellent system for provision of data that could be organised and used in a more comprehensive system to support planning policies, management and development of cities. An added value is the potential for using alternative tools for gathering information, thus diminishing the prices of mobile hardware and software tools and providing a rapid growth of social media.

Today the problem is not the availability of systems to collect and to store data but rather the production of information out of administrative documentation and alternative resources with an appropriate and useful level of detail, organised in a systematic way and updated regularly. This situation is urgent for the development of organisational systems and for a better integration of city related data into a more comprehensive system consistent with the nature of the city taken as a system.

\subsubsection{Towards agent-based simulations of a spatial behaviour through the use of 3D city models}

Urban models are envisioned as tools that can help decision-makers anticipate, plan and design cities that promote welfare, prosperity and sustainability. Designing habitable and sustainable cities with effective capabilities for avoiding and managing conflicts and potentially disruptive scenarios is a shared vision of both decision makers and people living in the city. In order to improve the process of urban modelling and to represent the urban dynamics through the use of a more natural metaphor, we have represented our efforts using a multi-agent model.

The term of "agent" is taken here with the meaning of a "social person", considered as a typical or else a standard individual.

An important aspect in our study was dedicated to the identification of the social-related knowledge categories that could help us explain the ways people 
navigate through and make use of urban space. The premise was that the more known about the factors affecting behaviour, trends and processes before we start modelling, the better design choices for agent modelling could be expected. In our approach, we focused on the macro-level (societal) aspects of the problem; an individual pedestrian behaviour served the purpose for aggregated agent modelling.

Concepts and processes related to knowledge management include knowledge creation, codification and transfer. The action starts by identifying, selecting and acquiring types of knowledge related to urban dynamics that can be accessed and obtained. As a basis for the model a variety of traceable information needed to exhaustively describe the urban space, disambiguate user behaviour patterns and the uncertainty of an environment has been identified. This knowledge is both generic and domain specific. It is clear that the inclusion of domain-specific entities, activities and connections besides those related to general urban processes is needed to provide a broader context view and to accommodate the search for answers to a variety of research questions.

Agent modelling has started by identifying different agent types to represent distinct entities and processes existing in the enclosed urban area. Several aggregated agent types were selected to represent different pedestrians at a strategic level, namely, tourists, transit pedestrians, employees and visitors of various service providers (public, private). One should note that visitors of religious objects and people in search of nightlife entertainment represent different stereotypical groups that entail the modelling strategy used. Agent design went through iterative refinements, empirically consistent with the existing knowledge, (surveys, historical data, statistical observations). Heterogeneity in the real world, observed through anthropological surveys and empirical studies, has provided valuable insights for distinguishing relevant aggregated agent types as well as for defining the rules governing their goal-directed behaviour. The social-related knowledge lies in a specialisation scale from generic (i.e., related to groups and aggregated behaviour) to individual. The results of all surveys were aggregated to distinguish behaviour and patterns based on a particular scenario and context, rather than of individual participants, so that aggregated agents could make independent decisions within previously established behavioural guidelines.

The identification of attractors governing pedestrian dynamics within a context of interest was one of the objectives for gathering exhaustive context knowledge. Space-syntax models were deemed more suitable for modelling tourist agent behaviour, while a utility-based approach was employed for modelling other agent types. A goal-oriented view was contrasted with its inherent randomness in human and crowd behaviour. Human randomness, group fuzziness and crowd behaviour were necessary for a more realistic modelling of pedestrian movements in an uncertain environment. Situations such as lunch breaks, happenings, crowded spaces and excessive situations were taken into account. Temporal aspects of pedestrian dynamics have improved our understanding of pedestrian behaviour, sometimes by constraining the goal-oriented behaviour of pedestrian agents, other times by generating new goals and motivations for the agents. 
Agents are situated in the environment, which affects their decision-making strategies and exhibited behaviour. A variety of urban context data (situational and environmental) and additional pragmatic factors were expected to play a prominent role in establishing an appropriate context for our particular investigation. Some of these categories represent invariant properties of the urban context that can be obtained from the domain-specific urban knowledge and the specificity of the particular scenario. Others have been drawn from the information collected from a variety of sources. Semantic enriched data for urban entities were initially gathered from well-known resources about the terrain. They were extended using data solicited through surveys and questionnaires, while further annotations and context knowledge, produced through aggregating history patterns and model outcomes were added to augment the existing knowledge.

The inclusion of situational and environmental factors provides a substantially greater sensitivity in agents behaviour, namely, the ability to adapt to physical and organisational constraints, or to the particularity of a given situation. Each urban entity, private and commercial, was defined as a possible attractor or goal, and described by several context attributes such as type, functionality, ownership, working hours, demographics, the number of employees, frequency of visitors, etc. Pedestrian routes and paths were described through their accessibility, obstacles, sun exposure, street light positions, dimensions and throughput, to take into account the characteristics of the real environment impact the activity spaces of agents. Entities and areas outside of the Old Bazaar perimeter (this example being taken from the modelling of the city of Skopie, Macedonia) were also included to account for the fact that their attraction, prominence and affordance may distinctively affect different agent type behaviour, hence to extend the agent goal space.

The visualisation of pedestrian data has revealed several patterns with a specific spatial and time distribution. It provides insight into both movement patterns and overall system behaviour. We have used a knowledge discovery approach to help us in the identification and the interpretation of patterns relevant to agent modelling. A number of data mining exploration studies to discover the associative and causal relationships between factors have been conducted and are still in progress. Discovering meaningful relationships between agent's components and the emerging collective behaviour has been a crucial step to increase the quality of the current agent representation and future validations. The observations have led to the identification of factors with a great sensitivity and relevance. We acknowledge the importance of the usefulness of data mining techniques in the early stages of agent model design.

Validation is a critical stage for modelling complex dynamic systems, hence integrated knowledge has been recognized to serve both purposes, interpretation and understanding as a basis for modelling, also to provide a way to evaluate outputs of the model given the way historical and empirical manifestations are captured and measured. The latter stresses our modelling approach of deriving the agent beliefs, goals and decision-making strategies directly 
from the knowledge related to individuals (surveys) and macro-level patterns commonly found in real life (statistical observations and sensing technologies). Our experience with multiple scenario-based case studies, preceding the agent modelling process, has been positive and illustrates the value of multiple forms of data collection and evaluation. The outcomes of multi-agents systems were also valuable tool in formalising and testing hypotheses about different aspects of pedestrian mobility.

Our experience points out to the relevance and the application of intelligent technologies, such as knowledge discovery and agent-based modelling, in support of urban modelling and development.

\subsubsection{Interactive 3D city models for city planners}

Urban and regional planning has to integrate a large amount of variables such as economic sustainability, citizens' needs, market requirements, environmental aspects, development opportunities or city plan rules. Furthermore, many professionals, politicians and citizens' representatives are called to take part in the planning process, involving different kinds of actors, usually coming from different disciplines, speaking different languages and holding different interests (MacEachren et al., 2004).

The personal background and technical skills of each actor engaged in the planning process limits the understanding of the technical data, subject of the discussions. Due to the complexity of the issues and the technical gap between technicians in charge of planning and actors involved in decision making processes, some information could be lost, ignored or misunderstood during the debates.

Experience demonstrates that visualisation increases the assessment capability and the comprehension of urban dynamics during the decision process. Today, Information and Communication Technologies (ICT) provide tools based on visual communication for enabling intuitive perception capabilities and improving information sharing. Visualisation enables an intuitive knowledge and can be a fruitful method to make decision makers aware of the elements under discussion, but it must be calibrated on different capabilities of the actors involved in the maps and diagrams reading processes.

\subsection{Towards a new paradigm for urban models}

There have been important changes in what a city represents, a deep re-structuring of the meanings and the spatial specificity and conceptual expression in the urban imaginary (Batty, 2011). The apparent development of the post-metropolis has raised the notion of human systems as systems that are far from equilibrium. Moreover, the spatial aspect of human systems has become more complex due to technological changes, a bigger mobility and social, cultural and demographic transitions of globalised processes. 
Cities are complex systems constituted of physical elements interrelated into elaborated spatial relations, with a complexity increasing as the shape and the structure are changing and evolving. To try to understand the dynamics and the processes shaping our cities, we must coherently model according to the dynamic and complex nature of cities, but also models should remain understandable and simple enough to be operationally useful. Hence, any attempt to model the spatial system and the dynamics of the cities should involve this non-determination and instability of the cities and this theoretical framework as one of its basic features. In the same time it should be followed with a strong knowledge and data management providing a necessary coherence with the nature of the city.

To do all that, we have to search for a new paradigm in the way of modelling urban form, thus allowing to free the process of representation from fixed types and pre-determined shapes of elements of the model and to introduce a concept that will be generative as much as it is analytical.

According to the new city paradigm and to the way we understand and use our cities, the way-forward is to embed this variety of information into a semantically enriched 3D city model that will serve simultaneously as a resource of integrated information and as a tool for the analysis, the evaluation and creation of a new urban knowledge as a basis of decision policies and urban development. This shift in the practice of urban information management would enable a substantial change of the process of decision making and planning practices, also in the way cities will be developed and maintained in the future.

The evolutionary leap in the field of urban management and planning could be achieved through developments and breakthroughs in a near future in the following areas:

- Using the existing infrastructure for gathering and storage of data and converging it into a system of easily accessible and open source urban information;

- Creating a 3D city model as an infrastructure for resourcing, collecting and storing data from both ends of the institutional vertical approach, from administration procedures at one end and from citizens, individual and legal entities working and communicating with the city on the other end. The model will become a tool for the integration and moderation of data coming from insources and outsources urban data, creating a vast platform of various urban information;

- Using this 3D city model as a platform for an horizontal integration of data sources and existing information infrastructure, like BIM, and real-time changes of urban structure into an integrated Urban Information Infrastructure (UIM);

- Using semantically enriched 3D city models as a modular system that would "only" model the part under the jurisdiction of the city, in order to suit specific 
needs of the users (from the city administration to citizens), but enabling a construction and an integration of this modules into bigger and more complex spatial modules relevant for metropolitan areas, regional or national level information infrastructure;

- Through this process, standards for information interchange will be embedded into the 3D city model based on the foundations laid out by the Open Geospatial Consortium;

- Semantically enriched 3D city models should be linked to a web service creating a bigger, open and usable system of urban information exchange.

The future of cities based on the idea of a creation of a society of knowledge lies in the creation of semantically enriched 3D city models as powerful tools for gathering, storing, evaluating and using urban information through a comprehensive open and accessible system coherent with the nature of the cities and the way we see and understand them. Urban Information Models can emerge from the horizontal and vertical integration of different information sources with an active contribution of institutions, companies and individuals creating a complex network of urban knowledge. This in return will enable cities to act as facilitators for the exchange of urban information with a high level of details and usability. This would also help to become more effective and efficient in the way of providing policies for city management and urban planning suited to the best interests of their citizens.

The change in the paradigm of the cities and the way we understand cities is a result of simultaneous and large efforts for producing new spatial configurations and activities but also collecting, processing and sharing information. Therefore, the next generation of leaders in design and planning should have skills and tools to understand how to develop an urban information infrastructure as a basis for a society of knowledge. Development of urban information and knowledge infrastructure is not simply an institutional or software issue that can be solved by waiting for organisational or computer advances in the coming years. Specification of information models urges for a new mode of scholarship that today leaders in institutions, firms, agencies and schools should be focused on.

3D city models must be seen as tools for the integration of information coming from a wide range of levels of detail and backgrounds, from buildings and activities representations to ground and underground infrastructures. A high level of integration and interoperability between existing data and GIS related information and simulation capacities of the model can be achieved. 3D city models can become an urban analytical tool capable of harvesting information from different fields of activities. They can also become tools to generate new information and understanding through a complex urban knowledge about the conditions of the city, revealing the future in a most comprehensive way for future users. This will be considered as the true beginning of the concept of smart cities and the society of knowledge. 


\subsection{City modelling in education, or education to 3D city modelling?}

The training process of students in architecture, urban planning, geomatics, geography, social sciences and humanities is focused on representing, understanding, modifying and evaluating urban places and spaces, thus constantly challenging the process of integration of many information and knowledge sources into a coherent model.

The large number of models produced requires a comprehensive system of organisation in order to enable a production of coherent knowledge based on the new information and added value. Let's consider Second Life and 3D virtual environment as tools for teaching urban modelling and planning.

\subsubsection{D virtual worlds}

During the last few years, three-dimensional virtual worlds have gained global popularity: today there are dozens of internet-based virtual environments (VEs) running on PCs. Advances in technology, lower hardware prices and popularity of the Internet have made it possible for three-dimensional VEs and particularly desktop computers. The greatest number of VE applications is used for games, but a certain number can also be used in socializing, education, risk assessment, military training, etc.. Second Life is one of the leaders in cost-effective virtual education solutions to create new models for collaborative learning.

The most advanced VEs provide the users with a detailed 3D graphical representation, animation, different communication methods and offer the possibility of building new objects and places. The traditional behaviourist approach centred on the memorizing of facts has to date been replaced with approaches such as a cognitive approach requiring genuine understanding and a constructivist approach focusing on the discovery of new knowledge.

\subsubsection{Second life game approaches}

The emergence of web based 3D virtual worlds provides new opportunities to collaborate in the design of spaces. The most popular advanced virtual world currently available is Second Life (SL), part of a larger group of internet-based applications known as social media. The flexibility of SL makes it different from other social media. As an open virtual environment, SL can be used in various ways and it is becoming one of the most compelling educational opportunities for adults in the 21 st Century. In SL applications, the users are represented through customizable virtual persons called "avatars" - pieces of software that are the audiovisual bodies people use to represent themselves and communicate with other people in the Metaverse. As a potential tool for collaboration and communication, the avatar is an instrument of user-expression and individuality. 
The extension of Second Life from the area of socializing to city decision-making can be interesting for urban planners of any modern city. It can substitute the distribution of the usual two-dimensional content-sharing of information to VE, with avatars having the possibility to explore their virtual environment in three dimensions. With no more restrictions than in real world, SL may be an optimal environment for experimentation-based learning where members of community have the opportunity to use their creative and expressive voice in activities that are fun, vital, special, real, useful, indigenous, celebratory and sustainable. Because the VE typically allows not only to observe, but also to interact, the actions of the users modify the state of the VE. The human-computer interaction is used to facilitate interactions between users and the $3 \mathrm{DVE}$, thus leading to a remarkable increase in terms of useful and positive feedback, an increase in public support of the development projects, and a decrease in the time necessary to explain the projects.

This kind of approach is seen with a growing interest among urban designers and planners for the design and planning of buildings, neighbourhoods and cities. The City of Boston (USA) is re-creating parts of the city and is developing teaching resources for the application of $3 D$ virtual technologies as a community engagement tool in urban planning initiatives. In addition to this example, different uses of $3 \mathrm{D}$ city models in the context of urban planning are being explored: in Portugal, $3 \mathrm{D}$ city models ar starting to bring a contribution to the 3D visualisation of the city, through cultural and useful information about restaurants, banks or about elements of the cultural heritage. 
7 KVSDJHIQMQWRQDQLOIVEOQN 


\section{Chapter 5 \\ Conclusions}

\subsection{Action's context and objectives}

Many urban or environmental models are defined with the objective of helping practitioners and stakeholders in their decision-making processes. Those models, particularly 3D city models are increasingly used in different cities and countries for an intended wide range of applications beyond mere visualisation. Indeed, unlike maps and drawings, 3D visualisation reflects a view of the environment that a lot of people are familiar with and act as a communication tool. Non-geometrical data (such as social, historic or acoustic data or statistics, for example) can be associated to urban geometrical objects (such as buildings or streets) that can be represented and visualised in $3 \mathrm{D}$, leading to a localisation as well as a better understanding of these data. By associating a domain (energy consumption, air quality, etc.) to these 3D models, we obtain richer 3D representations that can be used for simulations and reasoning (visual reasoning).

Considering sustainable development of cities implies investigating cities in a holistic way taking into account many interrelations between various urban or environmental issues. Could the above-mentioned 3D city models be used to integrate urban and environmental knowledge? How could they be improved to fulfil such role? We believe that enriching the semantics of current 3D city models, would extend their functionality and usability; therefore, they could serve as integration platforms of the knowledge related to urban and environmental issues allowing a huge and significant improvement of city sustainable management and 
development. But which elements need to be added to 3D city models? What are the most efficient ways to realise such improvement/enrichment? How to evaluate the usability of these improved 3D city models?

The Action TU0801 "Semantic Enrichment of 3D city models for sustainable urban development", presented in this report has tried to bring some elements of answer to those different questions.

The action started in November 2008 and ended in November 2012. The main motivation of the action was to explore ways to semantically enrich 3D models with urban knowledge and models, so as to extend their functionality and usability in a perspective of sustainability. It was an active research network of 75 permanent members gathering people from academia, industry, administration and regulation bodies from 23 participating countries.

The scientific goals were to identify knowledge (concepts) relevant for sustainable urban development that could enrich current 3D city models, to investigate means for integrating or interconnecting these concepts either directly either by defining articulation patterns (such as ontologies), to assess the usability of enriched 3D city models, relatively to various urban issues. Among the objectives of the action, let us mention also to promote the creation and use of enriched 3D city models, to provide a contribution towards European standards relative to 3D city models in relation with sustainable development, to provide a methodology for creating and maintaining enriched 3D city models and to produce recommendations for decision makers, scientists and for education purposes.

Given the high interdisciplinarity level of the Action, but also the diversity of the groups targeted (scientific communities dealing with urban issues (planners, geographers, sociologists...), computer scientists, designers, engineers, environmentalists or any actor of the urban field, decision makers, mapping agencies and data providers), the Action was internally structured in three working groups:

- WG 1: exchange platform about semantic and thematic 3D nature of urban space. This group was composed of urban experts as urban planners, urban geographers, sociologists, environmentalists, and of researchers from the spatial information field.

- WG2: focused on integration and interoperability issues when combining semantic information and models with 3D city models. This group was composed of researchers in information sciences and representation techniques.

- WG3: to address the stakes of information integration into decision processes to support urban development and sustainability. This implies a thorough understanding of those decision processes for a representative set of urban development and management processes, the identification of the users needs for related information and knowledge on the urban fabric. 


\subsection{Action's report}

The Action TU0801 has generated a lot of activities and contributions. The aim of this report was to provide the necessary complementary information to the existing action outputs. It must be considered as a guide to help practitioners, decision makers and scientists to get into the domain of 3D city modelling with the perspective of city dynamic modelling and smart cities.

The first chapter of the report is a state-of-the art about the main concepts that have to be handled when considering enrichment of $3 \mathrm{D}$ city models. This work is a specific contribution made by the members for this final report. Indeed, we have encountered a lot of misunderstanding at the beginning of the action between members coming from various disciplines. It was therefore important to provide a comprehensive study about the main concepts used during the action. The objective of this section was to set up a state of the art of the situation of urban models, city models and enrichment of city models at the beginning of the project and during the four years of the work done within the framework of the project. We needed at the beginning to clarify the notions of (3D) urban and (3D) city models, but also the meaning of the term of "enrichment".

The second chapter presents the outputs of the action and is divided into two parts. The first one concerns the scientific production of the action and lists all the activities, dissemination output (books, website...). The second part summarises the main action's breakthroughs and presents some research perspectives. At the beginning of the Action, 3D related concepts were diversely understood and used by the members. The main achievement of the Action has been to create a common vision of the natures and the usages of 3D city models. All the studied cases have shown that the use of 3D improves significantly the related applications (pollution /transport /visibility simulations, planning, disaster management, etc.) in a sustainable perspective. The role of 3D city models as integrator of urban and environmental knowledge has been strongly acknowledged. A new community has emerged and is spreading beyond the Action; the final conference and the interest shown by external participants is one very good example of such dissemination.

This emerging vision will have major impacts on standardisation bodies, decision makers, data producers and consequently on the industry but also on urban experts and scientists. Indeed, considering enriched 3D City Models as urban knowledge integration plafform implies a (re)definition of geospatial standards, new data production/ integration strategies, development of new applications... Enriched 3D City Models are the foundation of future smart cities.

Beyond these considerations, some conceptual and technical issues still remain unsolved: types of semantic enrichment, ways of enriching 3D City Models, ways of visualizing enrichment information and knowledge and even 3D City Models definitions are still debatable. Indeed, we have demonstrated that by considering 3D City Models we gather a lot of disciplines and applications, which are diverse and not traditionally integrated. In other words, 3D City Models is the basic ground 
for integrating urban knowledge, but such integration is complex and new. It is not just an extension of traditional 2D maps, or geometrical 3D City models, but rather a creation of spatial model of complex urban networks of relationships between elements, attributes and configurations. This integration and production of new urban knowledge has been exercised through several joint research projects within TU0801 where various tools and models have been used simultaneously for comprehensive modelling of urban environment.

The last chapter brings additional aspects, not specifically addressed by the different working groups but which tend to be important when considering the uses of 3D city models in a sustainable perspective. It gathers discussions about human and social aspects (cities as information generators, human spatial behaviour, interactive 3D city models for city planners...), some evolutions of urban modelling paradigms and finally some thoughts about 3D City modelling and education. The chapter focuses on the human aspects of $3 \mathrm{D}$ city models used to represent urban information: cities have been built by humans and for humans. As such they can be considered as very important generators/providers of information about humans, in relation to administrations and local authorities. 3D city models are aimed at humans; city planners provide an important category of users of this kind of information.

This data, or information, or else knowledge based approach of the city can be considered as a new paradigm of the urban model, with a strong influence on the way of teaching information about the city, also on the way the different professionals of the construction sector design and build the city. Virtual reality and games based on virtual environments contribute to increase the needs for 3D approaches of the city, since more and more young people, living in the city, are familiar with this kind of visualisation.

\subsection{Action's evaluation}

TU0801 it was:

- 9 workshops and 1 conference

- 15 STSMs

- 1 summer school

- 42 articles in 3 books.

It was also a website, a wiki... but most of all it is was a network of 75 researchers coming from 23 countries.

We can point out some particular successes of the Action:

- The emergence of a new community around 3D enriched city models, which has reached a very high level of integration at the end of the Action and particularly at the final conference in Nantes. 
- The establishment of recommendations for scientists (research program).

- The creation of active research sub-groups (3D pedestrian navigation, 3D historical modelling...).

- And more generally an active participation of early stage researchers through STSMs and summer school.

TU0801 was a "big action" and it was therefore difficult to get similar involvements of all the members. We realized that stability is important for WG works; at the beginning, we had to face a lot of movements of members between WGs, incoming new members, etc.. This slowed down WG's scientific productions for a while. Probably the number of participants in this kind of research project, above a certain limit, can, to some extent, be considered as a brake on the quality of the research results.

However, the Action reached the expected COST standard and was successfully evaluated by the TU Domain committee. Most of members have improved their involvement in the action. We have organised all the activities that had been previously planned, including workshops and STSM and the final conference in Nantes was a real success.

\subsection{As a matter of perspectives...}

The motivation behind the development of semantically enriched 3D city models is the belief that effective and useful urban models cannot be accomplished without proper knowledge base that integrates knowledge in a variety of formats and in a meaningful way. As a basis for urban models, an integrated knowledge base has been proposed as a container of a variety of traceable information needed to exhaustively describe the urban context. By organizing theoretically- and empirically-sound knowledge for semantically enriched representation of urban spaces in a coherent framework, we have attempted to improve the methodology of the modelling process.

There is an urgent need of converging knowledge representation that requires unity of models, strategies and perspectives, contributed by the relevant disciplines and experts. The knowledge base should provide a means for integrating and interconnecting heterogeneous data such as urban maps, photographs, cadastre data, and various unstructured data, as well as empirical studies, social surveys. This effort needs access to data, solicited and gathered by experts in diverse fields (e.g., architects, city planners, social science experts), using various solicitation and analytical methods. Semantic heterogeneity, terminology differences, inconsistency, redundant data and interoperability are some of the problems encountered. Neither to the technological aspects nor the social aspects is to be given primacy in the knowledge construction and pattern explanation. The knowledge categories should be derived from both, theoretical and empirical work in various disciplines. The knowledge space is expected to provide a starting point with 
enough possibilities to account for the complexity and relationship between urban dynamics of varying nature with the same depth as it was investigated in the past.

Context representation and employment of sound inferring techniques to understand and anticipate human activities, interactions and behaviour in the urban environment is an imperative. The new directions in information technologies directed toward pervasiveness and intelligence have increased the amount of raw data collection with a potential to increase our knowledge of different aspects of social urban life. Individual pieces of knowledge or a collection of categories do not constitute a model. The effort to find out how those pieces of information are related to one another (e.g., causal and associative relationship) is far more challenging. Employment of a number of tools and intelligent techniques could support the process of capturing and visualizing the observable manifestation of behaviour trends and patterns i.e., the urban dynamics. Establishing the relevance of these patterns and their proper inclusion in the models of urban dynamics is as complex as any reasoning in an uncertain, non-deterministic, dynamic system.

Urban context knowledge is crucial in disambiguating the meaning and the relevance of the exhibited patterns in regard to the model of urban dynamics. The main focus of our research to date has been to correlate discovered patterns with other urban-related knowledge that can help us make sense of the underlying complex systems. Extracting qualitative knowledge from large quantities of data is just the beginning in our search for the meaning and plausible explanation of urban dynamics. New platforms that combine urban informatics with the more traditional urban-related knowledge are yet to be developed and deployed.

This new enrichment and integration of information, structure and process, of course poses the biggest problem and raises many technical issues that are yet to be resolved. Integrating the interoperability between many different aspects of the spatial systems of the cities raises the questions of the unifying code that will provide us with the platform for performing such an operation. This also includes the agility of the city model to shift between different scales and the level of detail of the urban elements and urban systems and further on toward the exploration of integrated spatial data, allowing us to become aware on what are the mutual influences that affect spatial developments. The process of the urban development and the nature of the city itself are still at the brink of new understanding and development in theory and practice. The new and enriched understanding of the cities and their structure, partial through the use of city models will also affect the way we comprehend and represent the process of their creation and the models of the urban reality. 


\section{References}

Abadie N. (2009). Formal specifications to automatically identify heterogeneities, In: proceedings of the 12th International Conference on Geographic Information Science (AGILE'09), Pre-Conference Workshop "Challenges in Spatial Data Harmonisation", Hanover (Germany).

Abowd G.D., Dey A.K., Brown P.J., Davies N., Smith M., Steggles P. (1999). Towards a Better Understanding of Context and Context-Awareness. In Proceedings of the 1st international symposium on Handheld and Ubiquitous Computing (HUC '99), Hans-Werner Gellersen (Ed.). Springer-Verlag, London, UK, 304-307.

Amorim J.H., Rodrigues V., Tavares R., Borrego C. (2010). CFD Modelling of Tree-induced Effects on Flow and Dispersion of Traffic Emissions in City Centres. Advances in Urban Rehabilitation and Sustainability. Panagopoulos T., Noronha T. and Beltrão J. (Eds.). In The 3rd WSEAS International Conference on Urban Rehabilitation and Sustainability (URES '10), University of Algarve, Faro, Portugal, November 3-5.

Amorim J.H., Valente J., Cascão P., Rodrigues V., Borrego C. (2012a). Modelling the link between urban morphology, pedestrian dynamics and individual exposure to air pollution In: 3D Issues in Urban and Environmental Systems. R. Billen, M. Caglioni, O. Marina, G. Rabino, R. San José (Eds.). Società Editrice Esculapio, Italy. 103-1 10 p. ISBN: 978-88-7488-546-6.

Amorim J.H., Valente J., Pimentel C., Miranda A.I., Borrego C. (2012b). Detailed modelling of the wind comfort in a city avenue at the pedestrian level. In "Usage, Usability, and Utility of 3D City Models". T. Leduc, G. Moreau, R. Billen (Eds.). Edp Sciences, France: 03008p. 1-03008p.6. ISBN: 978-2-7598-0798-7. 
Anders K.-H. (2005). Level of Detail Generation of 3D Building Groups by Aggregation and Typification. In Proceedings of the XXII International Cartographic Conference.

Bartie P., Reitsma F., Clementini E., Kingham S. (2011). Referring Expressions in Location Based Services: The Case of the 'Opposite' Relation. In: Advances in Conceptual Modeling. Recent Developments and New Directions - Er 2011 Workshops - the Fifth International Workshop on Semantic and Conceptual Issues in Gis (Secogis 2011) (Ed. by O. De Troyer, C. Bauzer Medeiros, R. Billen, P.Hallot, A. Simitsis \& H.Van Mingroot), LNCS 6999, 231-240. Springer-Verlag, Berlin Heidelberg.

Batty M. (201 1). Visually-driven urban simulations: Exploring fast and slow changes in residential London, CASA, working papers series, n. 164, 03/201 1, UCL, London.

Bazzanella, Liliana. Caneparo, Luca. Corsico, Franco. Roccasalva, Giuseppe. (Eds) (2011). Future Cities and Regions. Simulation, Scenario and Visioning, Governance and Scales. New York, Heidelberg: Springer.

Bittner T., Donnelly M., Winter S. (2005). Ontology and semantic interoperability. In Prosperi, D., Zlatanova, S., eds.: Large-Scale 3D Data Integration: Challenges and Opportunities, CRCPress, Boca Raton, FL.

Borges K. A. V., Clodoveu D. A., Laender A. H. F. (2002). Integrity constraints in spatial databases. In Database Integrity, pages 144-171.

Borrego C., Tchepel O., Costa A., Amorim J., Miranda A. (2003). Emission and dispersion modelling of Lisbon air quality at local scale. Atmospheric Environment 37, 5197-5205.

Borrego C., Tchepel O., Salmin L., Amorim J.H., Costa A.M., Janko J. (2004). Integrated modelling of road traffic emissions: application to Lisbon air quality management. Cybernetic Systems: An International Journal. 35, 535-548.

Borrego C., Martins H., Tchepel O., Salmim L., Monteiro A., Miranda A.I. (2006). How urban structure can affect city sustainability from an air quality perspective. Journal of Environmental Modelling and Software. 21, 461-467.

Borrego C., Valente J., Amorim J.H., Rodrigues V., Cascão P., Miranda A.I. (2012). Modelling of tree-induced effects on pedestrian exposure to road traffic pollution. In the 18th International Conference on Urban Transport and the Environment (Urban Transport 2012). A Coruña, Spain. May, 15-17, 2012.

Bowman D.A., Kruijff E., Laviola J.J., Poupyrev I. (2004). 3D User Interfaces: Theory and Practice. Addison Wesley Longman Publishing Co., Inc., Redwood City, CA, USA.

Britter R.E., Hanna S.R. (2003). Flow and dispersion in Urban Areas. Annu. Rev. Fluid Mech, 35, 469-496. 
Buccolieri R., Gromke C., Di Sabatino S., Ruck B. (2009). Aerodynamic effects of trees on pollutant concentration in street canyons. Science of the Total Environment 407(19), 5247-56.

Bucher B., Falquet, G., Clementini, E., Sester M. (2012). Towards a typology of spatial relations and properties for urban applications, Conf.3u3d2012: Usage, Usability, and Utility of 3D City models, 29-31 October 2012, Nantes, France. http://dx.doi.org/10.1051/3u3d/201202010

Carrera F., J. Ferreira JR. (2007). The Future of Spatial Data Infrastructures: Capacity-buildingfor the Emergance of Municipal SDI's, in "International Journal of Spatial Data Infrastructures Research" vol.2, pp. 49-68.

Chang R., Butkiewicz T., Ziemkiewicz C., Wartell Z., Pollard N., Ribarsky W. (2008). Legible Simplification of Textured Urban Models. IEEE Computer Graphics and Applications, 28:27-36.

Civerolo K., Hogrefe C., Lynn B., Rosenthale J., Ku J.-Y., Solecki W., Cox J., Small C., Rosenzweig C., Goldberg R., Knowlton K., Kinney P. (2007). Estimating the effects of increased urbanization on surface meteorology and ozone concentrations in the New York City metropolitan region. Atmospheric Environment. $41,1803-1818$.

De Laat R., Van Berlo L. (201 1). Integration of BIM and GIS: The Development of the CityGML GeoBIM Extension. Advances in 3D Geo-Information Sciences: Lecture Notes in Geoinformation and Cartography, pages 211-225. Springer.

De Ridder K., Lefebre F., Adriaensen S., Arnold U., Beckroege W., Bronner C., Damsgaard O., Dostal I., Dufek J., Hirsch J., Intpanis L., Kotek Z., Ramadier T., Thierry A., Vermoote S., Wania A., Weber C. (2008a). Simulating the impact of urban sprawl on air quality and population exposure in the German Ruhr area. Part I: Reproducing the base state. Atmospheric Environment. 42, 7059-7069.

De Ridder K., Lefebre F., Adriaensen S., Arnold U., Beckroege W., Bronner C., Damsgaard O., Dostal I., Dufek J., Hirsch J., Intpanis L., Kotek Z., Ramadier T., Thierry A., Vermoote S., Wania A., Weber C. (2008b). Simulating the impact of urban sprawl on air quality and population exposure in the German Ruhr area. Part II: Development and evaluation of an urban growth scenario. Atmospheric Environment 42, 7070-7077.

Döllner J., Hagedorn, B. (2007). Integrating Urban GIS, CAD, and BIM Data by Service-Based Virtual 3D City-Models. In Urban and Regional Data Management: UDMS 2007 Annual, pages 157-170.

Egenhofer M. J., Mark D. M. (1995). Naive geography. In Proceedings of COSIT'95, pages 1-15. Springer LNCS 988. 
Fan H., Meng L., Jahnke M. (2009). Generalization of 3D Buildings Modelled by CityGML, Advances in GIScience: Lecture Notes in Geoinformation and Cartography. pages 387-405. Springer.

Fei L., He J. (2009). A Three-Dimensional Douglas-Peucker Algorithm and Its Application to Automated Generalization of DEM. International Journal of Geographical Information Science, 23(6):703-718.

Forberg A. (2004). Generalization of 3D Building Data Based on a Scale-Space Approach. In International Archives of the Photogrammetry, Remote Sensing and Spatial Information Sciences.

Gallagher J., Gill L.W., Mcnabola A. (2012). Numerical modelling of the passive control of air pollution in asymmetrical urban street canyons using refined mesh discretization schemes. Building and Environmnet. 56, 232-240.

Gallagher J., Gill L.W., Mcnabola A. (2011). A. Optimizing the use of on-street car parking system as a passive control of air pollution exposure in street canyons by large eddy simulation. Atmos Environ. 45(9), 1684e94.

Gibson J.J. (1986). The Ecological Approach to Visual Perception. Lawrence Erlbaum, Hillsdale, NJ, 332

Glander T., Döllner, J. (2009). Abstract Representations for Interactive Visualization of Virtual 3D City Models. Computers, Environment and Urban Systems, 33:375-387.

Glander T., Trapp M., Döllner J. (2011). Concepts for Automatic Generalization of Virtual 3D Landscape Models. In Proceedings of the Annual Conference of Digital Landscape Architecture, pages 127-135.

Göbel R., Zipf A. (2008). How to Define 3D Geoprocessing Operations fort he OGC Web Processing Service (WPS) Towards a Classification of 3D Operations. In O. Gervasi, B. Murgante, A. Laganá, D. Taniar, Y. Mun \& M. Gavrilova (Eds.), Computational Science and lts Applications - ICCSA 2008.

Grimmond C.S.B., Oke T.R. (1999). Aerodynamic properties of urban areas derived from analysis of surface form. Journal of Applied Meteorology 38, 1262-1292.

Gromke C., Buccolieri R., Di Sabatino S., Ruck B. (2008). Dispersion study in a street canyon with tree planting by means of wind tunnel and numerical investigations - evaluation of CFD data with experimental data. Atmospheric Environment 42, 8640-8650.

Guercke R., Brenner C. (2009). A Framework for the Generalization of 3D City Models. In Proceedings of 12th AGILE Conference on GIScience.

Guercke R., Gtzelmann T., Brenner C., Sester M. (2011). Aggregation of LoD 1 building models as an optimization problem. ISPRS Journal of Photogrammetry and Remote Sensing, 66(2):209-222. 
Hang J., Sandberg M., Li Y., Claesson L. (2009). Pollutant dispersion in idealized city models with different urban morphologies. Atmospheric Environment 43, $6011-6025$.

Hang J., Sandberg M., Li Y., CLAESSON L. (2009). Pollutant dispersion in idealized city models with different urban morphologies. Atmospheric Environment. 43, $6011-6025$.

He S., Moreau G., Martin J.-Y. (2012a). Footprint-Based 3D Generalization of Building Groups for Virtual City Visualization. In Proceedings of GEOProcessing 2012, pages 177-182.

He S., Besuievsky G., Tourre V., Patow G., Moreau G. (2012b). All Range and Heterogeneous Multi-Scale 3D City Models. In Proceedings of Usage, Usability, and Utility of 3D City Models. To appear.

Hix D., Hartson H.R. (1993). Developing User Interfaces: Ensuring Usability Through Product \& Process, ISBN: 978-0-471-57813-0.

Hornbæk K. (2006). Current practice in measuring usability: Challenges to usability studies and research. In Int. J. Human-Computer Studies 64 (2006) 79-102.

Ishaque M.M., Noland R.B. (2008). Simulated pedestrian travel and exposure to vehicle emissions. Transportation Research Part D. 13, 27-46.

Jahnke M., Krisp J. M., Kumka H. (201 1). How Many 3D City Models Are There? - A Topological Try. The Cartographic Journal, 48(2):124-130.

Jordan T., Raubal M., Gartrell B., Egenhofer M. (1998). An affordance-based model of place in GIS. In: Eight International Symposium on Spatial Data Handling, pp. 98-109.

Kavouras M., Kokla M., Tomai E. (2003). Determination, visualization, and interpretation of semantic similarity among geographic ontologies, In: Gould, M., Laurini, R., Coulondre, S. (eds) Proceedings of the 6th AGILE Conference on Geographic Information Science, Lyon, France, pp. 51-56.

Klien E., Lutz M., Kuhn W. (2006). Ontology-based discovery of geographic information services - An application in disaster management, In: Computers, Environment and Urban Systems 30(1) pp.102-123.

Kolbe T., Gröger G., Plümer L. (2005). CityGML - Interoperable Access to 3D City Models, In: Oosterom, P., Zlatanova, S., Fendel, F.(eds), Proceedings of the International Symposium on Geo-information for Disaster Management, Springer Verlag, Delft.

Kolbe T. (2009). Representing and Exchanging 3D City Models with CityGML, Th. Kolbe, in 3D Geo-Information Sciences J. Lee, S Zlatanova Eds, 2009 ISBN 9783540873945. 
Kopczynski M. (2006). Efficient spatial queries with sketches - In: Proceedings of ISPRS Technical Commission II Symposium, Vienna, Austria.

Kuhn W. (1996). Semantics of geographic information. Geo-info series, Vol. 7, Technical university Vienna, Dept. of Geoinformation, Austria.

Kuhn W. (2001). Ontologies in support of activities in geographical space, In: International Journal of Geographic Information Science, 15(7), 613-631, Taylor \& Francis Ltd., London, Great Britain.

Kühne T. (2006). Matters of (meta-) modeling. Softw Syst Model 5:369-385. Doi 10.1007/s10270-006-0017-9.

Kwan-Liu Ma (2009). In Situ Visualisation at Extreme Scale: Challenges and Opportunities. IEEE Computer Graphics and Applications 29(6): 14-19.

Li Z. (2008). Multi-Scale Digital Terrain Modelling and Analysis. Advances in Digital Terrain Analysis, Lecture Notes in Geoinformation and Cartography, pages 59-83. Springer Berlin Heidelberg.

Limbourg Q., Vanderdonckt J. (2004). Comparing Task Models for User Interface Design. In The Handbook of Task Analysis for Human-Computer Interaction Mahwah: Lawrence Erlbaum Associates.

Maceachren A.M., Gahegan M., Pike W., Brewer I. (2004). Geovisualization for knowledge construction and decision-support. in Computer Graphics \& Applications, 24(1): 13-17.

Marquez L., Smith N. (1999). A framework for linking urban form and air quality. Journal of Environmental Modelling \& Software. 14, 541-548.

Martins A., Cerqueira M., Ferreira F., Borrego C., Amorim J.H. (2009). Lisbon air quality - evaluating traffic hot-spots. International Journal of Environment and Pollution (IJEP) 39(3/4), 306-320.

Martins A., Cerqueira M., Ferreira F., Borrego C., Amorim J.H. (2009). Lisbon air quality - evaluating traffic hot-spots. International Journal of Environment and Pollution. 39, 306-320.

Mcnabola A. (2010). New Directions: passive control of personal air pollution exposure from traffic emissions in urban street canyons. Atmospheric Environment 44(24), 2940-2941.

Métral C., Falquet G., Karatzas K. (2008). Ontologies for the Integration of Air Quality Models and 3D City Models. In "Conceptual Models for Practitioners". J. Teller, C. Tweed, G. Rabino (Eds.), Società Editrice Esculapio, Bologna, Italy.

Métral C., Ghoula N., Falquet G. (2012a). Towards an integrated visualization of semantically enriched 3D city models: an ontology of 3D visualization techniques, Workshop 3D issues in urban and environmental systems, 12-13 April 2012, Madrid, Spain. 
Métral C., Ghoula N., Falquet G. (2012b). An ontology of 3D visualization techniques for enriched 3D city models, Conf. 3u3d2012: "Usage, Usability, and Utility of 3D City models", 29-31 October 2012, Nantes, France.

Milliez M., Carissimo B. (2007). Numerical simulations of pollutant dispersion in an idealized urban area, for different meteorological conditions. BoundaryLayer Meteorology. 122, 32 1-342.

Moreno A., Zlatanova S., Bucher B., Posada J., Toro C., García-Alonso A. (2011). Semantic Enhancement of a Virtual Reality Simulation System for Fire Fighting, Proceedings of the Joint ISPRS Workshop on 3D City Modelling \& Applications.

Morita T. (2007). Concept of a real scale map and the allocation of reference points in ubiquitous mapping, In: proceedings of the 23rd ICC conference, Moscow.

Müller P., Wonka P., Haegler S., Ulmer A., Van Gool L. (2006). Procedural Modeling of Buildings. ACM Transactions on Graphics, 25(3):614-623.

Mustière S., Gesbert N., Sheeren D. (2003). A formal model for the specifications of geographic databases, International Workshop GeoPro on Semantic Processing of Spatial Data, 5-7 November, Mexico (Mexico).

Nielsen J., Molich R. (1990). Heuristic evaluation of user interfaces. In Proceedings of the SIGCHI conference on Human factors in computing systems: Empowering people ( $\mathrm{CHI}$ '90), Jane Carrasco Chew and John Whiteside (Eds.). ACM, New York, NY, USA, 249-256. Doi=10.1145/97243.97281.

Nurminen A. (2008). Mobile 3D City Maps. IEEE Computer Graphics \& Applications, 28(4), pp. 20-31.

Pack M. (2010). Visualisation in Transportation: Challenges and Opportunities for Everyone, IEEE Computer Graphics and Applications, pp. 90-96, July/ August.

Pajarola R., Gobbetti E. (2007). Survey of Semi-Regular Multiresolution Models for Interactive Terrain Rendering. The Visual Computer, 23(8):583-605.

Penwarden A. D. (1973). Acceptable Wind Speeds in Towns, Building Science, Vol 8, Issue3, pp. 259-267.

Pisarski A.E. (2007). Vision of Visualisation - Communicating Problem-Solving Concepts to the Public, in Visualisation In Transportation: Empowering Innovation - in TR NEWS, n. 252, September - October 2007, pp. 4-6.

Portugali J. (1999). Self-Organization and the City. Springer-Verlag. Berlin.

Rau J.-Y., Chen L.-C., Tsai F., Hsiao K.-H., Hsu W.-C. (2006). LOD Generation for 3D Polyhedral Building Model. In Advances in Image and Video Technology, 
volume 4319 of Lecture Notes in Computer Science, pages 44-53. Springer Berlin / Heidelberg.

Ross L. (2010). Virtual 3D City Models in Urban Land Management - Technologies and Applications, Universität Berlin - Dissertation.

Schatzmann M., Olesen H., Franke J. (Eds.), (2010). COST 732 model evaluation case studies: approach and results. COST, Brussels.

Sebrechts M.M., Cugini J.V., Laskowski S.J., Vasilakis J., Miller M.S. (1999). Visualization of search results: a comparative evaluation of text, 2D, and 3D interfaces. In Proceedings of the 22nd annual international ACM SIGIR conference on Research and development in information retrieval (SIGIR '99). ACM, New York, NY, USA, 1999.

Sester M., Klein A. (1999). Rule Based Generalization of Buildings for 3D-Visualization. In Proceedings of The International Cartographic Conference.

Sini J.-F., Anquetint S., Mestayer P.G. (1996). Pollutant dispersion and thermal effects in urban street canyons. Atmospheric Environment. 30, 2659-2677.

Stoter J.E., Beetz J., Ledoux H., Reuvers M.L, Klooster R., Janssen P., Penniga F., Zlatanova S., Van Den Brink L. (2012). Implementation of a national 3D standard: case of The Netherlands, in (Pouliot, Daniel, Hubert and Zamyadi) Progress and new trends in 3D geographical information, Lecture Notes in Geoinformation and Cartography, pp. 277-275).

Szymanski M. (2004). CAVELib Support For PC Visualisation Clusters, Advanced Imaging, v. 19, n.8, p.39 (6).

Tang U.W., Wang Z.S. (2007). Influences of urban forms on traffic-induced noise and air pollution: Results from a modelling system. Environmental Modelling and Software. 22, 1750-1764.

Tardy, C., Moccozet, L., Falquet, G. (2012) Semantic alignment of documents with 3D city models. Conf.3u3d2012: Usage, Usability, and Utility of 3D City models, 29-31 October 2012, Nantes, France. http://dx.doi. org/10.1051/3u3d/201202011

Tegtmeier W., Zlatanova S., Van Oosterom P., Hack H.R.G.K. (2009). Information management in civil engineering infrastructural development: with focus on geological and geotechnical information. In: Kolbe, Zhang\&Zlatanova (Eds.), Proceedings of the ISPRS workshop, vol. XXXVIII-3-4/C3 Commission III/4, IV/8 and IV/5: Academic track of GeoWeb 2009 conference: Cityscapes International archives of photogrammetry, remote sensing and spatial information sciences (pp. 1-6). Berlin, Germany: ISPRS.

Thiemann F., Sester M. (2004). Segmentation of Buildings for 3D-Generalisation. In Proceedings of 7th ICA Workshop on Generalisation and Multiple Representation. 
Thiemann F., Sester M. (2006). 3D-Symbolization using Adaptive Templates. In Proceedings of ISPRS Technical Commission II Symposium, pages 49-54.

Tobler W.R. (1970). A computer movie simulating urban growth in the Detroit region. In Economic Geography, 46 (2), 234-240.

Valente J., Amorim J.H., Cascão P., Rodrigues V., Borrego C. (2012). Children exposure to PM levels in a typical school morning. In "Usage, Usability, and Utility of 3D City Models". T. Leduc, G. Moreau, R. Billen (Eds.). Edp Sciences, France: 03009p. 1-03009p.7. ISBN: 978-2-7598-0798-7.

Van Den Brink L., Stoter J., Zlatanova, S. (2013). UML-Based Approach to Developing a CityGML Application Domain Extension. Transactions in GIS, 17: 920-942. doi: 10.1111/tgis. 12026.

Vandysheva N., Sapelnikov S., Van Oosterom P., De Vries M., Spiering B., Wouters R., Hoogeveen A., Penkov V. (2012). The 3D Cadastre Prototype and Pilot in the Russian Federation, FIG Working Week 2012, May 2012, Rome, $16 \mathrm{p}$.

Van Oosterom P., Vandysheva N., Ivanov A., Pakhomov S., Spiering B., Stoter J., Zlatanova S. (2012). Design of 3D cadastre model in the Russian Federation, In: Geospatial World Weekly, Volume 8, 10, March 5 2012, 5 p.

Vardoulakis S., Fisher B.E.A., Pericleous K., Gonzalez-Flesca N. (2003). Modelling air quality in street canyons: a review. Atmospheric Environment. 37, 155-182.

Visser U., Stuckenshmidt H., Schlieder C. (2005). Interoperability in GIS-enabling technologies. In: AGILE Conference on Geographic Information Science, pp. 25-27.

Walenciak G., Stollberg B., Neubaver S., Zipf A. (2009). Extending spatial data infrastructures 3D by geoprocessing functionality. In S. Dragicevic, D. Roman \& V. Tanasescu (Eds.), International Conference on Advanced Geographic Information Systems \& Web Services (GEOWS 2009) (pp. 40-44). Cancun, Mexico: IEEE.

Wang J., Mülligann C., Schwering A. (2011). An Empirical Study on Relevant Aspects for Sketch Map Alignment, in proceedings of the 14th AGILE International Conference on Geographic Information Science (AGILE 2011). Utrecht, The Netherlands, LNGC, pp.497-518.

Weibel R. (1991). Digital Terrain Modelling. Geographical Information Systems: Principles and Applications, pages 269-297. Longman.

Weibel R. (1992). Models and Experiments for Adaptive Computer-Assisted Terrain Generalization. Cartography and Geographic Information Science, 19(3): $113-153$. 
Willemsen E., Wisse J. A. (2007). Design for wind comfort in The Netherlands: Procedures, criteria and open research Issues, Journal of Wind Engineering and Ind. Aerodynamics, Vol. 95, 1541-1550.

Zhang M., Zhang L., Mathiopoulos P.T., Xie W., Ding Y., Wang H. (2012). A Geometry and Texture Coupled Flexible Generalization of Urban Building Models. ISPRS Journal of Photogrammetry and Remote Sensing, 70:1-14.

Zlatanova S., Stoter J., Isikdag U. (2012). Standards for Exchange and Storage of 3D Information: Challenges and Opportunities for Emergency Response, In: T. Bandrova, M. Konecny, G. Zhelezov (Eds.); Proceedings of the 4th International Conference on Cartography \& GIS, Volume 2, Albena, June 2012, pp. 17-28.

Zlatanova S., Beetz J., Boersma A.J., Mulder A., Goos J. (2013). 3D Spatial Information Structure for the Port of Rotterdam, In: A. Karpik and V. Seredovich (Eds.), Proceedings of the International Workshop on Global Geospatial Information, 23-25 April 2013, Novosibirsk, Russia, pp. 102-113. 


\section{Annex 1 List of members}

\section{WG1 membership}

\begin{tabular}{|l|l|l|}
\hline \multicolumn{1}{|c|}{ Name } & \multicolumn{1}{c|}{ Affiliation } & \multicolumn{1}{c|}{ Country } \\
\hline Milena STAVRIC & TU Graz & Austria \\
\hline Roland BILLEN & University of Liège & Belgium \\
\hline Damir MEDAK & University of Zagreb & Croatia \\
\hline Odysseas KONTOVOURKIS & University of Nicosia & Cyprus \\
\hline Bjarne RUDIGER & The Royal Danish Academy of Fine Arts & Denmark \\
\hline Bruno TOURNAY & The Royal Danish Academy of Fine Arts & Denmark \\
\hline Mireille BATTON-HUBERT & Ecole des Mines de Saint-Etienne & France \\
\hline Jérôme GENSEL & $\begin{array}{l}\text { University Pierre Mendès France of } \\
\text { Grenoble }\end{array}$ & France \\
\hline Thomas LEDUC & $\begin{array}{l}\text { Institute of Science and Technics of } \\
\text { Nantes }\end{array}$ & France \\
\hline Giovanni RABINO & Politecnico di Milano & Italy \\
\hline Irina JACKIVA & TTI of Riga & Latvia \\
\hline Thomas PANAGOPOULOS & University of Algarve & Portugal \\
\hline Ognen MARINA & $\begin{array}{l}\text { University "St. Cyril and Methodius" } \\
\text { Skopje }\end{array}$ & $\begin{array}{l}\text { Former Yugoslav Republic } \\
\text { of Macedonia }\end{array}$ \\
\hline Bojan KARANAKOV & $\begin{array}{l}\text { University "St. Cyril and Methodius" } \\
\text { Skopje }\end{array}$ & $\begin{array}{l}\text { Former Yugoslav Republic } \\
\text { of Macedonia }\end{array}$ \\
\hline Rados SUMRADA & University of Liubljana & Slovenia \\
\hline Gregor BERGINC & University of Ljubljana & Slovenia \\
\hline Roberto SAN JOSE & Technical University of Madrid & Spain \\
\hline André STREILEIN & swisstopo & Switzerland \\
\hline
\end{tabular}




\section{WG2 membership}

\begin{tabular}{|l|l|l|}
\hline \multicolumn{1}{|c|}{ Name } & \multicolumn{1}{c|}{ Affiliation } & \multicolumn{1}{c|}{ Country } \\
\hline Andrew FRANK & TU Wien & Austria \\
\hline Rizwan BULBUL & TU Wien & Austria \\
\hline Lars BODUM & Aalborg University & Denmark \\
\hline Wan WEN & Aalborg University & Denmark \\
\hline Anna ERVING & $\begin{array}{l}\text { Aalto University. School of Science and } \\
\text { Technology }\end{array}$ & Finland \\
\hline Sanna ILTANEN & Tampere University of Technology & Finland \\
\hline Anne-Francoise CUTTING-DECELLE & Ecole Centrale de Lille & France \\
\hline Bénédicte BUCHER & IGN Paris & France \\
\hline Alina Dia MIRON & Joseph Fourier University of Grenoble & France \\
\hline Thomas LEDUC & Institute of Science and Technics of Nantes & France \\
\hline Thomas H. KOLBE & TU Berlin & Germany \\
\hline Monika SESTER & Leibniz University of Hannover & Germany \\
\hline Eliseo CLEMENTINI & University degli Studi dell'Aquila & Italy \\
\hline Barbara BARBONI & University of Rome & Italy \\
\hline Matteo CRISTANI & University of Verona & Italy \\
\hline Mattia COLLO & Polytecnico di Torino & Italy \\
\hline Francesco TARQUINI & University of L'Aquila & Italy \\
\hline Nadezda KOLMAKOVA & TTI of Riga & Latvia \\
\hline Sisi ZLATANOVA & OTB-TU Delft & Netherlands \\
\hline Hans SCHEVERS & Strategis & Netherlands \\
\hline José Paulo ALMEIDA & University of Coimbra & Portugal \\
\hline Ana Isabel MIRANDA & University of Aveiro & Portugal \\
\hline Jorge AMORIM & University of Aveiro & Portugal \\
\hline Iuliana ARMAS & University of Bucharest & Romania \\
\hline Jaroslav HOFIERKA & University of Presov & Slovak Republic \\
\hline Jorge POSADA & VICOMTech Research Centre & Spain \\
\hline Oihana OTAEGUI & VICOMTech Research Centre & Spain \\
\hline Claudine METRAL & University of Geneva & Switzerland \\
\hline Gilles FALQUET & University of Geneva & Switzerland \\
\hline & & \\
\hline
\end{tabular}




\section{WG3 membership}

\begin{tabular}{|c|c|c|}
\hline Name & Affiliation & Country \\
\hline Juha HYYPPA & Finnish Geodetic Institute & Finland \\
\hline Anssi JOUTSINIEMI & Technical University of Tampere & Finland \\
\hline Julien PERRET & IGN Paris & France \\
\hline Gullaume MOREAU & Ecole Centrale de Nantes & France \\
\hline Balazs HEGEDUS & Ybl Miklos Faculty of Architecture & Hungary \\
\hline Zsolt BARKOCZI & $\begin{array}{l}\text { VATI Hungarian Public Nonprofit Company for } \\
\text { Regional Development and Town Planning }\end{array}$ & Hungary \\
\hline Viktoria FERENCZ & $\begin{array}{l}\text { VATI Hungarian Public Nonprofit Company for } \\
\text { Regional Development and Town Planning }\end{array}$ & Hungary \\
\hline Giovanni RABINO & Politecnico di Milano & Italy \\
\hline Luca CANEPARO & Polytecnico di Torino & Italy \\
\hline Matteo CAGLIONI & Polytecnico di Milano & Italy \\
\hline Michael SAVRASOVS & TTI of Riga & Latvia \\
\hline Leon VAN BERLO & TNO Delft & Netherlands \\
\hline Ramzi HASSAN & Norwegian University of Life Sciences-UMB & Norway \\
\hline Knut WIK & Norwegian University of Life Sciences-UMB & Norway \\
\hline Thomas PANAGOPOULOS & University of Algarve & Portugal \\
\hline Ana Margarida COSTA & University of Aveiro & Portugal \\
\hline Maria DAN BOSTENARU & $\begin{array}{l}\text { Ion Mincu University of Architecture and } \\
\text { Urbanism }\end{array}$ & Romania \\
\hline Urbano FRA PALEO & University of Santiago de Compostela & Spain \\
\hline Aitor MORENO & VICOMTech Research Centre & Spain \\
\hline Anders OSTMAN & University of Gävle & Sweden \\
\hline Mohamed EL MEKAWY & & Sweden \\
\hline André STREILEIN & swisstopo & Switzerland \\
\hline François GOLAY & Ecole Polytechnique Fédérale de Lausanne-EPFL & Switzerland \\
\hline Laurent MOCCOZET & University of Geneva & Switzerland \\
\hline Claudio CARNEIRO & EPFL & Switzerland \\
\hline Carsten ROENSDORF & Ordnance Survey & United Kingdom \\
\hline Andrew BALDWIN & Loughborough University & United Kingdom \\
\hline
\end{tabular}


7 KVSDJHIQMQWRQDQLOIVEOQN 


\section{Annex 2 \\ WG's questionnaires}

\section{WG 1 questionnaire}

Sub-domain: Transport / Air quality models / Urban Morphology

Title:

Names:

\section{Project or research area presentation}

\{The author should describe his/her project or selected research area. I mean objectives, partnerships, funding institution, duration, current stage, etc. including references. At least 1 page, maximum 3 pages\}

\section{Related works and publications}

\{The author should give a brief state-of-the-art of related works as well as a list of related publications. At least 1 page, maximum 3 pages\}

\section{Description}

\{ln this section, the author should detail his/her project following our 3 step methodology. At least 3 page, maximum 6 pages $\}$ 


\section{Step 1}

\{First, the author should list elements of the current situation

- User types

- User needs

- Tasks to be performed

- Identification of OD-1D-2D-3D data used

- Specific process

- Complementary data (non 3D)

Then, the author should list potential improvement

- 3D data needed (enrichment - new objects)

- or information which has to be added to 3D objects lenrichment - new attributes ...)

The author has the opportunity to give some remarks

All this information must be presented as a list and after in the following diagram\}

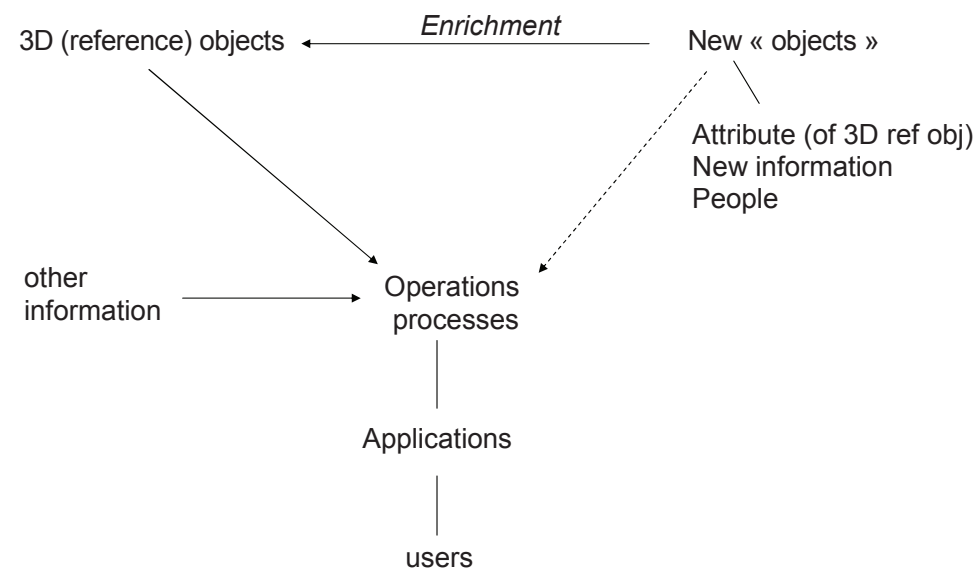




\section{Step 2}

In this section, the author should focus on the potential impact of new equipments (devices) on result of step 1

All this information must be presented as a list and after in the following diagram\}

3D (reference) objects

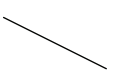

(New) sensors

Operations

processes

\section{Step 3}

\{ln this section, the author should focus on the creation of information

- Identification of 3D information created (through the processes)

- Discussion about the way to "keep" this new 3D information (enrichment new objects, attributes) into a global system

All this information must be presented as a list and after in the following diagram\}

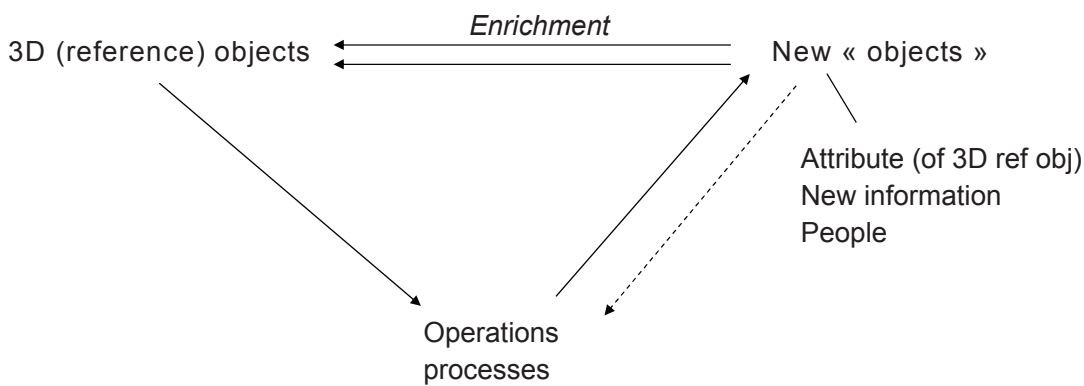

\section{Analysis}

In this section, the author has the opportunity to summarize the main points of his/her description and add comments. At least $1 / 2$ page, maximum 2 pages 


\section{WG2 questionnaire}

\section{Case study:}

author(s):

date:

\section{Aim and scope}

This questionnaire is intended to evaluate selected case studies (systems) that integrate or interconnect 3D city models with other knowledge and data sources. The goal of this evaluation is to

- identify problems encountered when building these systems

- analyze the methods and techniques used and see if they can be generalized

\section{General Information}

What is the purpose and who are the users of the application/model?

For what reasons do you consider this model/application as a 3D one?

What are the semantic enrichment aspects/features?

Is the application/model specific to a particular city, to a particular kind of city, or completely general?

\section{Functionalities of the application}

Describe the capabilities of the application/system. What are the tasks each type of (human) user can perform?

What kind of visualization? (maps, 3d scenes, graphics, ...) 
What type of interactivity? (navigation, interaction with displayed objects, manipulation/modification of displayed objects)

Describe the automated processes that use the model (within the application)

What are the services offered by this application through an API or through Web services?

\section{Model details}

List the (main) entity types, relationships, properties, attributes, that are included in the model (e.g. terrain, buildings, trees, bridges, topological relations)

What types of modelling paradigms are used (e.g. object based representation, relational model, field-based models, cellular automata, agent based, logical (description logics, first order logic, fuzzy logic), discrete events, ...).

Describe data models and ontologies (standards or ad hoc) used in the application.

Is there a specific handling of uncertainty, time, multiple representations, data quality, precision, object identifiers, etc.?

\section{Integration/interconnection mechanisms}

Describe the kind(s) of integration that was (were) performed

Integration only at the rendering/display level (e.g. show models in different windows, superimpose data from different models) 
Implicit integration: the application directly uses several models/datasets without any explicit integration phase (see Fig. 1)

Ontology/schema matching/alignment (manual/automated) (Fig. 2)

Individual/object matching (manual/automated) (Fig. 2)

Common ontology/federated schema creation: in addition to mappings, a common global ontology is created. The application accesses all the data through this shared vocabulary (see Fig. 3)

\section{Figures}

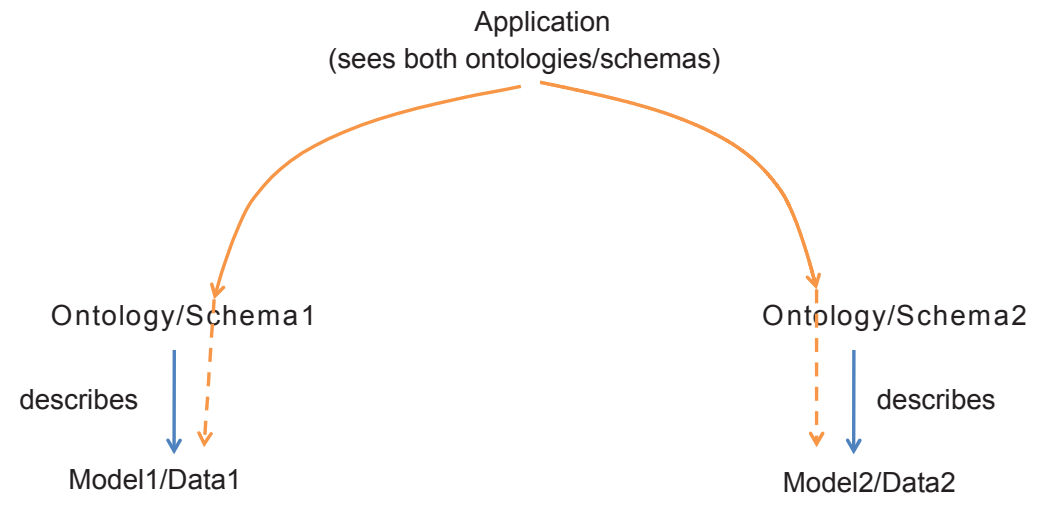

Figure 1. Implicit integration.

Application

Draw 3D buildings on top of a 2D map of the bus lines

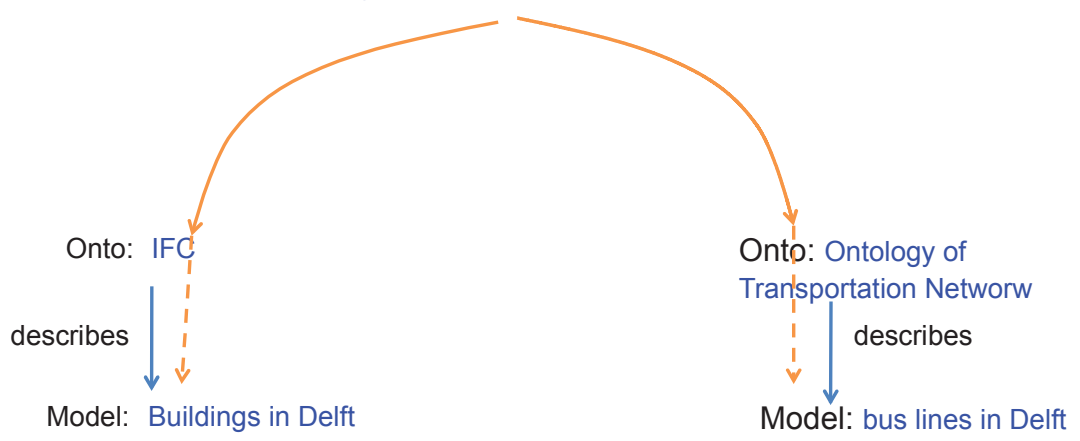

Figure 1b. Implicit integration example. 
Application

(sees both ontologies/schemas and the correspondences)

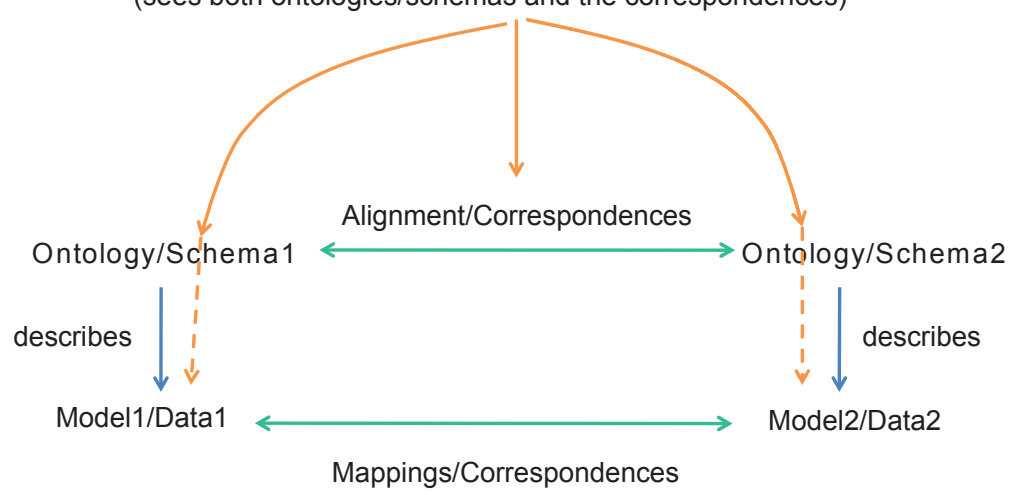

Figure 2. Ontology mapping

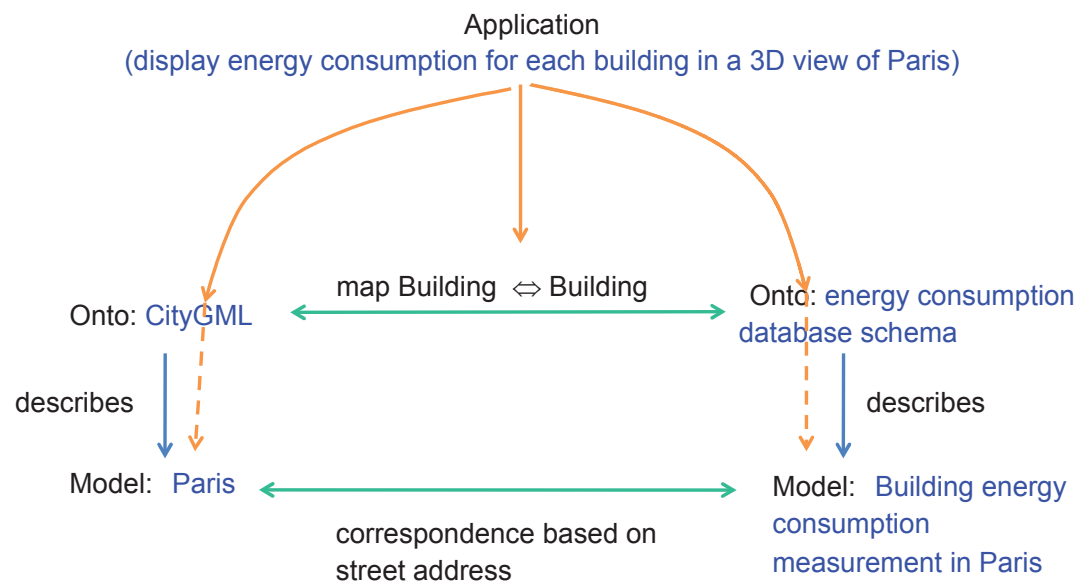

Figure 2b. Ontology mapping example. 


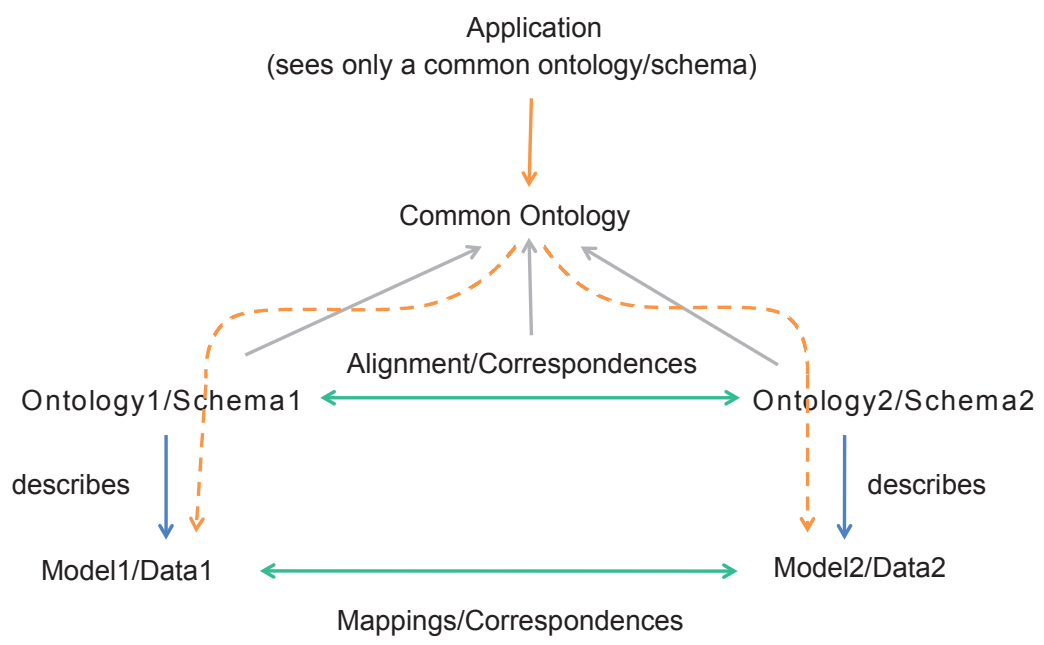

Figure 3a. Common ontology creation.

Application

(sees only a common ontology/schema)

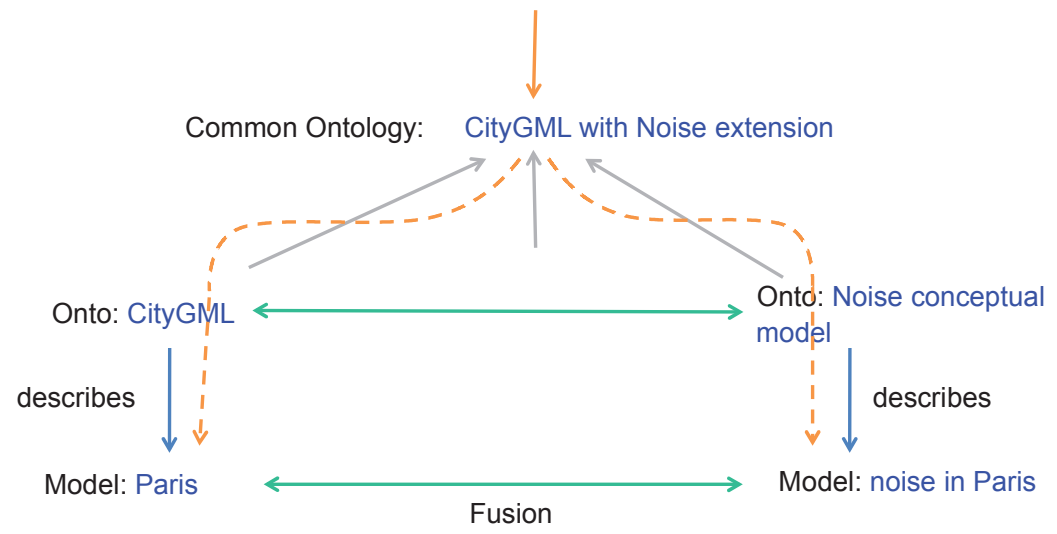

Figure 3b. Common ontology creation example. 


\section{An interesting reference}

Bucella, A. Cechich, A, Fillottrani, P. (2009) Ontology-driven geographic information integration: A survey of current approaches. Computers \& Geosciences 35, 710-723.

These are additional questions that could be worth answering, but not for every test case.

\section{Practical information}

What is the date of the production?

Who is the producer (responsible organization, developer)?

What are the updating procedures?

How to contact (contact point, other information)?

Accessibility of the application and the model (in terms of rights and distribution channel) How can the city model be accessed (web, viewer, software)? (e.g. it is in the DBMS and could be accessed by commercial GIS; the model is accessible via Digitial Earth browsers like Google Earth and Bing Maps 3D).

References: relevant publications, reports, internet portals

\section{Further information about the model(s)}

How are spatial characteristics modeled?

Qualitative or quantitative representations?

If quantitative, what type of geometries are being used (e.g. 2.5D/2.8D/3D, 3D Solids using B-Rep or CSG, Multisurfaces/Multipatches)?

Does the model include objects with fuzzy boundaries or parts? How are they represented? Is (3D) topology explicitly represented, and if yes, to what extent?

What are the used frames of reference? (e.g. absolute, i.e. using coordinate values; relative i.e. person or object centered)

How do the semantics of spatial relations depend on the used frame of reference?

Are spatial relations defined on the geometry/topology aspects or with respect to functional/semantic aspects?

Are there multiple representations of the same entities being used?

Multiple levels of details? (e.g. LOD1, some LOD2, LOD3 and LOD4)

Does the model contain dynamic elements? (e.g. varying attribute values, moving parts, functions)

How is/are the model(s) being stored and exchanged:

Inner format? (e.g. relational model, ArcGIS GeoDB, specific file format)

Exchange formats (please differentiate between read and write support)? (e.g. kml, citygml, vrml)

Size of the model (amount of features or other countable items)? (e.g. the number of buildings, number of trees)

How were the (instance) models formally represented?

3D City Models

User application domain models

How were the conceptual models (ontologies) formally represented?

3D City Models

User application domain models 
Have you aligned your models with previously existing modeling frameworks or even standards?

Have you translated an instance model or a conceptual model from one formalism to another (e.g. from relations database to XML, from flat files to RDF, from XML Schema to OWL, from relational database schema to RDFS)

During the integration process Did you perform some sort of semantic enrichment of the models to integrate? (e.g. transforming purely geometric data (KML, etc.) to IFC or CityGML data)

How are / have been similar or identical concepts and data (being) identified?

Difficulties in connecting entities of the different ontologies?

Manual or (semi-)automated processes?

If you created a new common ontology, did you use an ontology that is considered a base or reference ontology? In other words: are you / have you been extending the concepts of a reference/standard ontology? (e.g. ISO 191xx, EPSG, CityGML, GML, DOLCE, SUMO, CyC, ...)

If yes: why have you used / decided to use one base/reference ontology and not go for a direct integration/ combination? (e.g. specific applications only understand/support the base/reference ontology)

How/why did you choose the base/reference ontology?

What are the problems and shortcomings?

To which degree have you succeeded?

Have you been using standards? e.g. OWL, IFC, CityGML, RDF(S), mapping standards, ... How well did these standards fit to your concepts? 


\section{WG3 questionnaire}

\section{Case study:}

author(s):

date:

\section{Aim and scope}

This questionnaire is intended to evaluate selected case studies (systems) that use $3 \mathrm{D}$ city models. The goal of this evaluation is to

- Identify usability problems identified when using 3D data for specific applications.

- Identify criteria/measures that could be used to evaluation the usability of a 3D city model for such an application.

- Describe possible usability testing environments.

\section{Context}

What are the target groups in usability testing?

Which one would be most relevant for usability testing?

Give a list of tasks to be performed by users and possible criteria/measures

\section{Usability testing}

Which environments needed for testing (hardware, software, data)?

What kind of visualisation techniques are you using to display the information? Which other techniques could be used? 


\section{Benefits}

Describe the (expected) benefits and value that the enrichment model has created compared to the model you have started with

Describe lessons learned, open problems and issues to be addressed in the future? 


\section{Annex 3 \\ List of publications the COST-workshop "3D issues for transport system"}

MODELLING PEDESTRIAN MOBILITY AS A DESIGNER'S TOOL IN URBAN PROTECTED AREAS, Ognen Marina, Milena Stavric, Jovan Ivanovski, Bojan Karanakov, Ana Ivanovska, Ivana Topalovska, http://www.tsi.lv/Research/Conference/RelStat-1 1/Proceedings/ COST_Marina.pdf

PEDESTRIAN MODELLING AND CIRCULATION DIAGRAMS IN 3D ENVIRONMENT, Odysseas Kontovourkis, http://www.tsi.lv/Research/Conference/RelStat-1 1/Proceedings/ COST_Kontovourkis_OK.pdf

USING GPS DATA TO MEASURE THE PERFORMANCE AND RELIABILITY OF TRANSPORTATION SYSTEMS, Eric Scharnhorst, Edward McCormack, Wenjuan Zhao, http:// www.tsi.lv/Research/Conference/RelStat-11/Proceedings/COST_Scharnhorst_ McCormack_Zhao_corr_ED.pdf

TOWARDS A LANDSCAPE POTENTIAL. A METHOD BASED ON A SYSTEMATIC CHARACTERIZATION OF THE SURROUNDING URBAN FABRIC THROUGH THE VISUAL DYNAMICS OF PEDESTRIANS, Thomas Leduc, Philippe Woloszyn, http://www.tsi.lv/Research/ Conference/RelStat-1 1/Proceedings/COST_Leduc_Woloszyn_OK.pdf

STREET NETWORK ISSUES FOR DISASTER MANAGEMENT, Maria Bostenaru Dan, http://www.tsi. lv/Research/Conference/RelStat-1 1/Proceedings/COST_Bostenaru_Dan_corr_ED.pdf 
7 KVSDJHIQMQWRQDQLOIVEOQN 


\section{Annex 4 List of publications the COST book "3D issues in urban and environmental systems"}

\section{SEMANTIC ENRICHMENT}

Spatial Relations and Properties for Semantically Enhanced 3D City Models Bucher B., Falquet G., Clementini E., Sester M.

3D Historical Models: the case studies of Liege and Nantes

Billen R., Carré C., Delfosse V., Hervy B., Laroche F., Lefèvre D., Servières M., Van Ruymbeke M.

Delivering Semantic Enrichment of 3D Urban Models for Financial and Sustainability Decision Support

Schevers H.A.J., Zlatanova S., Seijdel R.R., Dullemond A.T.

Towards an Integrated Visualization of Semantically Enriched 3D City Models: an Ontology of 3D Visualization Techniques

Métral C., Ghoula N., Falquet G.

ENHANCED VISUALISATION

Stereo 3D Applications Potential for Heritage Disaster Management

Bostenaru Dan M.

From 3D Building Information Modeling Towards 5D City Information Modeling 
Stavric M., Marina O., Masala E., Pensa S., Karanakov B.

Interactive Visualization in Modeling Urban Development

Masala E., Marina O., Pensa S., Stavric M.

\section{D VISIBILITY ANALYSIS}

Towards a Mixed Approach Combining Visibility and Mobility Studies to Analyze the Eleftheria Square, Nicosia (CY)

Leduc T., Kontovourkis $\mathrm{O}$.

Visual Impact Assessment in the Context of Visual Landscape Management in Portugal

Panagopoulos T.

\section{D AIR QUALITY MODELS}

Urban Visualization of 3D Atmospheric Data with GVSIG-3D

San José R., Pérez J.L., González R.M.

Web Based Volume Rendering of Air Quality 3d Datasets at the City Scale

Moreno A., Congote J., Ruiz O., Pérez J.L., San José R.

Modelling the link between Urban Morphology, Pedestrian Dynamics and Individual

Exposure to Air Pollution

Amorim J.H., Valente J., Cascão P., Rodrigues V., Borrego C.

\section{D PEDESTRIAN MULTI AGENT SYSTEMS}

Ontologies in Multi-Agent Systems for Building Design the case of Risk Management inside a Stadium

Caglioni M., Rabino G.

Agent-Based Approach to Modeling Urban Dynamics

Gievska S. 


\section{Annex 5 List of publications of the book usage, usability, and utility of 3D city models}

3D models as a platform for urban analysis and studies on human perception of space

D. Fisher-Gewirtzman

Usage, Usability, and Utility of 3D City Models 01001 (2012)

DOI: http://dx.doi.org/10.1051/3u3d/201201001

Efficient visualization of urban spaces

A.E. Stamps

Usage, Usability, and Utility of 3D City Models 01002 (2012)

DOI: http://dx.doi.org/10.1051/3u3d/201201002

Measuring the impact of 3D data geometric modeling on spatial analysis: Illustration with Skyview factor

M. Brasebin, J. Perret, S. Mustière and C. Weber

Usage, Usability, and Utility of 3D City Models 02001 (2012)

DOI: http://dx.doi.org/10.1051/3u3d/201202001

Advances in 3D visualization of air quality data

R. San José, J.L. Pérez and R.M. González

Usage, Usability, and Utility of 3D City Models 02002 (2012)

DOI: http://dx.doi.org/10.1051/3u3d/201202002

Extending 3D city models with legal information

A.U. Frank, T. Fuhrmann and G. Navratil

Usage, Usability, and Utility of 3D City Models 02003 (2012)

DOI: http://dx.doi.org/10.1051/3u3d/201202003 
Interactive model of urban development in residential areas in Skopje

O. Marina, E. Masala, S. Pensa and M. Stavric

Usage, Usability, and Utility of 3D City Models 02004 (2012)

DOI: http://dx.doi.org/10.1051/3u3d/201202004

An ontology of 3D visualization techniques for enriched 3D city models

C. Métral, N. Ghoula and G. Falquet

Usage, Usability, and Utility of 3D City Models 02005 (2012)

DOI: http://dx.doi.org/10.1051/3u3d/201202005

All range and heterogeneous multi-scale 3D city models

S. He, G. Besuievsky, V. Tourre, G. Patow and G. Moreau

Usage, Usability, and Utility of 3D City Models 02006 (2012)

DOI: http://dx.doi.org/10.1051/3u3d/201202006

\section{Developing an ontology of space: Application to 3D city modeling}

R. Billen, C. Zaki, M. Servières, G. Moreau and P. Hallot

Usage, Usability, and Utility of 3D City Models 02007 (2012)

DOI: http://dx.doi.org/10.1051/3u3d/201202007

EnVIE project: A framework to produce urban data at large scale

V. Tourre, P. Cadio, G. Caniot and C. Papin

Usage, Usability, and Utility of 3D City Models 02008 (2012)

DOI: http://dx.doi.org/10.1051/3u3d/201202008

A generalized approach for historical mock-up acquisition and data modelling: Towards historically enriched 3D city models

B. Hervy, R. Billen, F. Laroche, C. Carré, M. Servières, M. Van Ruymbeke, V. Tourre, V. Delfosse and J.-L. Kerouanton

Usage, Usability, and Utility of 3D City Models 02009 (2012)

DOI: http://dx.doi.org/10.1051/3u3d/201202009

Towards a typology of spatial relations and properties for urban applications

B. Bucher, G. Falquet, E. Clementini and M. Sester

Usage, Usability, and Utility of 3D City Models 02010 (2012)

DOI: http://dx.doi.org/10.1051/3u3d/201202010

Semantic alignment of documents with 3D city models

C. Tardy, L. Moccozet and G. Falquet

Usage, Usability, and Utility of 3D City Models 02011 (2012)

DOI: http://dx.doi.org/10.1051/3u3d/201202011

Web based hybrid volumetric visualisation of urban GIS data - Integration of 4D Temperature and Wind Fields with LoD-2 CityGML models

J. Congote, A. Moreno, L. Kabongo, J.-L. Pérez, R. San-José and O. Ruiz

Usage, Usability, and Utility of 3D City Models 03001 (2012)

DOI: http://dx.doi.org/10.1051/3u3d/201203001 
A new concept of perceptual fidelity to augment virtual urban environments with microclimatic ambiances

T. Vigier, G. Moreau, D. Siret and L. Lescop

Usage, Usability, and Utility of 3D City Models 03002 (2012)

DOI: http://dx.doi.org/10.1051/3u3d/201203002

Microscopic transport model animation visualisation on KML base

I. Yatskiv and M. Savrasovs

Usage, Usability, and Utility of 3D City Models 03003 (2012)

DOI: http://dx.doi.org/10.1051/3u3d/201203003

Towards a collaborative and interoperable 3D Building database - A case study in Walloon region

R. Haiji and R. Billen

Usage, Usability, and Utility of 3D City Models 03004 (2012)

DOI: http://dx.doi.org/10.1051/3u3d/201203004

Preliminary investigations into the potential of improving rendering performance of 3D datasets using 2D generalisation

C. Ellul and J.A. Joubran

Usage, Usability, and Utility of 3D City Models 03005 (2012)

DOI: http://dx.doi.org/10.1051/3u3d/201203005

Integration of urban knowledge through visibility studies and pedestrian behavior analysis in Old Bazaar in Skopje

O. Marina, T. Leduc, G. Rabino, S. Gievska and B. Karanakov

Usage, Usability, and Utility of 3D City Models 03006 (2012)

DOI: http://dx.doi.org/10.1051/3u3d/201203006

Skyline matching: A robust registration method between Video and GIS

S. Zhu, M. Pressigout, M. Servières, L. Morin and G. Moreau

Usage, Usability, and Utility of 3D City Models 03007 (2012)

DOI: http://dx.doi.org/10.1051/3u3d/201203007

Detailed modelling of the wind comfort in a city avenue at the pedestrian level

J.H. Amorim, J. Valente, C. Pimentel, A.I. Miranda and C. Borrego

Usage, Usability, and Utility of 3D City Models 03008 (2012)

DOI: http://dx.doi.org/10.1051/3u3d/201203008

Children exposure to PM levels in a typical school morning

J. Valente, J.H. Amorim, P. Cascão, V. Rodrigues and C. Borrego

Usage, Usability, and Utility of 3D City Models 03009 (2012)

DOI: http://dx.doi.org/10.1051/3u3d/201203009

3D spatial information infrastructure: The case of Port Rotterdam

S. Zlatanova and J. Beetz

Usage, Usability, and Utility of 3D City Models 03010 (2012)

DOI: http://dx.doi.org/10.1051/3u3d/201203010 
7 KVSDJHIQMQWRQDQLOIVEOQN 


\section{Annex 6}

\section{Final round table mind map}

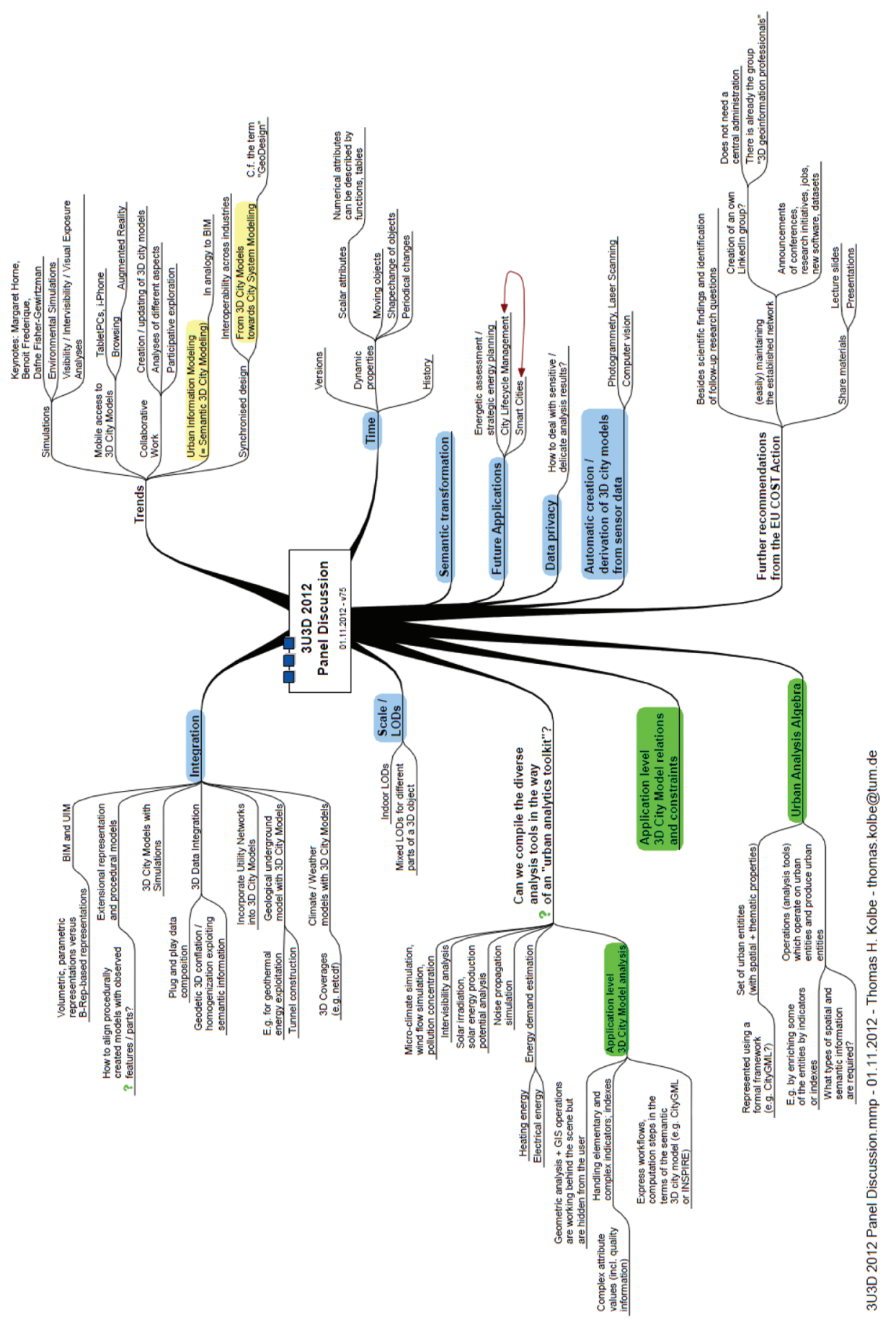


7 KVSDJHIQMQWRQDQLOIVEOQN 